FINAL REPORT

\title{
DESIGN AND CONSTRUCTION OF A FORCE-REFLECTING TELEOPERATION SYSTEM
}

Principal Investigator:

M.A. Ebadian, Ph.D.

Florida International University

Collaborator:

Sabri Tosunoglu -

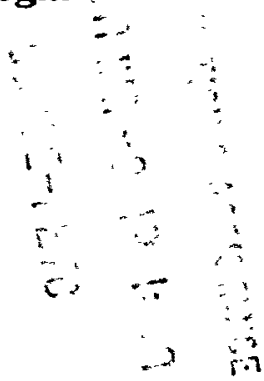

Prepared for:

U.S. Department of Energy Office of Environmental Management Office of Science and Technology

Hemispheric Center for Environuental Technology (HCET) Florida International University, Center for Engineering \& Applied Sciences 10555 West Flagler Street, EAS-2100, Miami, Florida 33174 305-348-4238 - FAX: (305) 348-1852 - World Wide Web Site: http://www.hcet.fiu.edu

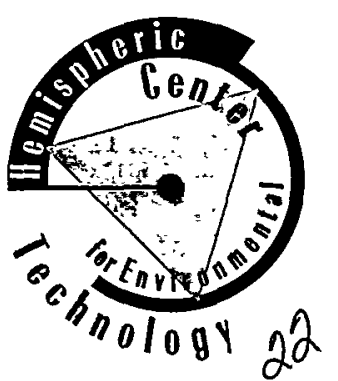




\section{DISCLAIMER}

This report was prepared as an account of work sponsored by an agency of the United States government. Neither the United States government nor any agency thereof, nor any of their employees, nor any of its contractors, subcontractors, nor their employees makes any warranty, express or implied, or assumes any legal liability or responsibility for the accuracy, completeness, or usefulness of any information, apparatus, product, or process disclosed, or represents that its use would not infringe upon privately owned rights. Reference herein to any specific commercial product, process, or service by trade name, trademark, manufacturer, or otherwise does not necessarily constitute or imply its endorsement, recommendation, or favoring by the United States government or any other agency thereof. The views and opinions of authors expressed herein do not necessarily state or reflect those of the United States government or any agency thereof. 


\section{DISCLAIMER}

\section{Portions of this document may be illegible in electronic image products. Images are produced from the best available original document.}




\title{
DESIGN AND CONSTRUCTION OF A FORCE-REFLECTING TELEOPERATION SYSTEM
}

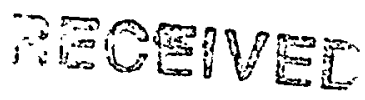 \\ JAN 052031 \\ Principal Investigator \\ OSTI \\ M.A. Ebadian, Ph.D. \\ Hemispheric Center for Environmental Technology \\ Florida International University \\ Miami, FL 33174
}

\section{Florida International University Collaborator} \\ Sabri Tosunoglu \\ Hemispheric Center for Environmental Technology \\ Florida International University \\ Miami, FL 33174
}

\section{January 1999}

\author{
Prepared for \\ U.S. Department of Energy \\ Office of Environmental Management \\ Office of Science and Technology
}

Under Grant No.: DE-FG21-95EW55094 


\section{ACKNOWLEDGMENTS}

This work is partially funded by the U.S. Department of Energy (DOE) through Florida International University's Hemispheric Center for Environmental Technology (FIU-HCET) in Miami. The authors gratefully acknowledge this support. The contributions of the Robotics and Automation Laboratory personnel in FIU's Department of Mechanical Engineering is also appreciated. Personnel include Pat Batsomboon, Vittorio Monteverde, Ernesto Romero, Victor DeRossi, Miguel Espina, Ray Reyes, and Igor Kirianov. 



\section{TABLE OF CONTENTS}

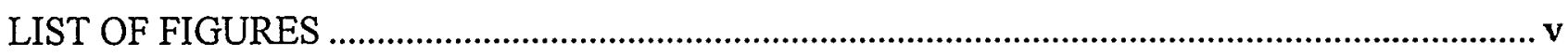

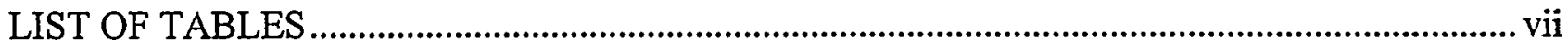

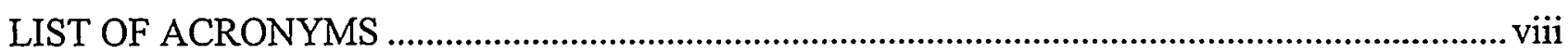

EXECUTIVE SUMMARY …….............................................................................................

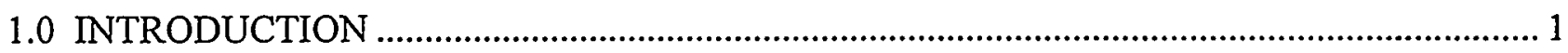

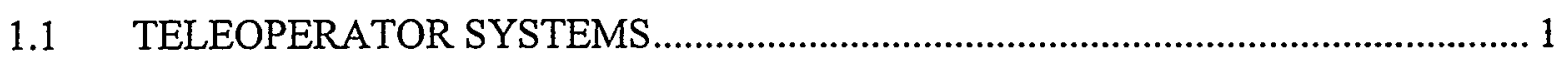

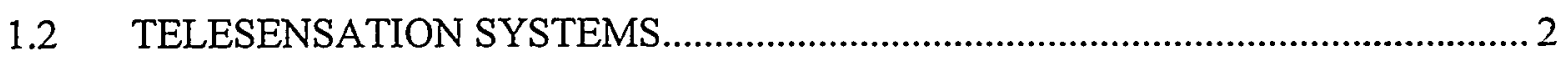

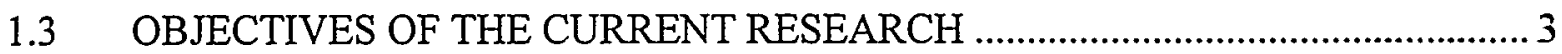

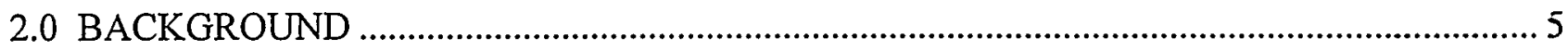

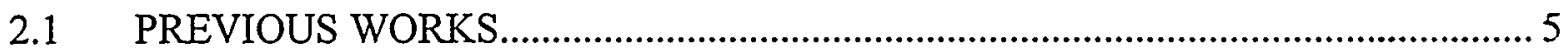

2.2 FORCE-REFLECTING TELEOPERATION SYSTEM........................................ 6

2.2.1 Mechanical Design of Force-Reflecting Manual Controllers........................... 6

Serial-Structured Force-Reflecting Manual Controller Designs...................................... 7

Parallel-Structured Force-Reflecting Manual Controller Designs............................... 10

2.2.2 Force-Reflecting Controller Design............................................................... 14

3.0 FORCE-REFLECTING TELEOPERATION SUBSYSTEMS..............................................

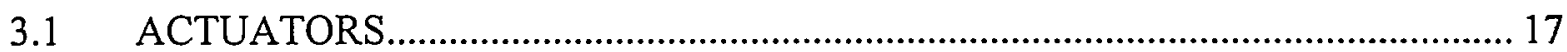

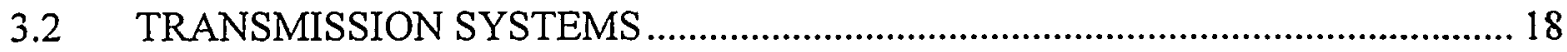

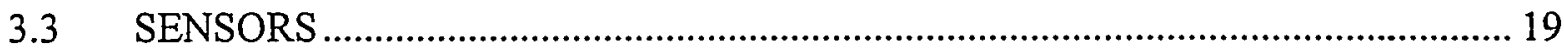

3.3.1 Position Sensing...................................................................................... 20

3.3.2 Speed Sensing .......................................................................................... 20

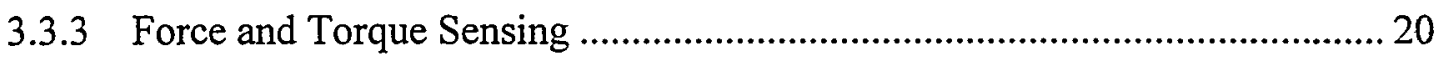

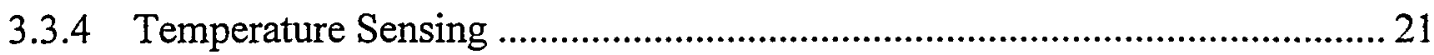

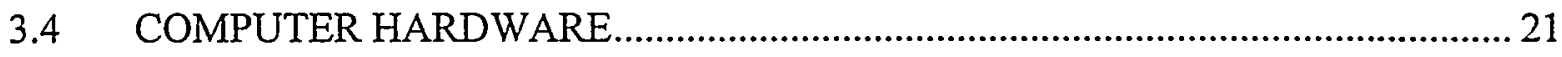

3.5 COMPUTER INTERFACE

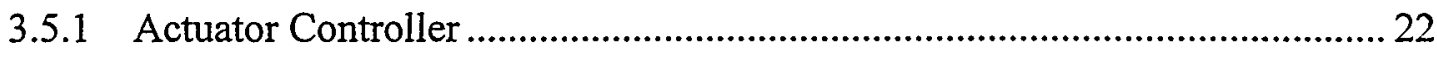

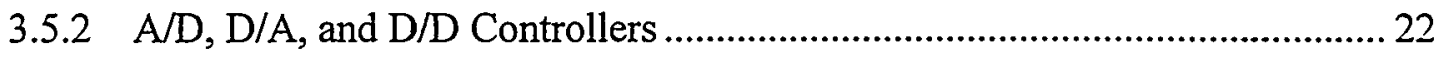

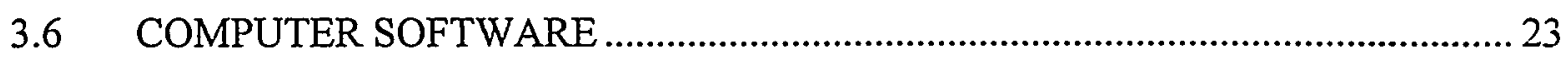

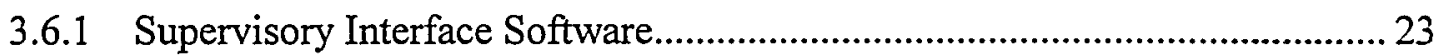

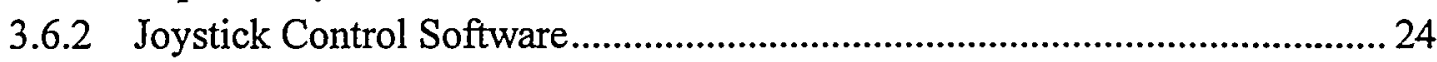

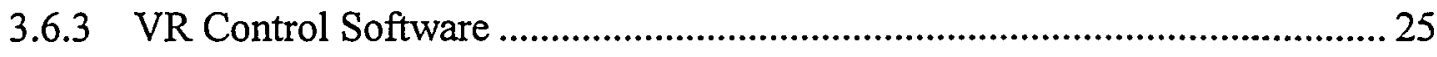

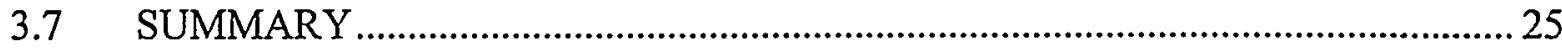

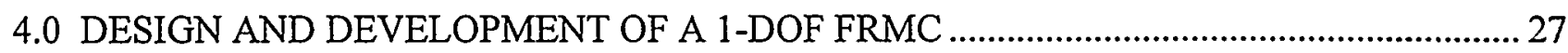

$4.1 \quad$ 1-DOF FRMC COMPONENTS ………………..................................................... 27 
4.2 SYSTEM SETUP AND SYSTEM CHARACTERISTICS....................................... 34

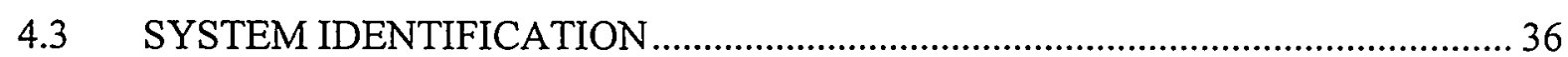

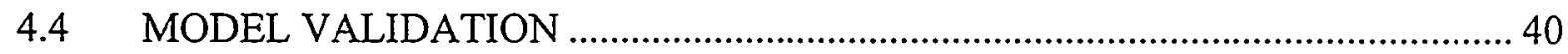

5.0 TESTING AND EVALUATION OF CONTROL METHODS FOR THE

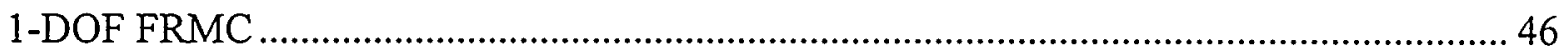

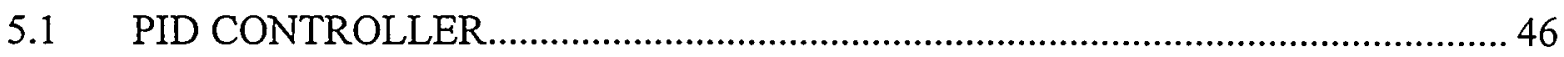

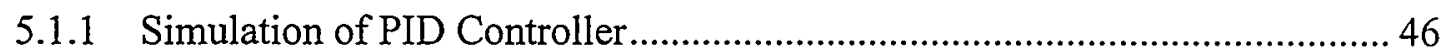

5.1.2 Experiments on 1-DOF FRMC by Implementing the PID

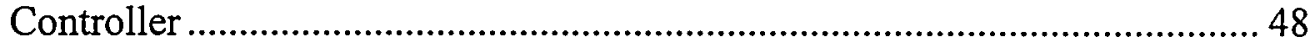

5.2 DEVELOPMENT OF FUZZY LOGIC CONTROLLER …................................... 51

5.2.1 Fuzzy Logic Controller Simulation .......................................................... 52

5.2.2 Experiments on the 1-DOF FRMC by Implementing the

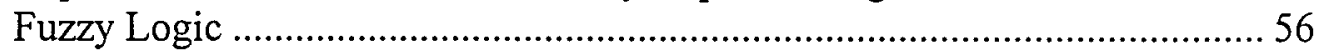

5.3 A COMPARISON OF THE SYSTEM PERFORMANCE OF PID CONTROLLER AND FUZZY LOGIC CONTROLLER ………………….............. 59

5.4 ERRORS CAUSED BY NONLINEAR SYSTEM ELEMENTS ….........................6 60

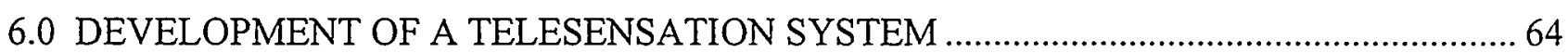

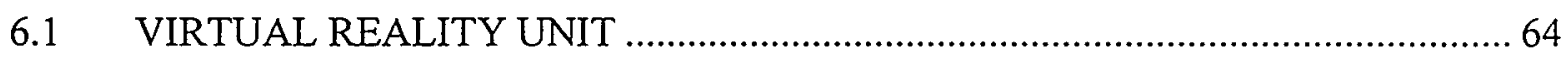

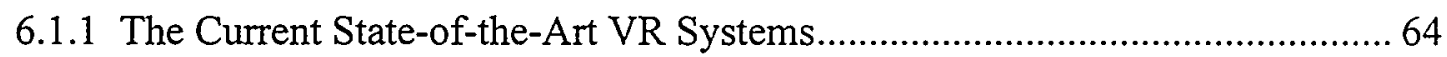

6.2 DESIGN OF A 3-DOF FORCE-REFLECTING MANUAL

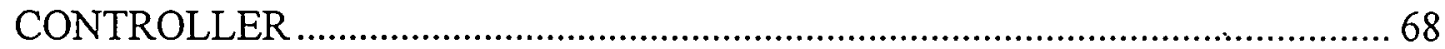

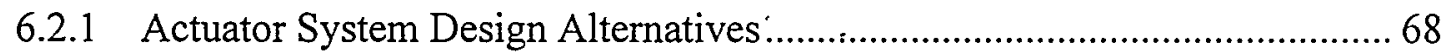

6.2.2 3-DOF FRMC Design Alternatives .......................................................... 73

6.3 DEVELOPMENT OF GRAPHICAL USER INTERFACE (GUI) ……………....... 77

7.0 CONCLUSIONS, RECOMMENDATIONS, AND FUTURE WORK ………….................... 81

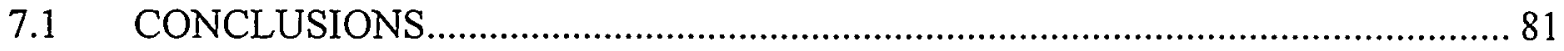

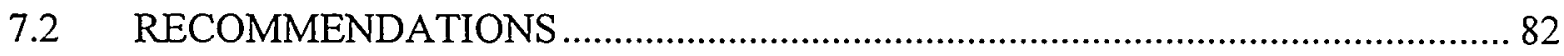

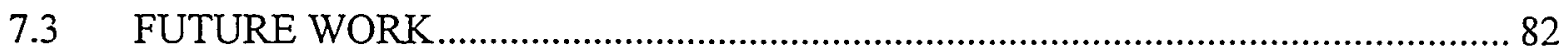

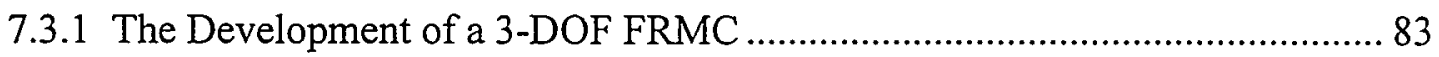

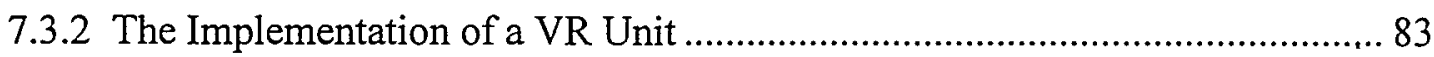

7.3.3 The Development of a Complete GUI Software............................................. 83

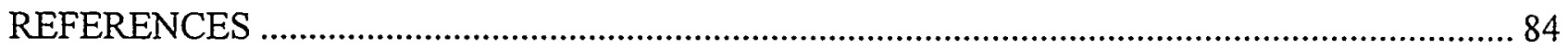




\section{LIST OF FIGURES}

Figure 1-1. Information Flow in Teleoperation Systems................................................... 1

Figure 1-2. Feedback Components of a Telesensation System ................................................ 2

Figure 1-3. A Pictorial Representation of Components in a Telesensation System ................... 3

Figure 2-1. Kraft Manual Controller ..................................................................................... 9

Figure 2-2. PER-Force 6-DOF Force-Reflecting Manual Controller....................................... 9

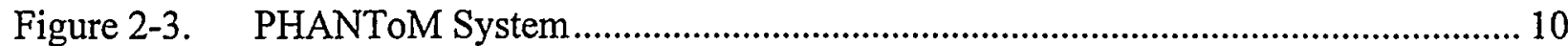

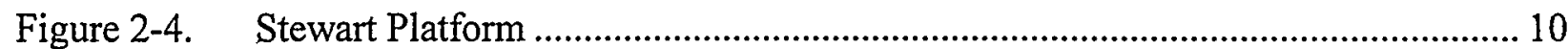

Figure 2-5. Six-DOF Nine-String Manual Controller ....................................................... 11

Figure 2-6. Three-DOF Shoulder Manual Controller............................................................... 12

Figure 2-7. FIU 3-DOF Force-Reflecting Manual Controller Design........................................ 13

Figure 2-8. Open-Loop Control of a Teleoperation System................................................. 14

Figure 2-9. Closed-Loop Control of a Teleoperation System .............................................. 15

Figure 3-1. Teleoperation System Software Structure Graphics Window. .............................. 23

Figure 4-1. 1-DOF FRMC Components.............................................................................. 28

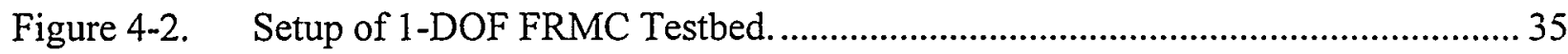

Figure 4-3. Input-Output Data Collected from the System. ...................................................... 38

Figure 4-4. Comparison of the Actual System Response with 2nd-, 3rd-,

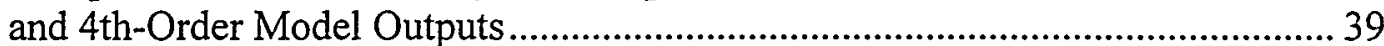

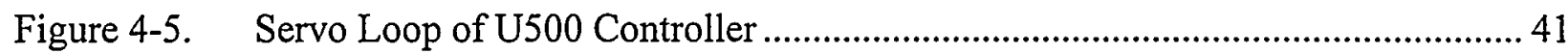

Figure 4-6. Comparison of the System Response between the Model and Actual System for the Gain Set ID1 .................................................................... 43

Figure 4-7. Comparison of the System Response between the Model and Actual System for the Gain Set ID2 .................................................................... 44

Figure 4-8. Comparison of the System Response between the Model and Actual System Output for the Gain Set ID3 .......................................................... 44

Figure 5-1. U500 PID Controller.................................................................................... 46

Figure 5-2. Simulated System Response under PID Controller ............................................... 48

Figure 5-3. Position Command and System Response of PID1 Gains................................... 49

Figure 5-4. Position Command and System Response of PID3 Gains.................................... 49

Figure 5-5. Position Command and System Response of PID6 Gains..................................... 50

Figure 5-6. Comparison of the Response Errors. ………………………................................ 50

Figure 5-7. Position Error Membership Functions.................................................................. 53 
Figure 5-8. Velocity Error Membership Functions. …........................................................ 53

Figure 5-9. Simulated System Response under Fuzzy Logic Controller................................... 56

Figure 5-10. Actual System Response under Fuzzy Logic Controller of

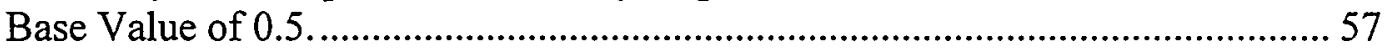

Figure 5-11. Actual System Response with Base Values between 0.35 to $0.5 \ldots \ldots \ldots \ldots \ldots \ldots \ldots \ldots . . .58$

Figure 5-12. Actual System Response with Base Values between 0.5 to $0.6 \ldots . . . \ldots \ldots \ldots . . . . . . . . . . . . .58$

Figure 5-13. A Comparison of System Response between PID and Fuzzy

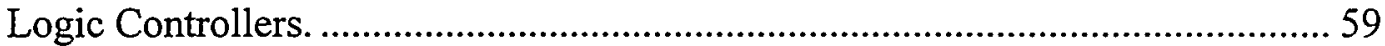

Figure 5-14. Force-to-Velocity Relation of Static Friction ..................................................... 60

Figure 5-15. Typical Input-Output Characteristics of an Amplifier with

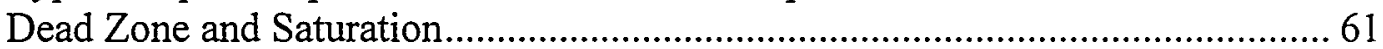

Figure 5-16. Typical Input-Output Characteristics of a Quantizer............................................. 62

Figure 5-17. Torque-Angle Curve of a Motor or Closed-Loop System with Coulomb Friction (Adapted from Kuo 1994) .........................................................6 63

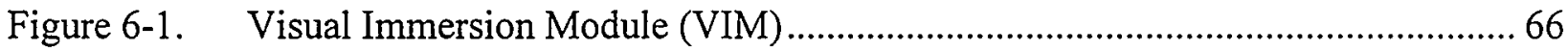

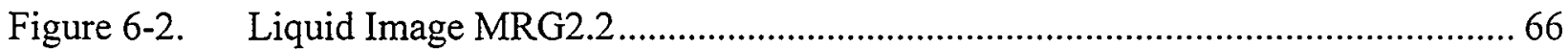

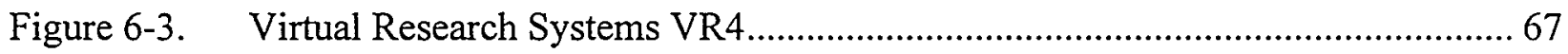

Figure 6-4. Personal Use Stereoscopic Haptic (PUSH) .....................................................67

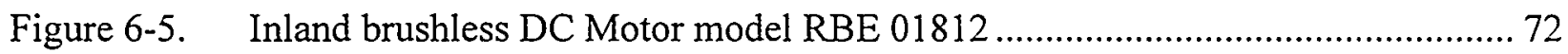

Figure 6-6. Proposed Design 1 (Parallel Configuration) ............................................................ 73

Figure 6-7. Proposed Design 2 (Parallel Configuration) ........................................................ 74

Figure 6-8. Proposed Design 3 (Parallel Configuration) .......................................................... 75

Figure 6-9. Proposed Design 4 (Serial Configuration) ........................................................ 76

Figure 6-10. Windows-Based Version of the Interface Software............................................. 78

Figure 6-11. DOS-Based Version of the Interface Software ....................................................... 79

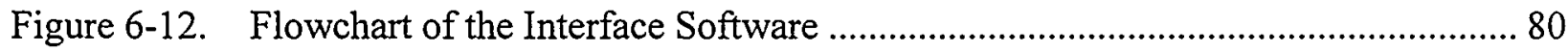




\section{LIST OF TABLES}

Table 2-1. Telerobotic Systems with VR Technologies for Medical Applications...................... 13

Table 4-1. Listing of Hardware/Software Components for 1-DOF FRMC System ..................... 27

Table 4-2. BM 200 Brushless Servo Motor Specifications ............................................................... 29

Table 4-3. Encoder Specifications ....................................................................................... 30

Table 4-4. BA20 Amplifier Specifications …………................................................................. 31

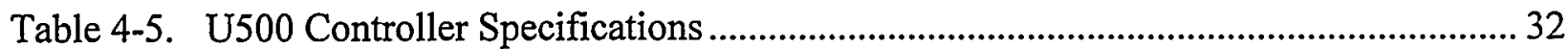

Table 4-6. Current Capacity Requirement for the BB501 Interface Board .................................. 33

Table 4-7. 100M40A-U760 Force/Torque Sensor Specifications ................................................... 34

Table 4-8. Models Represented by $2^{\text {nd }}, 3^{\text {rd }}$, and $4^{\text {th }}$ Order Systems.............................................. 39

Table 4-9. Gains Used in the System Identification Process ...................................................... 43

Table 5-1. Gains Used in Experiments on the Actual System...................................................... 49

Table 5-2. Centers for the Position Error and Velocity Error for the Membership

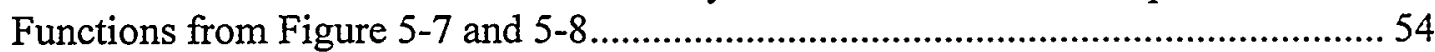

Table 5-3. Look-Up Table Representing Input Voltage of the Actuator ....................................... 55

Table 6-1. Brushless DC Motors with Frame (see notes below) ..................................................6 69

Table 6-2. Motor and Speed Reducer Combination Systems ...................................................... 70

Table 6-3. Surveyed Data of Frameless Brushless DC Motors Properties ................................... 71

Table 6-4. Comparison of Speed Reducer System and Direct Drive Properties ........................ 72

Table 6-5. Comparison of Design Parameters among Design Alternatives ................................ 77 


\section{LIST OF ACRONYMS}

\begin{tabular}{|c|c|}
\hline $\mathrm{A} / \mathrm{D}$ & Analog-to-Digital \\
\hline $\mathrm{ACML}$ & Advanced Controls Manipulation Laboratory \\
\hline AMLCD & Active Matrix Liquid Crystal Display \\
\hline ANL & Argonne National Laboratory \\
\hline ASM & Advanced Servo Manipulator \\
\hline CIMAR & Center for Intelligent Machines and Robotics \\
\hline $\mathrm{D} \& \mathrm{D}$ & Deactivation and Decommissioning \\
\hline $\mathrm{D} / \mathrm{A}$ & Digital-to Analog \\
\hline $\mathrm{D} / \mathrm{D}$ & Digital-to-Digital \\
\hline DC & Direct Current \\
\hline DOD & Department of Defense \\
\hline DOE & Department of Energy \\
\hline DOF & Degree of Freedom \\
\hline EVA & Extra-Vehicular Activity \\
\hline FIU & Florida International University \\
\hline FRMC & Force-Reflecting Manual Controller \\
\hline FOV & Field of View \\
\hline FT & Fault Tolerance \\
\hline GUI & Graphical User Interface \\
\hline HCET & Hemispheric Center for Environmental Technology \\
\hline HRTF & Head-Related Transfer Function \\
\hline JPL & Jet Propulsion Laboratory \\
\hline JSC & Johnson Space Center \\
\hline ORNL & Oak Ridge National Laboratory \\
\hline $\mathrm{LCD}$ & Liquid Crystal Display \\
\hline M-2 & Maintenance System \\
\hline PID & Proportional-Integral-Derivative Feedback Control \\
\hline PUSH & Personal Use Stereoscopic Haptic \\
\hline $\mathrm{R} \& \mathrm{~A}$ & Robotics and Automation Laboratory \\
\hline RMS & Remote Manipulator System \\
\hline SPIDAR & Space Interface Device for Artificial Reality \\
\hline
\end{tabular}


SRI Stanford Research Institute

VCASS Visually Coupled Airborne Systems Simulator

VIM Visual Immersion Module

VR Virtual Reality 


\section{EXECUTIVE SUMMARY}

For certain applications, such as space servicing, undersea operations, and hazardous material handling tasks in nuclear reactors, the environments can be uncertain, complex, and hazardous. Lives may be in danger if humans were to work under these conditions. As a result, a manmachine system-a teleoperator system-has been developed to work in these types of environments. In a typical teleoperator system, the actual system operates at a remote site; the operator located away from this system usually receives visual information from a video image and/or graphical animation on the computer screen. Additional feedback, such as aural and force information, can significantly enhance performance of the system.

Force reflection is a type of feedback in which forces experienced by the remote manipulator are fed back to the manual controller. Various control methods have been proposed for implementation on a teleoperator system. In order to examine different control schemes, a one Degree-Of-Freedom (DOF) Force-Reflecting Manual Controller (FRMC) is constructed and integrated into a PC. The system parameters are identified and constructed as a mathematical model. The Proportional-Integral-Derivative (PID) and fuzzy logic controllers are developed and tested experimentally. Numerical simulation results obtained from the mathematical model are compared with those of experimental data for both types of controllers.

In addition, the concept of a telesensation system is introduced. A telesensation system is an advanced teleoperator system that attempts to provide the operator with sensory feedback. In this context, a telesensation system integrates the use of a Virtual Reality (VR) unit, FRMC, and Graphical User Interface (GUI). The VR unit is used to provide the operator with a 3-D visual effect. Various commercial VR units are reviewed and features compared for use in a telesensation system. As for the FRMC, the conceptual design of a 3-DOF FRMC is developed in an effort to make the system portable, compact, and lightweight. A variety of design alternatives are presented and evaluated. Finally, a GUI software package is developed to interface with several teleoperation unit components. These components include an industrial robot, electric motor, encoder, force/torque sensor, and CCD camera. The software includes features such as position scaling, force scaling, and rereferencing and is intended to provide a sound basis for the development of a multi-DOF FRMC system in the future. 


\subsection{INTRODUCTION}

As technology becomes more advanced, machines become more complex and intelligent. For instance, industrial robots today are able to make decisions and work autonomously. However, for some tasks found, for instance, in nuclear waste cleanup operations or in space, even the most intelligent autonomous robot cannot perform successfully. In order to achieve this goal, humans must be part of the system.

The concept of "man in the loop" is introduced in the so-called teleoperator system. Humans guide machines to properly do tasks that they cannot perform themselves because environmental conditions may be harmful. In some cases, the human remote site may be a thousand miles away from the machine operating station. Therefore, to carry out operations safely and reliably, better interface between these two stations is a must.

\subsection{TELEOPERATOR SYSTEMS}

Teleoperation is a general term that refers to a human-machine remote control system. The system usually consists of two robot manipulators connected in such a way as to allow the human operator controlling one of the manipulators (the master arm) to generate commands that map to the remote manipulator (the slave arm). A teleoperator system generally consists of a manual controller, control hardware/software, sensory feedback, and a remote manipulator. Teleoperation tasks are distinguished by the continuous interaction between a human operator, teleoperator system, and the environment as illustrated in Figure 1-1.

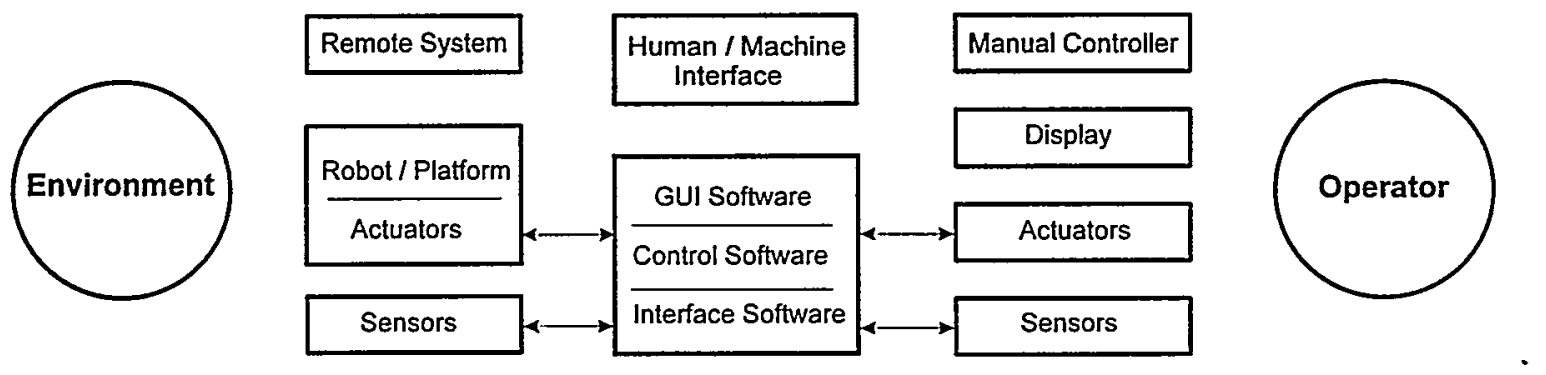

Figure 1-1. Information Flow in Teleoperation Systems.

The main function of the teleoperator system is to allow the operator to perform and accomplish complex, uncertain tasks in hazardous and less-structured environments, such as space, nuclear reactors, and underwater operations, with ease, comfort, and fidelity. For instance, robotic technologies have been used to inspect, maintain, and service nuclear power plants [Tosunoglu and Hamel 1994]. As a result, the radiation exposure of workers at the plants has been reduced to the lowest possible level [Rochelear and Crane 1991]. In a typical teleoperator system, the operator receives feedback information that includes aural, tactile, and force feedback. Although the audio channel may be useful to the operator, the sound is often limited from the system [Draper 1995]. 


\subsection{TELESENSATION SYSTEMS}

In past decades, teleoperator systems have been developed to the point where human operators are able to perceive feelings as if they were in the actual environment. Such a system is also referred to as telepresence or telesensation. Telesensation refers to a remote-control system that combines the use of computer vision, computer graphics, and virtual reality [Terashima 1994]. The word "telesensation" has also been used in the literature to describe a telecommunication system using teleconferencing, where people from different remote locations in the real world are able to hold a meeting or work cooperatively in the same artificial world.

In the field of robotics, the term "telesensation" implies the advanced teleoperator system that provides the operator with sensory feedback by employing the five senses (if possible). As a result, the operator is able to perceive the "feel" of presence at a remote site while he/she is actually at a safe workstation. The feel of presence can be provided by visual, aural, tactile, and force feedback as represented in Figure 1-2.

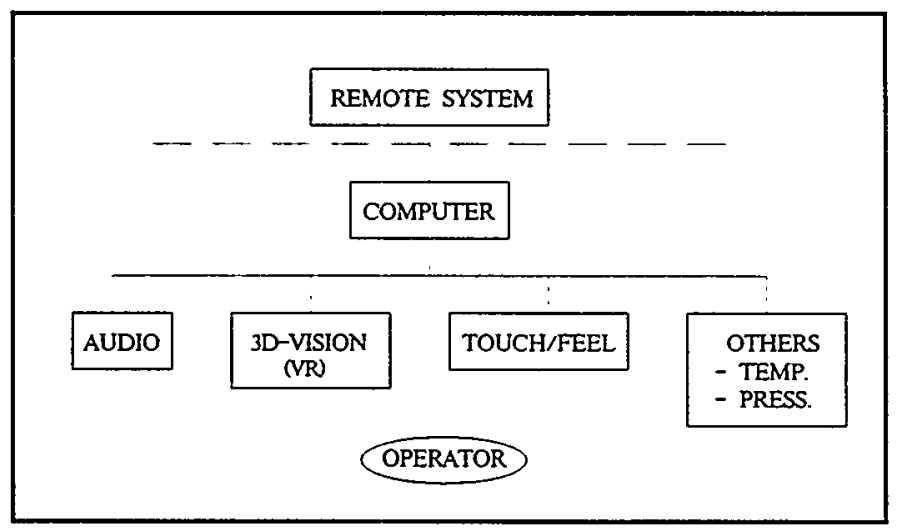

Figure 1-2. Feedback Components of a Telesensation System.

A flexible programming environment and better integration of human and computer capabilities highlight the advanced teleoperation technology [Schenker et al. 1991]. The telesensation system as depicted in Figure 1-3 integrates the use of an advanced operator interface, virtual reality unit, force-reflecting manual controller, and sensor-based manipulator to provide the feel of presence at the remote site [Batsomboon et al. 1996b]. Thus, with a skilled operator and the sophisticated systems, the tasks can be accomplished in the most efficient and effective manner. 


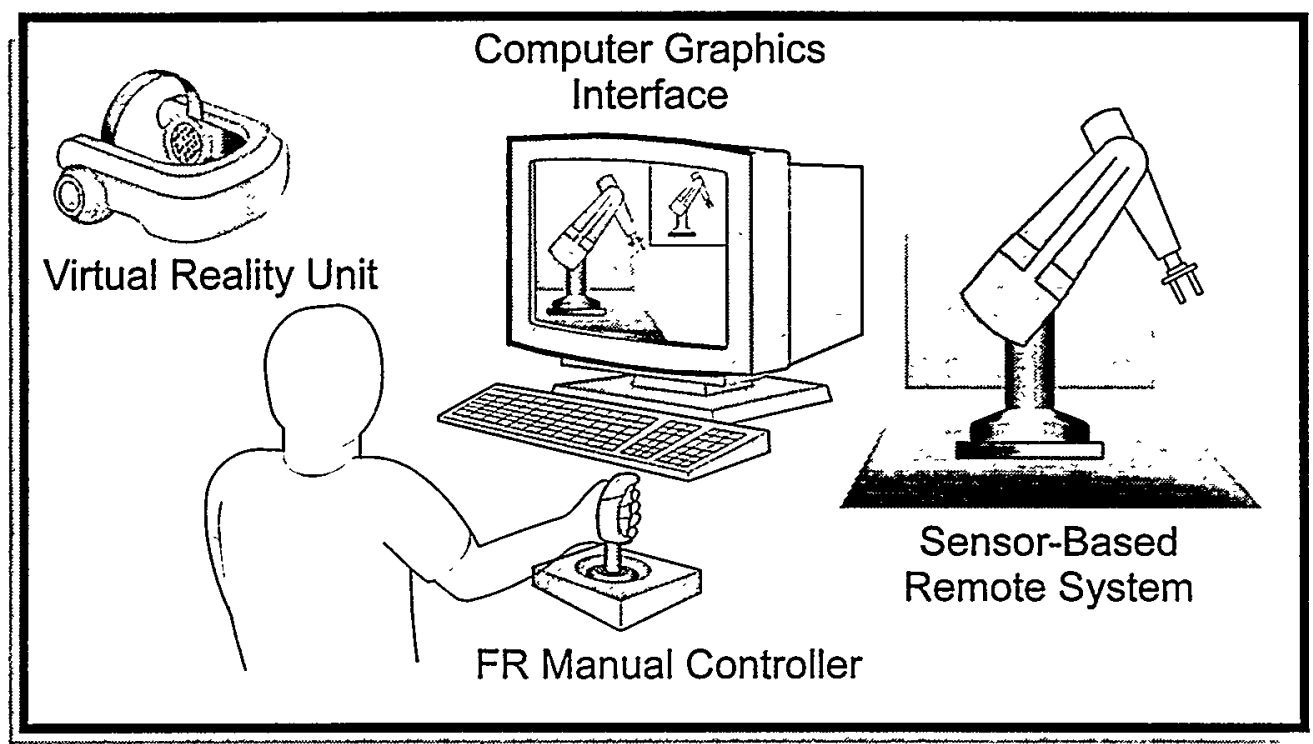

Figure 1-3. A Pictorial Representation of Components in a Telesensation System.

\subsection{OBJECTIVES OF THE CURRENT RESEARCH}

One of the desired objectives in the development of teleoperator systems is to design and develop a system that provides the operator with sensory feedback. A force-reflecting manual controller is one component in the system that provides the operator with force feedback. Unfortunately, most of the manual controllers are bulky, complicated, and expensive. For the system to be used in a practical situation, it must be portable, compact, lightweight, easy to use, and easy to manufacture. Other requirements include large workspace, sufficient force reflection, and safe design.

In this work, the design and development of a portable force-reflecting manual controller is addressed as a design problem, including conceptual design of the system, construction of a testbed, system parameter identification for the testbed, development of control strategies and interface software, system integration, testing and laboratory demonstration.

In order to satisfy these requirements, previous works have been investigated for mechanical and control designs. In addition, a survey of mechanical components such as actuator systems and sensors has been conducted to identify lightweight, compact, high-performance components. The conceptual designs of 3-DOF force-reflecting manual controllers are presented, while the principle of force-reflection is demonstrated on a 1-DOF testbed.

The contents of each section are summarized as follows:

Section 1: The concept of teleoperator and telesensation systems is introduced. Then the objectives and the scope of this work are outlined.

Section 2: Background on force-reflecting teleoperation systems is presented by first listing the history of the previous work in chronological order. Some of these works are reviewed in detail 
with respect to their mechanical designs. The control strategies of these systems are also presented.

Section 3: The components of a force-reflecting teleoperation subsystem are reviewed. These components are divided into three main categories: actuators, sensors, and computers.

Section 4: Telesensation system development is presented. This includes three main components of the telesensation system: virtual reality unit (VR), force-reflecting manual controller (FRMC), and graphical user interface software (GUI).

Section 5: The 1-DOF force-reflecting manual controller prototype is discussed. This section provides information on the system components and setup. In addition, the system parameters are identified in order to obtain a mathematical model for the system.

Section 6: Testing of the 1-DOF testbed and evaluation of results are presented. Two control strategies, one based on PID and the other on fuzzy logic, are developed and tested on the 1-DOF system. The PID represents traditional, and fuzzy logic more recent, controller development efforts. Evaluation is based on the comparison of experimental results to that of numerical simulations.

Section 7: The conclusions and recommendations derived from this work and future work to be conducted are presented. 


\subsection{BACKGROUND}

In this section, the milestones in teleoperation system development are presented, and some of the previous teleoperation system designs are reviewed.

\subsection{PREVIOUS WORKS}

- 1947. Ray Goertz and his group developed the first manual controllers at the Argonne National Laboratory (ANL). The system was mechanically and electrically connected.

- 1948. Ray Goertz and his companies developed the Model-1 bilateral mechanical masterslave manipulator.

- 1948. General Mills produced the Model-A unilateral manipulator in which the arms and hands were driven by switch-controlled motors rather than by direct mechanical or electrical linkage to the operator.

- 1954. Ray Goertz and his group developed the first bilateral force-reflecting servomanipulator.

- 1958. First mobile manipulator with TV was built at ANL. This teleoperator was called a "slave robot."

- 1958. Ralph S. Mosher and coworkers at General Electric produced a manipulator that included force reflection and an exoskeleton master controller called the Handyman ElectroHydraulic manipulator.

- 1961. The first manipulator was fitted to a manned deep-sea submersible when a General Mills Model 150 manipulator was installed on the Trieste.

- 1966. Jones and Thousand developed one of the first dextrous master manipulators using pneumatic bladders.

- 1968. Allen and Karchak at Rancho Los Amigos Hospital constructed position-controlled anthropomorphic manipulators.

- 1970s. NASA developed an advanced teleoperator system. The Remote Manipulator System (RMS) was developed for the space shuttle.

- 1977. Teleoperator System Corporation created a force-reflecting manipulator called SM229 , which was designed to be used in a nuclear plant.

- 1970s. The Center for Intelligent Machines and Robotics (CIMAR) of the University of Florida developed a 6-DOF nine-string manual controller and a 4-DOF force-reflecting planar controller.

- 1980. Hill and Salisbury at Stanford Research Institute (SRI) joined by Bejczy at Jet Propulsion Laboratory (JPL) developed a bilateral 6-DOF force-reflecting manual controller.

- 1980s. Oak Ridge National Laboratory (ORNL) developed the M-2 Maintenance System and the Advanced Servomanipulator (ASM) master-slave, force-reflecting teleoperator system for use in maintenance at a nuclear plant. 
- 1980s. Whitney at Draper Laboratory at MIT designed and developed a hand controller that implemented resolved motion rate control.

- 1985. Tesar and Tosunoglu at the University of Texas at Austin developed a 6-DOF ninestring force-reflecting manual controller and a 3-DOF spherical force-reflecting shoulder controller.

- 1985. Landsberger and Sheridan developed a parallel-structured arm using cables in tension and a single passive compressive spine.

- 1992. Rutgers University Computer Aids for Industrial Productivity (CAIP) Center developed portable I/O device called Rutgers Master.

- 1993. German Space Agency (DLR) developed the first space telerobot called "Rotex Experiment."

- 1993. EXOS Inc. developed the first commercial systems designed for virtual object manipulation called Touch Master and SAFIRE Master.

- 1993. MIT Artificial Intelligence Laboratory developed the PHANToM Master designed for virtual force feedback. The system was made available commercially.

\subsection{FORCE-REFLECTING TELEOPERATION SYSTEM}

In a force-reflecting teleoperation system, the operator uses the manual controller to direct the remote manipulator and receives visual information from a video image and/or graphical animation on the computer screen. A virtual reality unit may be provided to improve perception. While the input motion moves the remote system, forces experienced by the system are reflected at the manual controller, so that the operator feels the forces acting on the system.

Force reflection is most helpful when other sensory feedback such as vision is absent [Draper et al. 1987]. In such situations where there are dust or gases involved or when the environment is dark, viewing by television cameras is difficult or almost impossible. The force reflection becomes the most important information for the operator to complete the tasks. The operator with force reflection tends to make fewer attempts to complete a given task than the operator who receives no force reflection [Draper 1995].

\subsubsection{Mechanical Design of Force-Reflecting Manual Controllers}

The architecture of force-reflecting manual controllers can be divided into two main categories: serial and parallel. Most of the force-reflecting manual controllers use a serial structure because of its design simplicity and large workspace. However, the parallel structure is a promising design in some aspects. The parallel design allows the actuators to be located on the fixed base. Thus, it provides higher stiffness and better precision [Batsomboon and Tosunoglu 1996a; Conklin and Tosunoglu 1996]. In addition, parallel mechanisms tend to be more compact than serial mechanisms. Some of the well-known serial- and parallel-structured manual controllers are reviewed below. 


\title{
Serial-Structured Force-Reflecting Manual Controller Designs
}

\author{
Teleoperator System SM-229
}

In 1977, Teleoperator System Corporation developed a bilateral force-reflecting servo masterslave manipulator called SM-229. It had seven degrees of freedom with a $3.7 \mathrm{~m}^{3}$ workspace. It was designed to serve the requirements of a variety of new installations in nuclear plants. Conceivably, the SM-229 was the first member of a family of force-reflecting electric masterslave manipulators designed to be produced commercially and maintainable [Martin and Kuban 1985].

\section{Bilateral Force-Reflecting 6-DOF Manual Controller}

In 1980, Jet Propulsion Laboratory (JPL) and Stanford Research Institute (SRI) developed a universal, bilateral force-reflecting 6-DOF manual controller [Kim 1991]. The design effort was to minimize friction, backlash, and inertia at the handgrip. The system used a cable/pulley-based counter-balancing and power-transmitting mechanism that was capable of generating a force up to $35 \mathrm{oz}$ at the handgrip. In addition, a counterbalance assembly was included in the system to reduce gravitational effects [Bejczy and Salisbury 1980].

\section{Handyman}

The Handyman electrohydraulic manipulator was developed by General Electric company in 1985 [Kim 1991]. The system includes articulated fingers and an exoskeleton force-reflecting master arm. However, the Handyman did not prove to be practical for several reasons. One of the biggest factors was the limitation of the technology at that time. Other factors included its large size and overall reliability [Mosher and Wendel 1960].

\section{Remote Manipulator System (RMS)}

In the 1970s, NASA developed the Remote Manipulator System (RMS) for the space shuttle [Kim 1991]. The system uses two 3-DOF hand controllers: one for translational motion and the other for rotational motion of the end effector [Ravindran et al. 1984]. The controllers do not reflect forces experienced by the RMS. The RMS uses a resolved unilateral rate control of the individual joints; hence, it essentially controls only position of the remote system.

\section{Maintenance System (M-2)}

The Model M-2 Maintenance System was developed at the Oak Ridge National Laboratory (ORNL) in an effort to improve remote manipulation technology for nuclear fuel reprocessing and other remote applications [Martin and Kuban 1985]. The system consists of two forcereflecting master controllers for two servo manipulator arms, television viewing, lighting, and auxiliary lifting capabilities. The touch-screen system was used as an interface between the operator and the remote manipulators. The features include force ratio selection, camera/lighting control, and system status diagnostics. 


\section{Advanced Servo Manipulator (ASM) System}

This remote maintainable force-reflecting servo manipulator system was also developed at ORNL [Martin and Kuban 1985]. The main objective of the ASM was to use it in reprocessing maintenance that required reliability, radiation tolerance, and corrosion resistance. The ASM uses eight remotely replaceable module types where each module weighs less than $23 \mathrm{~kg}$ so that it can be carried by another ASM. The servo manipulator used torque tubes to provide a payload capacity of $23 \mathrm{~kg}$. One of the main differences between the ASM and the traditional system is the anthropomorphic (elbow-down) geometry. The reason for this was that the system was designed to work on objects in a vertical plane.

\section{MEL Master Arm}

The Mechanical Engineering Laboratory of the Ministry of International Trade and Industry (MITI) developed the MEL master arm for teleoperation and VR applications [Kotoku et al. 1989; Kotoku et al. 1992]. The workspace is about $40 \times 42 \times 30 \mathrm{~cm}$ and is able to provide force feedback up to $20 \mathrm{~N}$ in translation and $0.4 \mathrm{~N}$-m torque about the arm handle. Unlike the 6-DOF JPL universal master arm, the MEL arm has four degrees of freedom and uses direct-drive AC brushless motors. A SUN 25-MHz Sparc workstation is used to display VR simulations.

\section{Dextrous Arm Master}

The Dextrous Arm Master has a total of 10 degrees of freedom, seven DOF in the arm and three DOF at the wrist [Jacobsen et al. 1991]. Each joint contains a hydraulic actuator/servo valve, a load cell, and a high-precision potentiometer. The system has a relatively high bandwidth of 100 $\mathrm{Hz}$ at the wrist and provides a maximum torque of $5.5 \mathrm{~N}-\mathrm{m}$ at the hand $(97.7 \mathrm{~N}-\mathrm{m}$ at shoulder and $22 \mathrm{~N}-\mathrm{m}$ at wrist). The system was originally developed by SARCOS Co. for underwater teleoperation applications [Burdea 1996].

\section{FREFLEX Master}

The 7-DOF electrical Force-REFLecting EXoskeleton Master was developed for research at the Wright-Patterson Air Force Base [Burdea 1996]. The system provides $25 \mathrm{~N}$ of force feedback at the handgrip using cables to transmit forces to the user's hand. However, due to the large inertia, gear friction, and backlash, the system bandwidth is limited to $20 \mathrm{~Hz}$ though the control bandwidth is about $200 \mathrm{~Hz}$.

\section{Kraft KMC-9100}

The Kraft KMC-9100 force-reflecting hand controller shown in Figure 2-1 is produced by Martin Marietta/Kraft. This compact system has six degrees of freedom and is able to reflect forces up to five pounds when fully extended. It is kinematically similar to the human arm, which creates an intuitive relationship between the operator's movements and those translated to the manipulator. It was intended to be used for the Flight Telerobotic Servicer (FTS). 


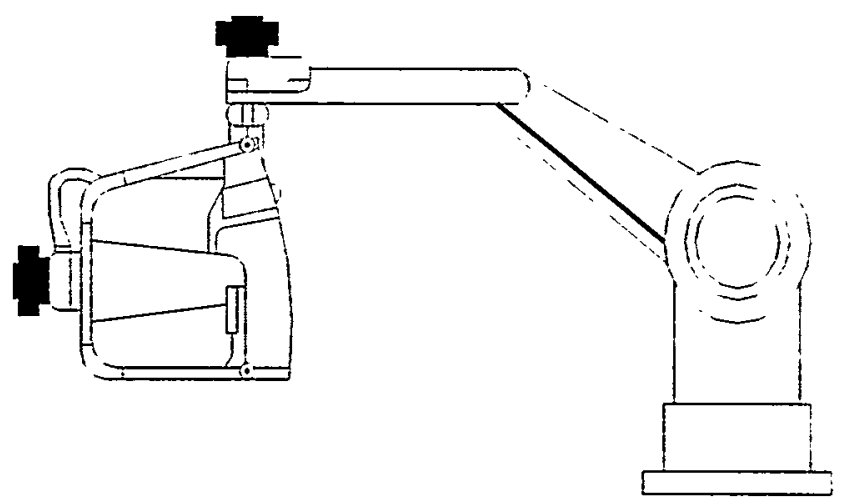

Figure 2-1. Kraft Manual Controller.

\section{Cybernet System PER-Force}

Two versions of PER-Force, $3 \mathrm{DOF}$ and $6 \mathrm{DOF}$, have been produced by the Cybernet System Corporation. The 3-DOF version consists of three $30 \mathrm{oz}$-in brushless DC motors. It is capable of reflecting a maximum force of 9 pounds, and yet the joystick unit weighs only 4.5 pounds. The 6-DOF version (Figure 2-2) incorporates three linear axes with the position resolution of 0.0003 " per location and three revolute axes with $1 / 90$ degree or 40 seconds position resolution. The unit was originally designed for the Space Station. Both versions can be controlled by IBM, VME, or Macintosh-compatible computers.

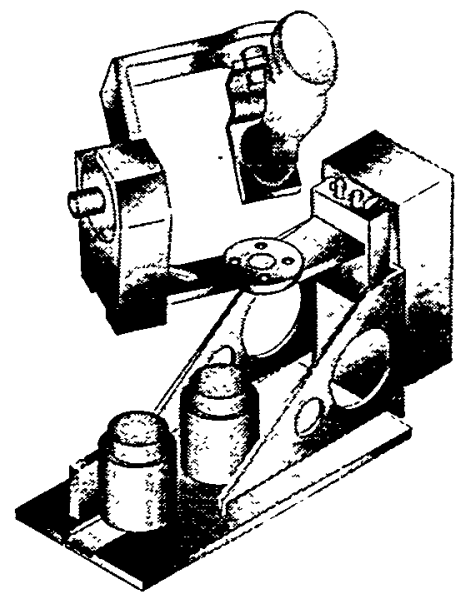

Figure 2-2. PER-Force 6-DOF Force-Reflecting Manual Controller.

\section{PHANTOM}

The Personal Haptic Interface Mechanism, PHANToM, is a 3-DOF "thimble-gimbal" desktop device that provides a force-reflecting interface between a human user and a computer [Massie and Salisbury 1994]. The system shown in Figure 2-3, which was developed at the MIT Artificial Intelligence Laboratory, enables the user to manipulate and feel the virtual objects. 
PHANTOM consists of three DC brushed motors with encoders and the human finger. The encoders are used to track the operator's finger-tip in the $\mathrm{x}, \mathrm{y}$, and $\mathrm{z}$ coordinates, while the motors control the forces exerted upon the operator. The system is able to provide a maximum force reflection of $10 \mathrm{~N}$ and continuous force of $1.5 \mathrm{~N}$.

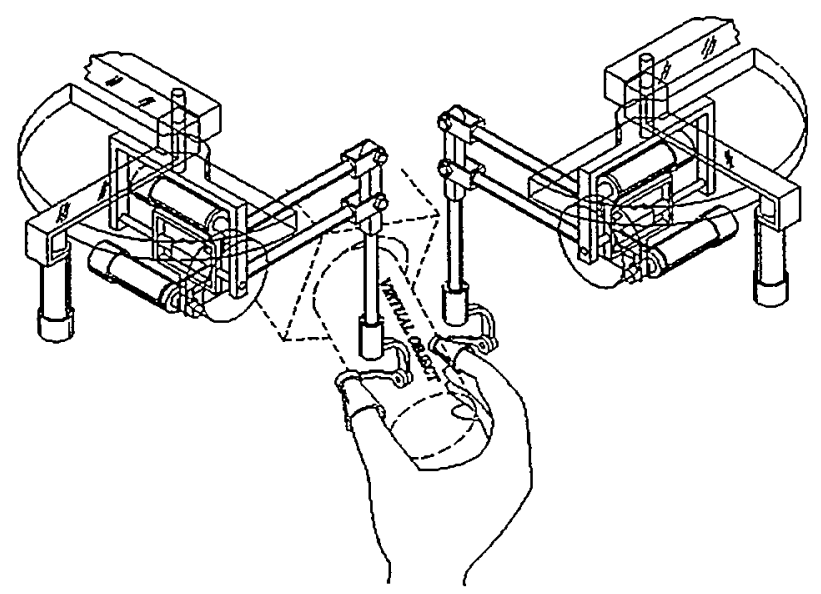

Figure 2-3. PHANTOM System.

\section{Parallel-Structured Force-Reflecting Manual Controller Designs}

\section{Stewart Platform}

The Stewart Platform (Figure 2-4) was first introduced by Stewart [Kim 1991]. It has six degrees of freedom and uses all six actuated prismatic joints. The prismatic actuators are usually not backdrivable, but with the addition of a load cell in the actuators, the Stewart Platform can be made backdrivable and able to provide force feedback. This design has attracted many teleoperation system developers because of the high force feedback produced by the system [Burdea 1996].

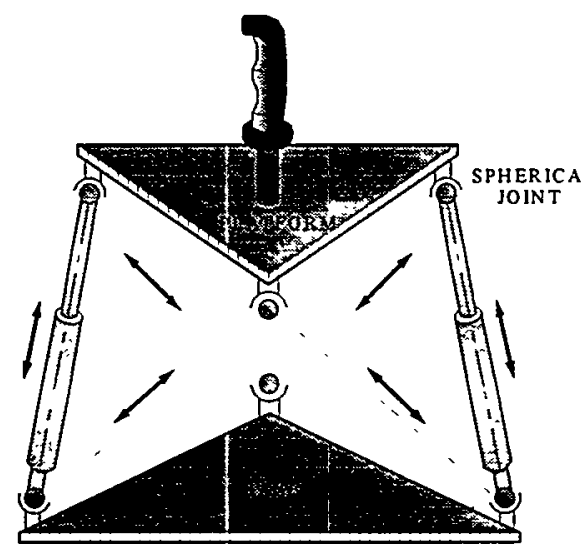

Figure 2-4. Stewart Platform. 


\section{Haptic Master}

Based on the Stewart Platform design and an earlier prototype developed by Iwata at the University of Tsukuba, Nissho Electronics Co. of Japan has produced Haptic Master [Burdea 1996]. Haptic Master has six degrees of freedom but uses nine actuators to eliminate kinematic singularities in the workspace. The system workspace is a $40-\mathrm{cm}$-diameter sphere centered on the mobile platform and can provide a maximum of $69 \mathrm{~N}$ of force feedback.

\section{Nine-String Force-Reflecting Six-DOF Manual Controller}

Nine-string six-DOF manual controller (Figure 2-5) has been developed at the University of Texas at Austin [Lindemann et al. 1987]. The system is capable of reflecting forces up to 10 pounds by using nine actuators to control nine string tensions. In addition, three constantpressure air cylinders are used to provide constant compression forces where the strings cannot provide the force needed. The workspace has no singularities, and because the motion of each string is measured by a potentiometer, the computational burden is reduced. On the other hand, the system is rather bulky and has relatively high friction from the pneumatic cylinders.

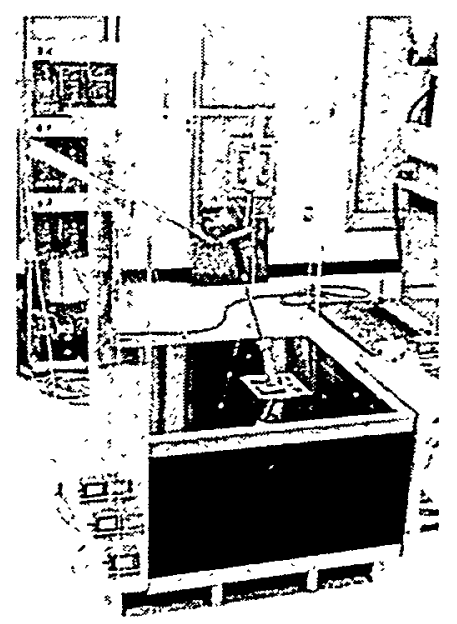

Figure 2-5. Six-DOF Nine-String Manual Controller.

\section{Three-DOF Spherical Shoulder Manual Controller}

A three-DOF spherical shoulder manual controller (Figure 2-6) has also been developed at the University of Texas. This system has almost the same features as the nine-string controller except that it has only three degrees of freedom. As in most parallel-structured mechanisms, the spherical shoulder allows the location of heavy actuators on the base, thus increasing the payload capacity. However, because each actuator is integrated with a harmonic drive system with a 60:1 gear ratio, the system exhibits high magnitudes of friction, backlash, and inertia forces due to the high gear-ratio reducers in the actuator modules [Kim 1991]. 


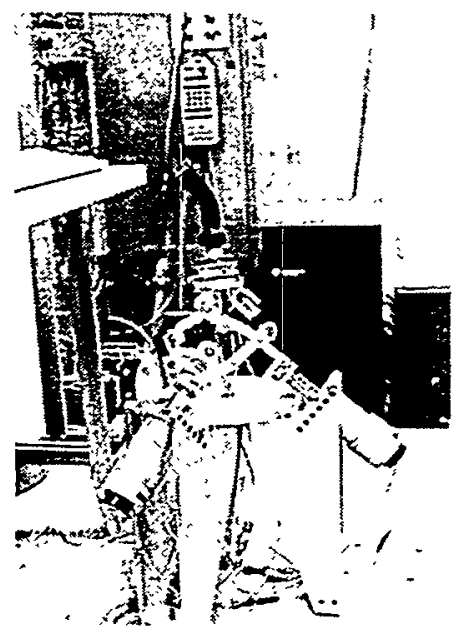

Figure 2-6. Three-DOF Spherical Shoulder Manual Controller.

Space Interface Device for Artificial Reality (SPIDAR)

SPIDAR uses a stringed force-feedback interface as does the 6-DOF Texas Nine-String manual controller, but it is simpler and more compact [Burdea 1996]. SPIDAR was developed by Ishii and Sato at the Tokyo Institute of Technology [Ishii and Sato 1993]. The system initially had four strings attached to a cap worn on the user's pointer but later had eight strings to provide force feedback to thumb and pointer finger. To manipulate virtual objects, SPIDAR II was created. Two SPIDAR IIs were combined on a single support frame to allow the user to operate with both hands. Each hand had a 30-cm-diameter spherical workspace within a planar $120 \times 60$ cm structure.

\section{FIU Three-DOF Manual Controller}

The conceptual design of a three-DOF force-reflecting manual controller, which was developed at Florida International University, is shown in Figure 2-7. The system utilizes a direct drive setup, which eliminates the need for intermediate transmission elements such as gears or belts. As a result, it promises zero backlash and virtually no friction. The system consists of three powerful, small rare-earth permanent magnet brushless DC motors that provide a maximum reflected force of five pounds. The design is expected to be one of the most compact three-DOF manual controllers. 


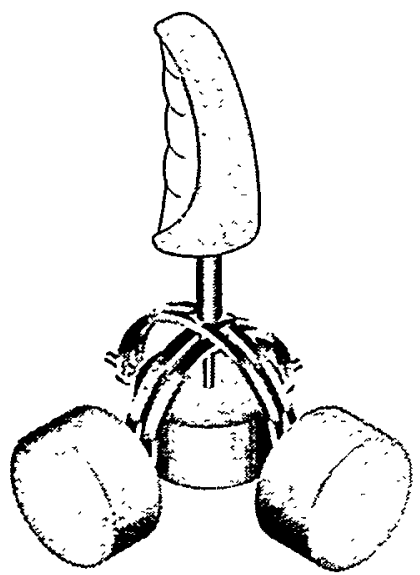

Figure 2-7. FIU 3-DOF Force-Reflecting Manual Controller Design.

Recently, telerobotic systems and VR technologies have attracted many researchers in the field of medicine, especially for surgical training [Burdea 1996]. Interactive CD-ROM anatomy and surgical training systems have been available commercially. Table 2-1 briefly describes some of the systems. The detailed descriptions of these systems can be found in [Burdea 1996].

Table 2-1.

Telerobotic Systems with VR Technologies for Medical Applications

\begin{tabular}{|l|l|l|}
\hline \multicolumn{1}{|c|}{ System } & \multicolumn{1}{|c|}{ Developed by } & Description \\
\hline $\begin{array}{l}\text { Lumbar-puncture } \\
\text { simulator }\end{array}$ & $\begin{array}{l}\text { Bostrom and } \\
\text { colleagues }\end{array}$ & $\begin{array}{l}-3 \text {-DOF haptic interface } \\
-1 \text { mm position accuracy } \\
-10 \mathrm{~N} \text { maximum resistive force }\end{array}$ \\
\hline $\begin{array}{l}\text { Laparoscopic impulse } \\
\text { engine for force } \\
\text { feedback in VR MIS } \\
\text { simulations }\end{array}$ & $\begin{array}{l}\text { Rosenberg and } \\
\text { Stredney }\end{array}$ & $\begin{array}{l}-5 \text { DOF with workspace of } 5 \times 9 \times 9 \text { in. } \\
-2 \text { lb maximum translational resistive } \\
\text { force and } 60 \text { oz-in torque about the pivot } \\
\text { axes }\end{array}$ \\
\hline $\begin{array}{l}\text { Telerobotic system for } \\
\text { microsurgery }\end{array}$ & Salcudean and Yan & -3 magnetically levitated wrists \\
& & $\begin{array}{l}-0.002 ~ N \text { force resolution for maximum } \\
\text { cutting force of } 1.2 \mathrm{~N}\end{array}$ \\
\hline $\begin{array}{l}\text { Telerobotic system for } \\
\text { training needs of } \\
\text { ophthalmic surgery }\end{array}$ & Hunter and & - A pair of 6-DOF master-slave \\
& colleagues & $\begin{array}{l}\text { A Head-Mounted Display (HMD) is } \\
\text { used to receive audio and visual } \\
\text { feedback. }\end{array}$ \\
\hline
\end{tabular}




\subsubsection{Force-Reflecting Controller Design}

The control method of the force-reflecting teleoperation system can be divided into two categories: position-position and position-force [Vertut and Coiffet 1986]. In the positionposition method, the difference of the position between the master arm and the slave arm is used to derive the force feedback. This method is used when the two arms have similar kinematic configurations. For dissimilar arms, the position-force method is used. This method uses direct force feedback rather than position error. The external force that the slave arm experiences is measured by a force/torque sensor attached to the wrist of the robot. This force is reflected to the operator hand via the master arm according to the force scaling factor. Since this feedback signal is more precise than the position error signal, the position-force method can provide better forcereflection characteristics to the operator [Cha et al. 1996].

For the position-force scheme, two control modes, position and force, must be implemented in the control loops. Whitney notes that when a force is exerted by the end-effector on the environment, a force control mode is perpendicular to the environment, and the position control mode can be exerted to the environment tangentially [Whitney 1977].

Figure 2-8 depicts the concept of an open-loop control in the position-force method. This control strategy is called open loop because each of the position and force reflection commands is fed in a forward (open loop) sense. For instance, when the force feedback feature is implemented, the reflected force will be adjusted by comparing the difference between the desired and actual values as shown in Figure 2-8. Such an open-loop scheme may not provide satisfactory results because the control system is unmodelled for dynamics, friction, backlash, and delay between the teleoperator and remote system. As a result, the system may become unstable.

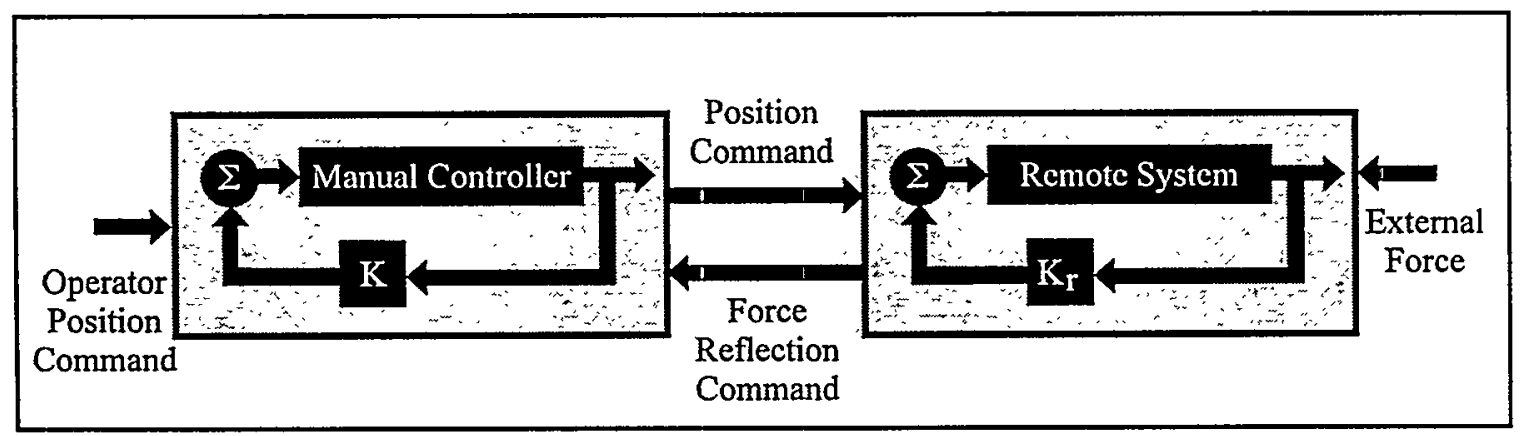

Figure 2-8. Open-Loop Control of a Teleoperation System.

A more sophisticated control scheme, the closed-loop control, is shown in Figure 2-9. The output of the remote system is fed directly back to the input of the manual controller, while the local feedback loops still remain in the control loop. This closed-loop control accounts for dynamics, friction, backlash, delay, and, perhaps, beam damping, which is an important parameter for the long-reach manipulator [Jansen et al. 1991]. 


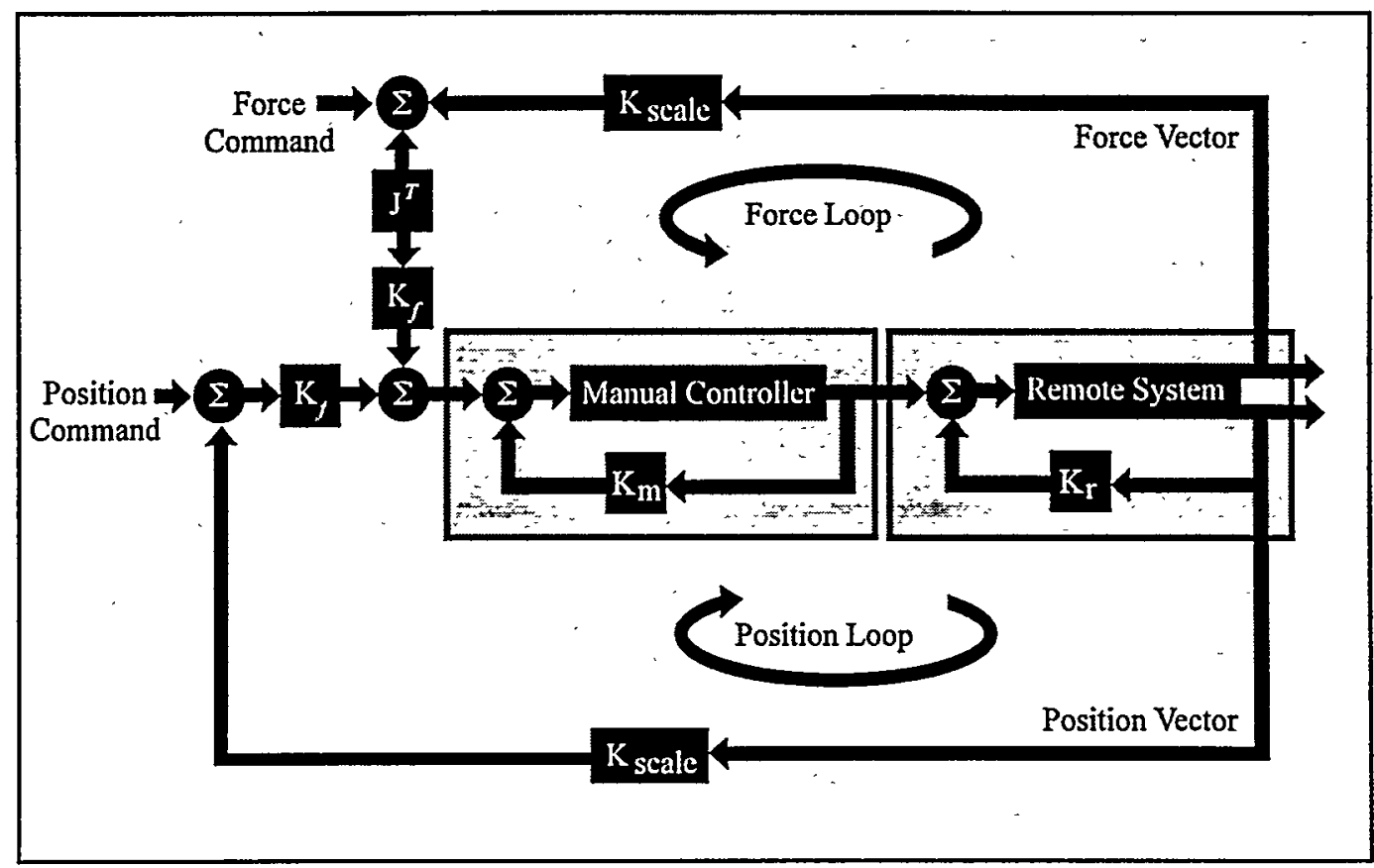

Figure 2-9. Closed-Loop Control of a Teleoperation System.

One of the crucial issues to be addressed in the force-reflection control system is time delay. The round-trip delay can be as much as two seconds in the deep ocean or six seconds in the case of the earth-orbiting space shuttle [Sheridan 1993]. Under the presence of time delay in the teleoperation system, force reflection becomes troublesome. According to Ferrell's experiments, it is unacceptable to feed force continuously back to the operator because the unexpected disturbance can cause the system to be unstable [Ferrell 1966]. Several alternatives have been proposed to deal with the time-delayed force feedback, such as displaying force feedback in the visual form, feeding the reflected force to a different master arm, and predicting the force feedback to compensate for the delay [Sheridan 1993].

Currently, some of the well-known position-force control methods used for a force-reflecting teleoperation system are kinesthetic force feedback, shared compliant control [Kim et al. 1992] and "telemonitoring" sensory feedback [Lee and Lee 1993]. These methods provide force feedback except that kinesthetic force feedback has a stiffer system. In kinesthetic force feedback, the forces sensed by the remote manipulator are fed back and reflected through the operator's manual controller, whereas in a shared compliant control, the human operator shares the control task with the autonomous compliant control of the remote manipulator. In the telemonitoring control mode, the system consists of a position control with a position error-based force reflection and remote site compliance [Lee et al. 1985]. Its control mode basically is under a shared compliant control but has telemonitoring force feedback.

When there is no significant time delay involved, all three control modes perform the given task at about the same efficiency. However, under the presence of time delay in the teleoperation system, such as in underwater operations or in space operations, force reflection causes problems. The system displays oscillation and, most critically, may become unstable. 
Experimental results show that the kinesthetic force feedback control mode cannot be operated at time delays above 0.5 to 1 second because of the instability problem [Kim et al. 1992].

Shared compliant control has been implemented as a new feature added to the force-reflecting telerobot system. In shared compliant control, the human operator controls the compliant robot hand. The compliant hand reduces the contact force between robot manipulator and objects. Thus, it improves smoothness of mechanical contact and safety.

W.S. Kim, B. Hannaford, and A.K. Bejczy at Jet Propulsion Laboratory (JPL) have proved the superiority of shared compliant control over a kinesthetic force feedback system [Kim et al. 1992]. Their experiment demonstrates that shared compliant control is able to perform the task at time delays above 1 second. This is possible because the entire feedback loop remains in the remote side. As a result, time delay in communication does not cause a stability problem. In addition to the time-delay advantage, the completion time is also reduced when shared compliant control is used instead of kinesthetic force feedback [Kim et al. 1992].

S. Lee and H.S. Lee at the Advanced Teleoperation (ATOP) Laboratory of JPL have developed a teleoperator control system called "telemonitoring" sensory feedback [Lee and Lee 1993]. The control mode consists of position control with position error-based force reflection and remote site compliance [Lee et al. 1985]. Basically, its control mode is under shared compliant control while having telemonitoring force feedback. Experiments have been conducted to evaluate and compare the performance of various manual control methods, including conventional force feedback, shared compliant control, and telemonitoring force feedback. The telemonitoring force feedback was always ranked first [Lee and Lee 1993]. Under shared compliant control mode, the operator tends to make larger positional and/or orientational command errors. This is because the operator does not know how much force on the remote manipulator is shared by the compliant control. As a result, the operator feels uncertain in evaluating commands, which causes more erroneous and hesitant control behavior. Lee and Lee also suggest that when the proposed system is compared to the conventional force feedback and shared compliant control, it is expected to perform better where time delay is significant, although this has not yet been verified. 


\subsection{FORCE-REFLECTING TELEOPERATION SUBSYSTEMS}

This section reviews some of the components for a teleoperation system. The material covers the major components, such as actuators, transmission systems, sensors, computer hardware, computer interface, and computer software.

\subsection{ACTUATORS}

Input power for teleoperated systems is provided by hydraulic, pneumatic, or electric actuators, each of which is briefly reviewed below.

\subsubsection{Hydraulic Actuator}

Hydraulic actuators are usually used for large telemanipulators because hydraulic power can generate relatively high forces in a small volume with good rigidity and servo control of position and velocity [Todd 1986]. Thus, the manipulators can be lightweight, which allows them to carry more weight for the same power output provided by an electric motor. However, one of the biggest problems with hydraulic systems is their tendency to leak oil, which is not suitable for most teleoperation applications [Poole 1989].

\subsubsection{Pneumatic Actuator}

Pneumatic systems are based on the pressure available from a compressed air reservoir, and their valves are either fully on or fully off, where each actuator stops only at the end of its travel. Therefore, pneumatic actuators are often used only for the gripper of an electric or hydraulic manipulator, where its elasticity is useful as it automatically limits the force [Todd 1986]. In addition, a pneumatic gripper actuator is very light and needs to be connected only by a narrow flexible tube that is easy to feed through complex mechanisms such as a wrist.

\subsubsection{Electric Actuator}

At present, electric actuators represent about 70 percent of all the actuators used in robotics. Some of the advantages of the electric motors that make them more popular in industry are as follows:

- High reliability

- Low friction

- Easily controlled by a computer or a microprocessor

- Compact size, volume, and weight with respect to the power output: High Torque/Weight ratio

- Less frequent maintenance requirements

- Precise, responsive, clean and quiet operation

- Longer life. 
Electric motors can be categorized in several ways, but for the teleoperation applications, the field is further narrowed, and only the stepper and servo motors are presented.

\section{Stepper Motor}

A stepper motor is simple to use and control in an open-loop configuration. Commutation and position are controlled by step and direction pulses. A stepper motor provides excellent torque at low speeds, which is suitable in robot applications. However, stepper motors can cause slippage during rapid acceleration and when overloaded. The error produced by this slippage can go undetected and cause damage. Thus, in order to control an open-loop system accurately, the pulse frequency must be varied during times of acceleration. On the other hand, when driving light loads, stepper motors have resonance effects. They oscillate around the stopped position and overshoot. To eliminate vibration or resonance effects and suppress overshoot, a damping system is required. Generally, a stepper system does not provide any kind of feedback information. Therefore, a feedback device must be added to verify position; otherwise, torque cannot be controlled.

\section{Servo System}

A servo motor is used in a closed-loop configuration. The servo control systems include those elements that interface with the controller and the manipulator. Each servo mechanism has two sensors (one receives signals from and the other sends signals to the controller) that create a closed-loop feedback system. The control system, as a whole, uses data generated by the feedback system to monitor movement. The computer then performs calculations to determine the next motion and directs the servo mechanisms to move accordingly.

Typical servo motors include integrated position and velocity sensors. Unlike the stepper motor with added feedback devices that make the necessary corrections between actual and desired position after the move, the servo motor continuously monitors actual information, such as position and velocity, and compares those values to desired values and makes necessary corrections to compensate for any error.

There are two types of DC servo motors: brush and brushless. Conventional DC motors have brushes and commutators. The main drawback of this type of motor is a maintenance problem. When the motor is loaded, the sliding contact between the brushes and the commutators causes an arc, and both components must be replaced when they wear out.

The other type of DC servo motor is the brushless type. It displays the same torque-speed characteristics as a conventional DC brush motor. Recently, there has been an increasing interest in using brushless motors in high-performance applications. A number of practical advantages accrue from the elimination of the brushes and commutator. The brushless motor has longer life, better heat dissipation, and is free of maintenance.

\subsection{TRANSMISSION SYSTEMS}

Since an actuator output is typically at higher speeds than needed in teleoperation systems and actuators are too large, heavy, and bulky relative to the output power, transmission systems are 
used. Hence, transmission elements are added to provide the system with higher torque while keeping the actuator systems compact.

Typical transmission components are gears, tendons, and linkages. However, for advanced teleoperator systems, gears are the most common components used because they are capable of carrying larger payloads and are more accurate than the other two types mentioned above. The harmonic drives and direct-drive systems have also become popular in industry.

\subsubsection{Gears}

Gears are the most common transmission elements because they can transmit large torques with the use of small-sized motors. Hence, the systems are compact. However, many problems are encountered when using gearing systems. One of the biggest problems is backlash, which causes inaccurate motion control. In addition, when designing a gearing system, the designer must consider the mechanical nonlinear properties such as friction and deflection.

\subsubsection{Harmonic Drives}

Harmonic drives, which use a special gear architecture, are usually used with revolute joints. A number of advantages of harmonic drives over the other transmission elements can be summarized as follows: high gear ratios, compactness, and almost zero backlash. These features increase accuracy. However, because of the tight mechanism, contact area between the teeth is considerably larger, which causes high friction.

\subsubsection{Direct Drive}

Recently, the development of motors has been greatly improved. With these improvements, motors have been able to provide high torques with relatively small sizes. This advantage allows the designer to develop the system by coupling the system's load directly to the motor without the use of transmission elements, such as belts or gears. Such a system is known as direct drive. The elimination of the intermediate transmission provides the system with greater accuracy since there is no friction or backlash introduced to the system. The reliability of the system is also improved because a smaller number of components are used. However, one of the main problems that direct-drive motors encounter is overheating. As the intermediate transmission elements are eliminated, the load must be carried by the motor entirely and directly. Thus, the motor must be able to exert a large amount of continuous torque with very efficient cooling; otherwise, the motor may be burned out.

\subsection{SENSORS}

In telesensation systems, the goal is to provide the operator with the feeling of presence at the remote site. To accomplish this, various types of sensors must be used in the system. The sensors must be able to reproduce faithfully those physical properties of the working environment, and they must be sufficient in providing sensory feelings to the operator so that he/she can complete the required jobs with relative ease [Johnsen and Corliss 1971]. For the purpose of this work, the sensors are divided into four main categories: position sensing, speed sensing, force and torque sensing, and temperature sensing. 


\subsubsection{Position Sensing}

\section{Encoders}

Encoders are used to control position by translating mechanical motion into electronic signals. There are a number of types used, but the most widely used are the optical encoders. The encoder consists of a glass and a mylar or metal wheel with alternating clear and opaque stripes. The positions are monitored by the detection of the stripes by optical sensors to generate the output position in digital form. Two types of optical encoders used are incremental and absolute encoders.

- Incremental encoder: This form of optical encoder produces a pulse for a given increment of shaft rotation. Shaft angular rotation is determined by counting the encoder output pulses.

- Absolute encoder: An absolute encoder has a number of output channels. Each position of the shaft is determined by the unique code. As a result, an absolute encoder is preferable for applications that require high accuracy.

\section{Resolvers}

Resolvers are electromagnetic feedback devices which convert angular shaft position into analog signals. These signals can be processed in various ways, such as with a resolver-to-digital converter to produce digital position information. Resolvers are rugged devices compared to encoders, but they are relatively noise-insensitive and able to transmit data over long distances.

\subsubsection{Speed Sensing}

\section{Tachometers}

Tachometers are electromagnetic sensors that generate an output voltage signal proportional to shaft velocity. A small permanent magnet DC motor can be used as a tachometer. The manufacturers often include a tachometer in DC servo motors so that they are able to produce low-cost and high-performance products.

\subsubsection{Force and Torque Sensing}

\section{Force and Torque Sensors}

Force sensors measure the reaction forces between the object and the environment; thus, they are classified as external sensors. On the other hand, joint torques are sensed with internal sensors. In order to obtain accurate results from force sensors, they should be installed directly on the gripper, instead of between the wrist and the end-effector. This is because the weight of the endeffector can take up most of the dynamic range of the sensors.

Strain gauges are usually the basic sensing elements of force sensors. A torque sensor has a transducer in a sealed unit and includes a microprocessor unit to resolve the measurements that 
are applied to the transducer into six equivalent Cartesian force/torque components. It then gives the output information via a standard interface.

\subsubsection{Temperature Sensing}

\section{Thermistors}

Changes in temperature can be measured and sensed by a device called a thermistor. It responds to changes in temperature by a change of resistance in the sensing element. Thermistors can be as small as 0.005 in in diameter and react to temperature changes quickly. Thus, they can be used in point sensing. However, the output of thermistors is nonlinear with temperature. As a result, the computer must be able to interpret the output with the response curve of the particular thermistor.

\section{Thermocouples}

Thermocouples have been used as temperature sensors for years. They consist of two dissimilar metals that are in thermal and electrical contact. As the temperature increases, the output of the thermocouple increases but nonlinearly. Thermocouples can be made very small and can cover a wide range of temperatures. However, in addition to nonlinear output, thermocouples also suffer from low signal outputs.

\subsection{COMPUTER HARDWARE}

\subsubsection{Buses}

Buses carry and link information between the components or between subsystems. When selecting a bus system, several factors should be considered. Preferable characteristics include the following: [Tooley 1988]

- Industry-standard architecture

- High data transfer rate

- Support of a wide range of processors (8-, 16- and 32-bit types)

- Standard size.

VME, STE, and PCI form the standard buses currently used in control systems.

\section{VME Bus}

VME bus supports fast data transfer rates and uses a single connector to provide a 16-bit data path. In the case of the extended bus that supports 32-bit addresses, a second connector is used. However, the VME bus may be considered expensive for simpler applications. 


\section{STE Bus}

One of the advantages of the STE bus is that the bus signals and protocols are standardized. Various processors from different manufacturers can be implemented in the system. Thus, the designer can be confident in interconnecting STE bus products from different companies.

\section{PC Bus}

Industry-standard PCI specifications have recently emerged and been supported by PCcompatible computers and PowerMacs. Hence, the new systems targeting PC platforms should consider the PCI architecture.

\subsection{COMPUTER INTERFACE}

An interface represents a connection between a computer and other components in the system. In the field of robotics and telesensation, the computer interface is very important, as the control system must be accurate and fast. The computer interfaces discussed here are actuator controllers and $\mathrm{A} / \mathrm{D}, \mathrm{D} / \mathrm{A}, \mathrm{D} / \mathrm{D}$ converters.

\subsubsection{Actuator Controller}

The controller of actuators can have various control methods. Two of the most popular control methods used in industry today are standalone and bus-based architectures whose main advantages and disadvantages are described in the following sections.

\section{Standalone}

This type of controller operates without the need for data or other control signals from elsewhere. A standalone unit usually consists of a keypad for data entry and a simple display device. Since the unit is unique, it has its own commands that vary from manufacturer to manufacturer. Although some of the products include more than 100 commands, it is relatively easy to write elementary programs because the commands are usually word-descriptive.

\section{Bus-Based Systems}

Bus-based systems are considered to be very flexible, since the design is open to various options for optimizing the performance without affecting system compatibility. In addition, since the system comes in the form of computer cards, users are able to keep up with the rapid improvement in technology by replacing or upgrading the old card instead of changing the whole system. Thus, time is conserved, and obsolescence is prevented with relative ease. However, one of the disadvantages of the bus-based control system is related to the integration between the motion and $\mathrm{I} / \mathrm{O}$ structure. It is necessary to obtain software integration of different programming languages for different cards (controllers).

\subsubsection{A/D, D/A, and D/D Controllers}

Conversion between analog and digital quantities can be considered as the heart of computer control systems. Since most of the natural parameters, such as speed and distance, are analog, in 
order to use a computer to control the system, it must first convert these quantities into digital form using $A / D$ converters. The computer system then does the calculations, converts back to analog signals using $\mathrm{D} / \mathrm{A}$ converters, and then sends the signals back to the devices. For some devices, such as encoders, the quantities are measured in digital type, so D/D converters are used. Some of the most important features when selecting these cards are high speed, low noise, and low cost [Hnatek 1976].

\subsection{COMPUTER SOFTWARE}

\subsubsection{Supervisory Interface Software}

The general specifications of the software structure are presented in Figure 3-1. Some of the desirable aspects of the interface software are described below.

\section{Menu-Driven Interface}

In a telesensation system or an advanced teleoperator system, a friendly graphical user interface (GUI) that supports a menu-driven Windows environment is a very important element. This type of sophisticated software enhances the performance of the operator to accomplish the required tasks more efficiently.

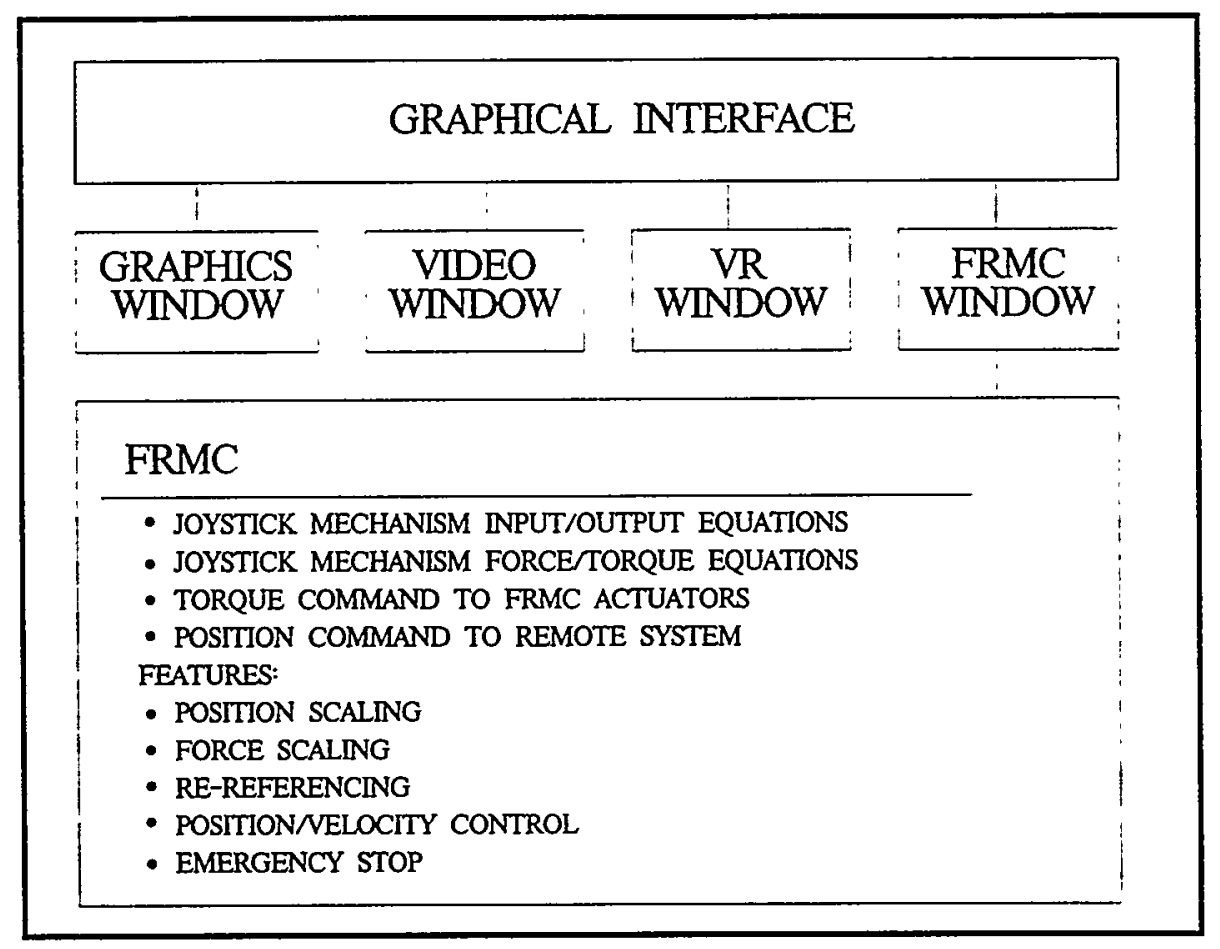

Figure 3-1. Teleoperation System Software Structure. 


\section{Graphics Window.}

By providing graphics window displays in the telesensation system, the operator is able to interface with the remote system by means of pictorial communications [Kim 1993]. The purpose of the graphics system is not only for the use of control interface but also for off-line task analysis, for planning, and for use as an animation environment for sensor-based mobile robots [Kim et al. 1993]. The amount of detail and accuracy in the displayed model depends on the fidelity of the system. The fidelity also includes the smoothness of an animated remote manipulator and the update time between the operator's motions and the simulation's motions [Kim and Bejczy 1991]. By using such graphics software, the mobile robotic systems can be designed, developed, and operated in a more efficient and reliable fashion.

In the past, the instability of the visual feedback due to time delay was avoided by the open-loop control strategy called "move and wait," wherein the operator controls the master arm and waits for the action of the slave system over the round-trip delay time before he/she issues another command. To enhance the performance of the bilateral teleoperator system, a predictor display is introduced [Sheridan 1993]. The predictive display technique provides a real-time computer graphics generation and a detailed display of static objects from the delayed video for predicting the robot arm motion before the actual operations occur [Bejczy et al. 1990].

In May 1993, the telerobotic experiment that involved the Jet Propulsion Laboratory (JPL) as the simulated ground control station and, 2500 miles away, the Goddard Space Flight Center (GSFC) as the remote site was performed using a high-fidelity predictive/preview display technique [Kim and Bejczy 1993]. The experiment successfully demonstrated that under a time delay of several seconds, this method could be implemented to the system to compensate in real time for the operator's visual perception of the task.

\subsubsection{Joystick Control Software}

\section{Position and Force Scaling}

This type of joystick control software allows the user to input the scaling values of position and force reflection between the joystick and the manipulator. In the position mode, as the operator moves the joystick a certain distance, the manipulator would move according to the set scaling value. In the force mode, the operator is able to input the scaling value of reflected force at the manual controller. For instance, when the robot experiences a certain amount of force, the magnitude of the reflected force is scaled by the operator. This is especially important to prevent fatigue. This flexibility makes it possible to accomplish various tasks at any level of delicacy.

\section{Rereferencing}

As the operator moves the joystick, the manipulator moves a certain distance. However, in order to move the manipulator further, the operator must define a reference point so that he/she can make further joystick movements. This is accomplished by temporarily suspending the joystick/remote system connection, moving the joystick to a desirable reference position within its workspace, and then establishing the connection with the remote system. This can be achieved by placing a connect/disconnect toggle switch on the joystick. 


\section{Joystick Mechanism Input-Output and Force Equations}

The joystick input-output motion equations and force reflection equations must be written and carried out by special software. This software computes the forward and inverse kinematic analysis of the manual controller and remote manipulator. These equations should be written as efficiently as possible so that they can be used in real-time computer control.

\subsubsection{VR Control Software}

One of the main advantages in implementing VR control software in a telesensation system is that VR is capable of moving the human-robot interface to a new intuitive and user-friendly level [Davies 1993]. The interaction between human and computer is much more perceptive than that of using a mouse to change the view in a flat screen display. In addition, operators become familiar with the environment rapidly and require little instruction in how to use the system. In designing the VR control software, a main requirement is that the tracking of the user's head must be accurate in terms of position and orientation.

\section{Latency and Update Rate}

Aside from accurate tracking, the prime considerations of the system designer are minimizing latency and maximizing update rate. The software must be able to modify images rapidly and keep up with the user's head movements [Sheridan 1995]. Both parameters are indications of whether a VR system will serve as a useful device or frustrate the user [Vince 1995].

\section{VR Input Capability}

The interaction between the operator and the VR system can be made through an immersive stereo viewer and voice input. An example of such a system has been developed at ACML for application in the cleanup of massive Underground Storage Tanks (UST). This system uses audio feedback to continuously guide the operator and to provide command confirmation [Miner and Stansfield 1994].

\subsection{SUMMARY}

A typical teleoperation system consists of many components. Depending on how these components are classified, actuators, transmission systems, sensors, and computer systems are always parts of such a system.

The types of actuators used in robotic systems are determined largely from the types of applications. Hydraulic actuators are generally used for heavy-duty applications, such as underwater operations, whereas most industrial robot systems use electric actuators for clean, precise, and quiet operations. Also, a brushless DC servo motor is preferred if maintenance is minimal. As for pneumatic actuators, they are commonly used in the gripper mechanism because of their light weight.

Transmission systems, such as gears and linkages, are used to reduce the load carried by the actuators. Gears are the most common transmission elements since they can transmit large torques, but the system will sustain friction and backlash. A more compact design is harmonic 
drives, which provide high gear ratios and almost zero backlash. Nevertheless, harmonic drives suffer from friction because of the tight mechanism.

Sensors are also important elements of the system. They provide feedback of the system to the operator. Position feedback can be achieved by using an encoder (incremental and absolute) or resolver, whereas velocity feedback is available through the use of a tachometer. Force and torque sensors provide force feedback through the operator by attaching the device at the wrist of the robot. In addition, with the use of thermistors or thermocouples, the environment temperature can be perceived at the operating site.

Computer systems are always a major factor of any teleoperation systems. Computer hardware, such as a system bus that carries and links information between the components or between subsystems, must be carefully selected. Preferable characteristics are high data transfer rate and standard size. The standard buses used in control systems are usually VME, STE, or PCI.

An actuator controller and $\mathrm{A} / \mathrm{D}, \mathrm{D} / \mathrm{A}$, and $\mathrm{D} / \mathrm{D}$ converters provide the interface between a computer and other components. Two of the most popular control methods are standalone and bus-based systems, where each has advantages and disadvantages over the other. For instance, a standalone system is simple to use but incapable of handling the changes of configurations, while bus-based systems are flexible but must use the software compatible with the cards.

Computer software in the teleoperation system is divided into three parts:

1. Supervisory interface software: This level consists of a menu-driven interface and graphics window to provide the operator with a friendly user interface.

2. Joystick control software: The position and force scaling, rereferencing, and joystick mechanism input-output and force equations are included in this level. This level attempts to provide the operator with all the parameters and options to control the remote system.

3. VR control software: The software must minimize latency and maximize update rate and provide input capabilities, such as voice input, so that the VR unit will serve as a useful device not frustrate the user. 


\subsection{DESIGN AND DEVELOPMENT OF A 1-DOF FRMC}

The 1-DOF Force-Reflecting Manual Controller (FRMC) version has been designed and constructed to demonstrate the basic principles of the force-reflecting teleoperation system. The specifications of the system components and the system characteristics are given in this section. In addition, the system parameters are identified in order to construct a mathematical model. This model will be used to test different control methods as described in the next section.

\subsection{1-DOF FRMC COMPONENTS}

At this stage, the dimensions of the system are not a concern of the development of the 1-DOF FRMC, since the intention here is to establish the necessary connection and to demonstrate the basic principles of the system. Many companies have been contacted to discuss their actuator and controller systems. Though a motor from one company can be used with a controller from another company, the decision was made to purchase the complete system from a single company. One of the main reasons is that it is relatively easy to establish the connections of the components that come from the same company [Tosunoglu et al. 1996a]. Should any problems arise, they can be resolved with relative ease.

The actuator and controller systems, which included a rare-earth permanent magnet brushless DC servo motor with 1000-line encoder, PC bus-based controller with PID feedback, amplifier, and interface board, were purchased from the Aerotech Company. Aerotech was selected because of its competitive price and suitability of hardware components. Other components comprising the 1-DOF FRMC include the force/torque sensor and processor. The industrial robot PUMA 760 is used to simulate the robotic device at a remote site. Table 4-1 provides a summary of the purchased hardware components and software for the 1-DOF FRMC, whereas Figure 4-1 shows the system components. The specifications of each item are given in the relevant section below.

Table 4-1.

Listing of Hardware/Software Components for 1-DOF FRMC System

\begin{tabular}{|c|c|c|}
\hline Components & Model & Company \\
\hline Brushless DC servo motor & BM200 & Aerotech \\
\hline Encoder & MS-E1000H & Aerotech \\
\hline Controller & UNIDEX500 & Aerotech \\
\hline Amplifier & BA20 & Aerotech \\
\hline Interface Board & BB501 & Aerotech \\
\hline Force/Torque Sensor & $100 \mathrm{M} 40 \mathrm{~A}-\mathrm{U} 760$ & JR3 \\
\hline ISA-Bus Receiver/Processor & P/n 1523 & JR3 \\
\hline Control Software & C++4.0 & Borland \\
\hline Computer & IBM Pentium 166 MHz. & Dell \\
\hline Remote System Industrial Robot & PUMA 760 6-DOF Robot & Unimation \\
\hline
\end{tabular}




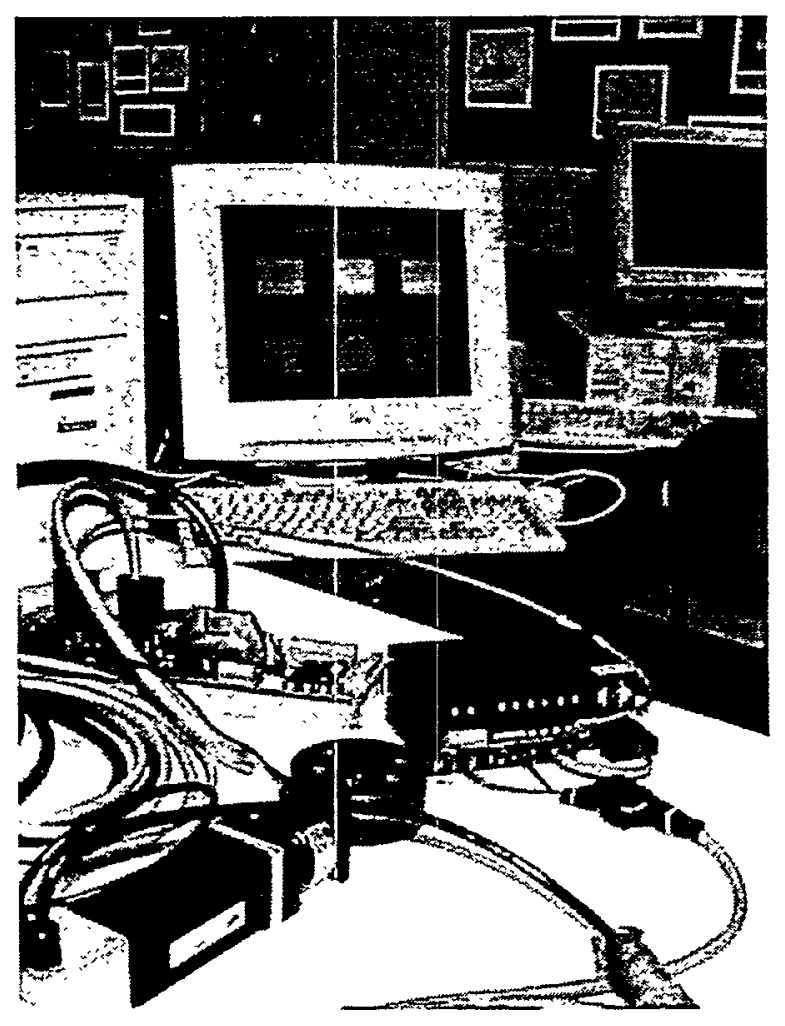

Figure 4-1. 1-DOF FRMC Components.

\subsubsection{Actuator}

In the past decade, the technological development of motors has been greatly improved. Highperformance motors have become smaller and better. This results from using the latest magnet materials, which are Samarium Cobalt and Neodymium magnets, also known as "rare-earth" magnets. These types of permanent magnet materials are classified as the highest available energy product. Less material is used in producing high-performance motors. Thus, the sizes of the rare-earth magnet motors are smaller than other magnet material types such as Ferrite or Alnico.

The motor used in the 1-DOF FRMC is made from rare-earth neodymium magnets. Therefore, the dimension of the system is relatively compact. The motor is attached to a 1000-line encoder. The detailed specifications of the motor and encoder are given in Tables 4-2 and 4-3, respectively. 
Table 4-2.

BM 200 Brushless Servo Motor Specifications

\begin{tabular}{|c|c|}
\hline Parameters & Values \\
\hline Continuous Stall Torque & $200 \mathrm{oz}$-in \\
\hline Peak Torque & 500 oz-in \\
\hline Maximum Speed & $8000 \mathrm{rpm}$ \\
\hline Rated Speed & $4000 \mathrm{rpm}$ \\
\hline Rated Power & $0.60 \mathrm{hp}$ \\
\hline Torque Constant (Stall) & $28.6 \mathrm{oz}$-in/amp (RMS) \\
\hline Maximum Continuous Stall Current & $10 \mathrm{~A}$ \\
\hline Continuous Stall Current & $7 \mathrm{~A}$ \\
\hline Maximum Peak Current & $30 \mathrm{~A}$ \\
\hline RMS Peak Current & $21 \mathrm{~A}$ \\
\hline Back EMF Constant (line-line) & 17.2 Volt (peak) $/ \mathrm{krpm}$ \\
\hline Terminal Resistance (line-line) & $1.1 \mathrm{ohms}$ (cold) \\
\hline Armature Inductance (line-line) & $1.1 \mathrm{mH}$ \\
\hline Inertia & $0.0019\left(\right.$ oz-in-sec $\left.{ }^{2}\right)$ \\
\hline Maximum Acceleration & $270000 \mathrm{rad} / \mathrm{sec}^{2}$ \\
\hline Motor Constant & $19 \mathrm{oz}$-in $/ \mathrm{watt}^{1 / 2}$ \\
\hline Static Friction Torque & 4 oz-in \\
\hline Maximum Armature Temperature & $155^{\circ} \mathrm{C}$ \\
\hline Electrical Time Constant & $1.1 \mathrm{msec}$ \\
\hline Thermal Time Constant & $12 \mathrm{~min}$ \\
\hline Thermal Resistance & $109^{\circ} \mathrm{C} /$ watt \\
\hline Maximum Radial Load & $20 \mathrm{lb}$ \\
\hline Maximum Axial Load & $20 \mathrm{lb}$ \\
\hline $\begin{array}{l}\text { Motor Weight } \\
\text { (includes encoder and end cover) }\end{array}$ & $4.3 \mathrm{lb}$ \\
\hline
\end{tabular}


Table 4-3.

Encoder Specifications

\begin{tabular}{|c|c|}
\hline Parameters & Values \\
\hline Input Power & $5 \mathrm{VDC} @ 400 \mathrm{~mA} \max$ \\
\hline Sink/Source Current & $20 \mathrm{~mA}$ \\
\hline Output Configuration & Differential line driver (26LS31) \\
\hline Output Frequency & $100 \mathrm{KHz}$ (all channels) \\
\hline Operating Temperature & $-10^{\circ} \mathrm{C}-85^{\circ} \mathrm{C}$ \\
\hline Storage Temperature & $-30^{\circ} \mathrm{C}-100^{\circ} \mathrm{C}$ \\
\hline Resolution & $1000 \mathrm{Cycles} / \mathrm{Rev}$ \\
\hline Commutation & 4 Cycles/Rev \\
\hline
\end{tabular}

\subsubsection{Amplifier}

The brushless servo amplifier for this 1-DOF FRMC is the model BA20 from Aerotech, Inc. The BA amplifiers can be integrated into a system using three basic configurations: velocity command, current command, and dual-phase command. In the velocity command configuration, the speed of the motor is controlled by the amplifier. A feedback signal from the encoder is monitored by the amplifier. From this signal, the amplifier adjusts the velocity of the motor accordingly, depending upon the velocity command from the external controller. In this configuration, the amplifier closes and controls the velocity loop. In the current command configuration, the output current to the motor is proportional to the current command input. The advantage to this configuration is the sine and cosine signals sent to the amplifier; therefore, a tachometer is not required. Finally, the dual-phase command configuration is used in the 1-DOF FRMC. In this mode, the differential input, pre-amplifier, and self-commutation circuits are bypassed. The dual-phase inputs, which are sinusoidal, are $120^{\circ}$ out of phase from each other. The third phase is generated by the amplifier. The advantage of this configuration is that it provides the smoothest possible motion.

The specifications of this amplifier are given in Table 4-4. 
Table 4-4.

BA20 Amplifier Specifications

\begin{tabular}{|c|c|}
\hline Parameters & Values \\
\hline Standard Voltage Configuration & $160 \mathrm{~V}$ \\
\hline Peak Output Current & $20 \mathrm{~A}$ \\
\hline Continuous Output Current (peak) & $10 \mathrm{~A}$ \\
\hline DC Bus Voltage Range (Nominal VDC) & $80-160 \mathrm{~V}$ \\
\hline
\end{tabular}

\subsubsection{Controller}

The UNIDEX 500 (U500) base model is the basic version of the U500 PC bus-based controller from Aerotech Inc. The servo control system includes the following:

- 24-bit DSP processor

- $0.24 \mathrm{msec}$ simultaneous update rate for all axes

- Lead error correction and multi-dimensional error mapping

- Dual-loop positioning to eliminate effects of VGA backlash and other forms of lost motion.

Detailed specifications are given in Table 4-5. 
Table 4-5.

U500 Controller Specifications

\begin{tabular}{|c|c|}
\hline Axes & 1 to 4 ax \\
\hline & \\
\hline & ID with velocity and acceleration feedforward; les \\
\hline On-board Memory & firmware, $d$ \\
\hline Bus Compatibility & ISA bus specification, full-ler \\
\hline Acceleration Profiles & 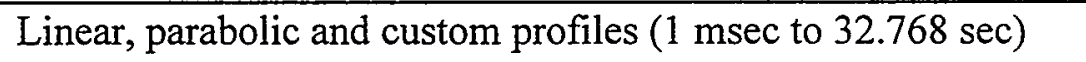 \\
\hline Process Time & Command $\mathrm{e}$ \\
\hline \multicolumn{2}{|c|}{$\begin{array}{l}\text { Position Feedback } \\
\text { - Resolution - Incremental encoder, times-4 multiplying } \\
\text { - Accuracy/Repeatability }-+/-1 / 2 \text { count of multiplied feedback transducer signal }\end{array}$} \\
\hline \multicolumn{2}{|c|}{$\begin{array}{l}\text { Motion Types } \\
\text { - Independent Motions - Point-to-point incremental; target position or velocity profiles; } \\
\text { time based; free run } \\
\text { - Coordinated Motions - Advanced queuing and deferred execution features for } \\
\text { simultaneous command execution } \\
\text { - Interpolated Motions - Four axis linear interpolation; velocity profiling; corner } \\
\text { rounding } \\
\text { - Digitally Geared Motions - 1:1 master/slave; n:n gear ratio for } 1 \text { master and up to } 3 \\
\text { slaves or } 2 \text { masters with } 1 \text { slave each } \\
\text { - Trajectory Adjustment - On-the-fly trajectory modification }\end{array}$} \\
\hline \multicolumn{2}{|c|}{$\begin{array}{l}\text { - Position }-2^{47}-1 \text { counts } \\
\text { - Velocity }-2^{15} \text { steps } / \mathrm{msec} \\
\text { - Acceleration }-2^{15} \text { steps } / \mathrm{msec}^{2}\end{array}$} \\
\hline \multicolumn{2}{|c|}{$\begin{array}{l}\text { Programming } \\
\text { - Languages - Hard-coded machine tool G-code (RS-274), equivalent BASIC-like and } \\
\text { 'C' function calls (via software) } \\
\text { - Software Compatibility - 'C', Visual Basic, QuickBASIC; 32-bit 'Quick Libraries' } \\
\text { available for direct DSP manipulation }\end{array}$} \\
\hline
\end{tabular}




\subsubsection{Interface Board}

The BB501 interface board provides the ability to interface the U500 control board to the BA20 amplifier. This board provides two U500 interface connectors, four axes of amplifier and feedback connectors, one joystick port, three I/O connectors, one D/A connector, one brake connector, and an external power supply connector. Also contained on this board are several jumpers that permit the BB501 to be configured for different options and hardware.

The BB501 interface board requires $+5 \mathrm{~V}$ at less than $0.1 \mathrm{~A}$, which it obtains through the main signal connector. An additional $5 \mathrm{~V}$ supply may be required to power the encoder and limit circuitry if the amplifiers are not capable of supplying the current. If an external power supply is required, it should meet the following minimum requirements.

Current capacity requirement for a typical system is represented in Table 4-6. However, some systems may require higher amperage supplies.

Table 4-6.

Current Capacity Requirement for the BB501 Interface Board

\begin{tabular}{|c|c|}
\hline Parameter & Values \\
\hline Power Supply Requirements & $+5 \mathrm{~V}$ \\
\hline Nominal Voltage (min.- max.) & $4.9 \mathrm{~V}-5.25 \mathrm{~V}$ \\
\hline Ripple (P-P volts) & less than $100 \mathrm{mV}$ P-P \\
\hline Current Capacity & 0.5 A/axis minimum \\
\hline
\end{tabular}

\subsubsection{Force/Torque Sensor}

The force/torque (F/T) sensor model 100M40A-U760 50L200 was obtained from JR3, Inc. It is a six-axis force and torque transducer with a force-measuring capacity of $50 \mathrm{lbs}$ and a torquemeasuring capacity of $200 \mathrm{lb}$-in. The cylindrical unit is $100 \mathrm{~mm}$ in diameter, $40 \mathrm{~mm}$ high, and weighs $1.4 \mathrm{lb}$. It has captive bolts that allow direct connection to the Staubli Unimation Puma 760 robot. The 100M40 model uses metal foil strain gages bonded to strain rings as the sensing element that produces linear outputs. It has signal-conditioning electronics integrated into the sensor body. Included in the electronics are amplifiers, analog-to-digital converter (A/D), and EEPROM containing calibration data and RS-485 serial drivers. The $100 \mathrm{M} 40$ outputs a 2 megabit per second serial data stream that contains complete 6 -axis data at $8 \mathrm{kHz}$ and can be read by ISA (IBM-AT) bus receiver/processor.

The ISA-bus receiver uses the cable to provide power to the sensor as well as to receive the highspeed serial data from the sensor. The ISA-bus receiver requires no external power. It draws power directly from the ISA bus. The receiver uses the following voltage and currents:

$5 \mathrm{~V}: 650 \mathrm{~mA}$ typical

$12 \mathrm{~V}: 25 \mathrm{~mA}$ typical (without sensor)

$-12 \mathrm{~V}: 5 \mathrm{~mA}$ typical (without sensor) 
The sensor will also draw anywhere from 200 to $400 \mathrm{~mA}$ from the $+12 \mathrm{~V}$ and possibly as much as $100 \mathrm{~mA}$ from the $-12 \mathrm{~V}$.

The ISA-bus receiver uses an Analog Devices ADSP-2105, a 10 Mips digital signal processing chip. This chip has the ability to provide decoupled and filtered data at $8 \mathrm{kHz}$ per axis. Some of the signal processing functions performed by the ISA-bus receiver include decoupling, coordinate transformation (translation and rotation), low-pass filtering, vector magnitude calculation, maximum and minimum peak capture, threshold monitoring, and rate calculations.

The ISA-bus receiver communicates to the host computer through two 16-bit I/O ports. Using the I/O ports, the host computer reads directly from a dual-port RAM.

The general specifications of this force/torque sensor are given in Table 4-7.

Table 4-7.

100M40A-U760 Force/Torque Sensor Specifications

\begin{tabular}{|c|c|c|c|c|}
\hline Parameter & $\mathbf{F}_{\mathbf{x}}, \mathbf{F}_{\mathbf{y}}$ & $\mathbf{F}_{\mathbf{z}}$ & $\mathbf{M}_{\mathbf{x}}, \mathbf{M}_{\mathbf{y}}$ & $\mathbf{M}_{\mathbf{z}}$ \\
\hline Capacities (lb, in-lb) & 50 & 100 & 200 & 200 \\
\hline Resolutions (lb, in-lb) & 0.013 & 0.05 & 0.05 & 0.05 \\
\hline Stiffness (klb/in, kin-lb/rad) & 130 & 1350 & 1950 & 650 \\
\hline Permissible Single Axis Overloads (lb, in-lb) & 590 & 2000 & 1700 & 1500 \\
\hline
\end{tabular}

\subsubsection{PUMA 760 Robot}

For the purpose of the experiment and evaluation of the 1-DOF FRMC, the PUMA 760 industrial robot is used to simulate the remote site. The PUMA 760 robot is a member of the Unimate PUMA 700 series robot manufactured by Unimation, a Westinghouse Company, of Danbury, Connecticut, (recently newer models produced by Stäubli). The robot consists of six revolute joints driven by permanent-magnet servo motors. It weighs 640 pounds $(290 \mathrm{~kg})$ and has a maximum static payload of $10 \mathrm{~kg}$. The PUMA 760 workspace is 1.25 meters (spherical volume) with the shoulder at the center.

The system software that controls the robot is called VAL. VAL is a high-level language that is specially designed for the use of the Unimation industrial robots. It provides the ability to define the tasks that robots perform either task-by-task (single-line command) or as a complete program. Real-time computations are performed during the actual running of the robot program to convert the stored data to position information.

\subsection{SYSTEM SETUP AND SYSTEM CHARACTERISTICS}

The setup of 1-DOF FRMC is shown in Figure 4-2. The principle of the control system can be summarized as follows. First, the joystick is used to control the motion of the robot. The control 
software reads in the extent of the joystick movement and computes the data according to the operation parameters, such as control modes (position or velocity), scaling values for position or velocity, and re-referencing parameters input by the user.

Forces experienced by the manipulator are received through the Force/Torque $(F / T)$ sensor. The $\mathrm{F} / \mathrm{T}$ driver receives the signals, processes the data, and transmits it to the control software. The control software carries out the calculations, such as force feedback scaling and position scaling. Once the calculations are completed, the program sends the data to the controller, U500, which accepts high-level commands. The controller then computes the necessary torque needed and passes the signals as low-level command signals to the interface board, BB501. The interface board $\mathrm{BB} 501$ on the other end is connected to the amplifier BA20, which is used to amplify the signal and deliver the power to operate the motor. The motor drives the joystick that is attached directly to the motor.

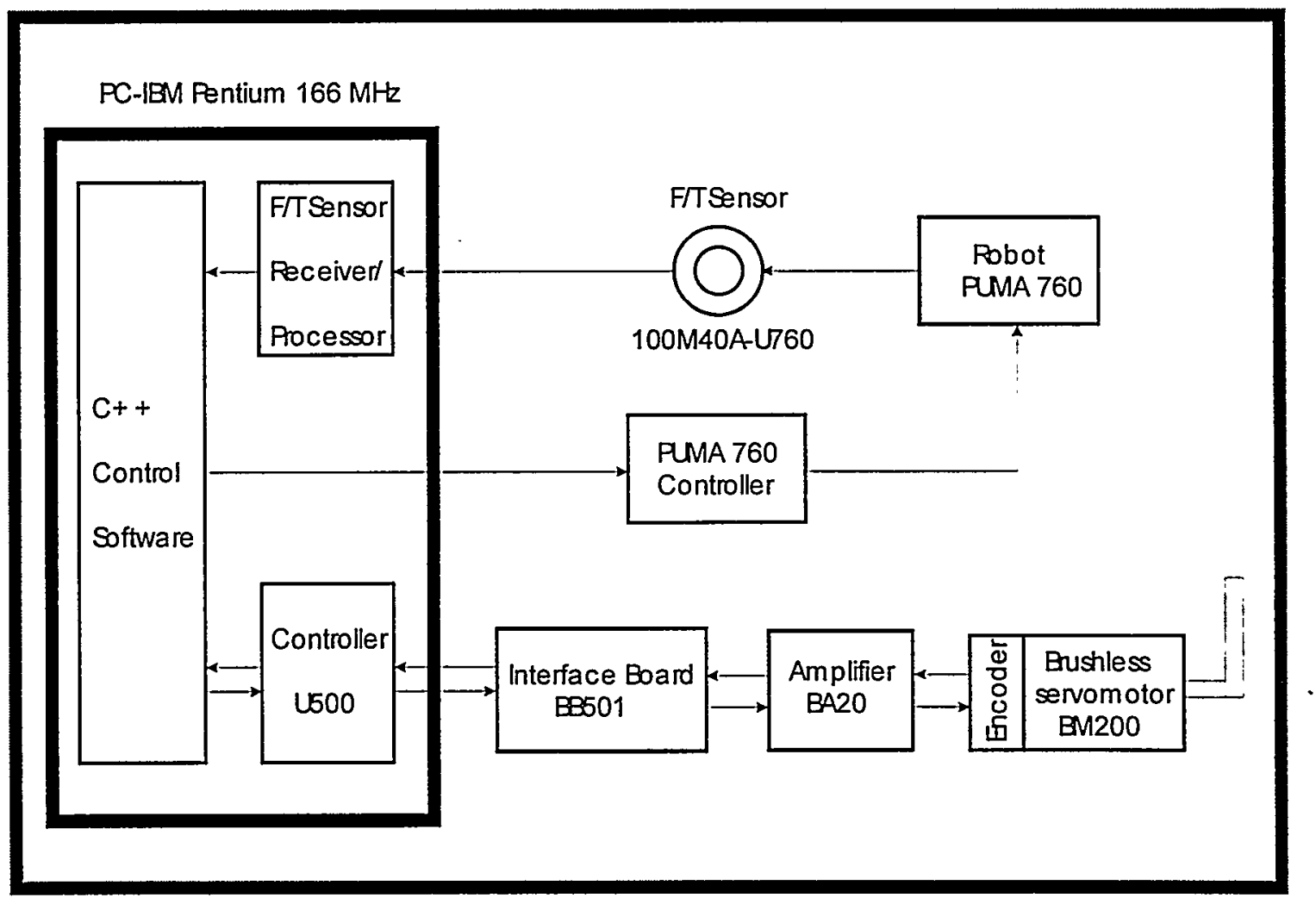

Figure 4-2. Setup of 1-DOF FRMC Testbed.

For the setup shown in Figure 4-2, the system is able to provide a peak torque of $404 \mathrm{oz}-\mathrm{in}$. With the length of the handgrip at $5 \mathrm{in}$, the 1-DOF FRMC prototype can produce a maximum force reflection of $5 \mathrm{lb}$. The update rate of the system is approximately $0.002 \mathrm{sec}$ or $500 \mathrm{~Hz}$. Note that the system is set up in the direct-drive configuration. Therefore, more force reflection can be obtained by implementing a gear set to the system. However, the system will sustain higher friction and backlash as a result of using a gear system. 


\subsection{SYSTEM IDENTIFICATION}

The main purpose of constructing a model is to predict the output of the system. A mathematical model is also a useful tool to prevent damages to the system that result from unexpected system response. In addition, it serves as a means to experiment for various control schemes, such as PID, fuzzy logic, adaptive, neural, and other emerging controllers.

System identification is the process of estimating a model of a system based on observed inputoutput data. According to Ljung, a mathematical model can never be used to represent the true description of the system, but rather it can be best regarded as a sufficient description of certain aspects that are of particular interest [Ljung 1987].

The following are the common procedures used to carry out the system identification process [Hsia 1977]:

1. Select a set of candidate models that represents the system to be identified.

2. Apply an appropriate test signal (input) and collect the data (output).

3. Perform the parameter identification to select the suitable model.

4. Perform the model validation.

5. The process ends if the model is valid. If not, another set of candidate models will be selected. Repeat steps 2-4 until the model is valid.

The choice of an identification method and model type depends on the nature of the system and the purpose of identification. Parametric system models are usually more preferable than nonparametric models because modern control theory and system design techniques require the state variable description of the system dynamics [Hsia 1977]. As for the choices between discrete and continuous models, it is more practical to estimate the system as a discrete model, since digital computers are commonly used to control and store the data in discrete forms. In addition, difference equations are easier to manipulate and identify than differential equations.

For a parametric, single-variable, linear, time-invariant discrete system, the input-output relationship can be represented by an $n$th order linear difference equation:

$$
y(k)+a_{1} y(k-1)+\ldots .+a_{n} y(k-n)=b_{0} u(k)+b_{1} u(k-1)+\ldots .+b_{n} u(k-n)+e(k)
$$

where $y(k)$ and $u(k)$ are the measured output and input data, respectively.

Equation (4.1) can be written as

$$
A\left(q^{-1}\right) y(k)=B\left(q^{-1}\right) u(k)+e(k)
$$

where

$$
\begin{gathered}
A\left(q^{-1}\right)=1+a_{1} q^{-1}+\ldots . .+a_{n} q^{-n} \\
B\left(q^{-1}\right)=b_{0}+b_{1} q^{-1}+\ldots . .+b_{n} q^{-n}
\end{gathered}
$$

The transfer function of this system is defined by 


$$
G(z)=\frac{B\left(z^{-1}\right)}{A\left(z^{-1}\right)}
$$

Equation (4.1) is also referred to as the ARX model (AR refers to the autoregressive part $A\left(q^{-1}\right) y(k)$ and $X$ to the extra input $\left.B\left(q^{-1}\right) u(k)\right)$.

The $a_{i}$ and $b_{i}$ terms of the ARX model are estimated using the least squares estimation method. This method is described as follows [Hsia 1977]:

Equation (4.2) is rewritten as

$$
y(k)=-\sum_{i=1}^{n} a_{i} y(k-i)+\sum_{i=0}^{n} b_{i} u(k-i)+e(k)
$$

Defining the $2 \mathrm{n}+1$ input-output vector $x(t)$ as

$$
\underline{x}(k)=[-y(k-1), \ldots .,-y(k-n), u(k), \ldots . ., u(k-n)]^{T}
$$

the $\mathrm{n}$ parameter vector $\theta$ as

$$
\underline{\theta}=\left[a_{1}, \ldots . ., a_{n}, b_{0}, \ldots . . b_{n}\right]^{r}
$$

Equation (4.4) becomes

$$
y(k)=\underline{x}^{T}(k) \underline{\theta}+e(k)
$$

This can be set up as a system of $\mathrm{N}$ equations (for $\mathrm{k}=1, \ldots .,(\mathrm{N}+\mathrm{n})$ ) as

$$
\underline{y}=\underline{X \theta}+\underline{e}
$$

where

$$
\begin{gathered}
\underline{y}=[y(n+1), y(n+2), \ldots \ldots, y(n+N)]^{T} \\
\underline{e}=[e(n+1), e(n+2), \ldots . ., e(n+N)]^{T} \\
\underline{X}=\left[\begin{array}{c}
x^{T}(n+1) \\
x^{T}(n+2) \\
: \\
: \\
x^{T}(n+N)
\end{array}\right]=\left[\begin{array}{ccc}
-y(n), \ldots . ., & -y(1), & u(n+1), \ldots \ldots u(1) \\
-y(n+1), \ldots . ., & -y(2), & u(n+2), \ldots \ldots u(2) \\
: & : & : \\
: & : & : \\
-y(n+N-1), \ldots ., & -y(N), & u(n+N), \ldots \ldots u(N)
\end{array}\right]
\end{gathered}
$$

Using the vector Equation (4.6), in which $y$ and $\underline{X}$ are given, $\theta$ can be estimated by means of least squares. This approach was first derived by Guass. The complete solution is provided below.

The least-squares method states that the estimate $\theta$ is chosen so that the value of $\theta$ minimizes the error function J:

$$
J=\sum_{k=n+1}^{N+n} e^{2}(k)=\underline{e}^{T} \underline{e}
$$




$$
=(y-\underline{X} \underline{\theta})^{T}(y-\underline{X} \theta)
$$

Upon setting

$$
\left.\frac{\partial J}{\partial \theta}\right|_{\theta=\hat{\theta}}=0
$$

the least-squares estimate $\hat{\theta}$ can be obtained by

$$
\hat{\theta}=\left(\underline{X}^{T} \underline{X}\right)^{-1} \underline{X}^{T} y
$$

assuming that $\mathrm{X}^{\mathrm{T}} \mathrm{X}$ is nonsingular.

To obtain sufficiently rich output that contains the maximum information about the dynamic modes of the system, the system must be excited with frequencies that span a wide range. Under these conditions, the parameters can be estimated with high accuracy. For the particular system at hand, the maximum input voltage that can be applied is limited between -10 to 10 volts. To achieve these limits, the system was excited in the open-loop environment by a sinusoidal signal with a frequency of $7 \mathrm{~Hz}$ and sampling time of 0.001 second. Figure 4-3 shows the measured input-output data collected from the system.
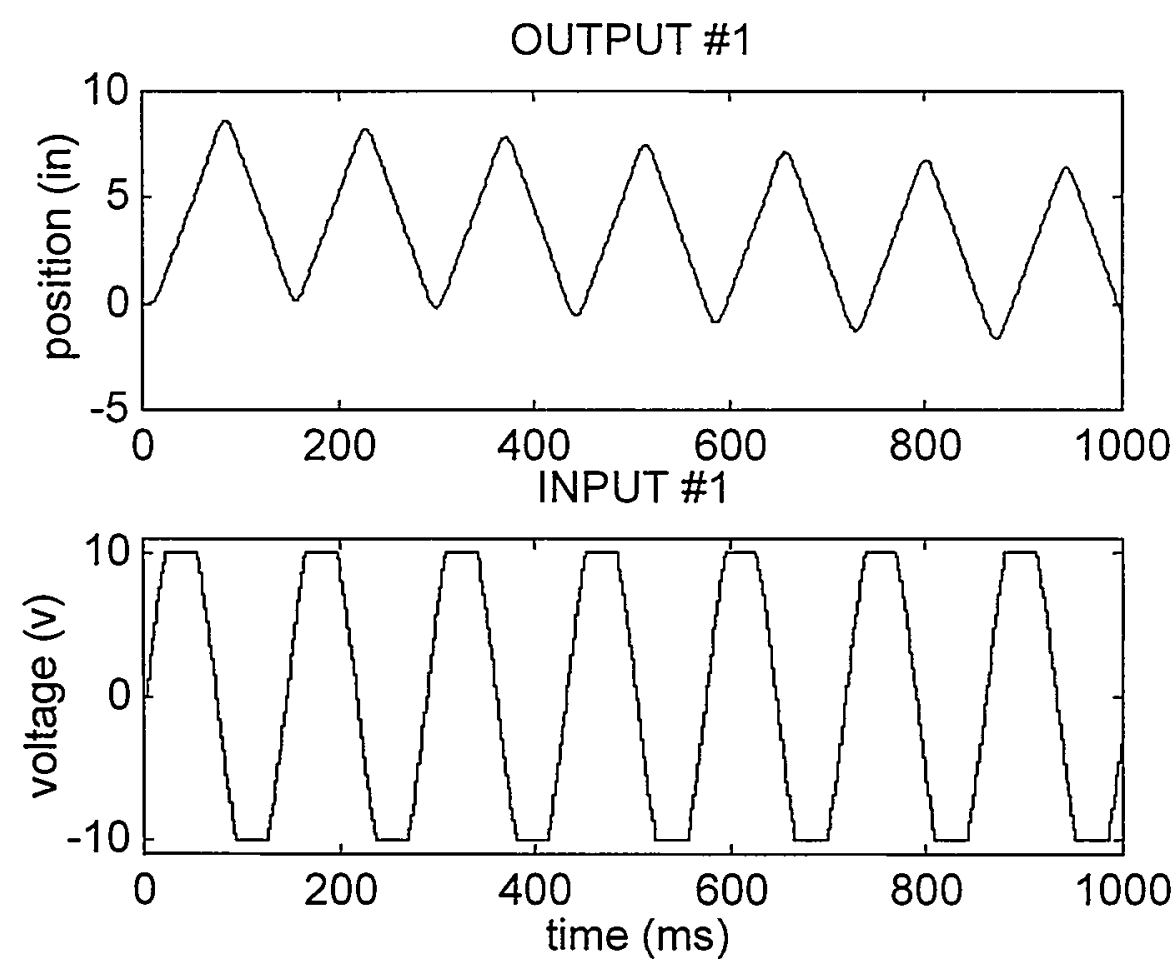

Figure 4-3. Input-Output Data Collected from the System.

Figure 4-4 shows the comparison of the output obtained from the actual system and from different models that is described by different order systems represented by transfer function in Table 4-8. 
Table 4-8.

Models Represented by Second-, Third-, and Fourth- Order Systems

\begin{tabular}{|l|l|}
\hline Model & Transfer Function \\
\hline Second-Order & $G(s)=\frac{0.0296 s+0.042}{s^{2}+1.8944 s+0.8950}$ \\
\hline Third-Order & $G(s)=\frac{0.01 s^{2}+0.001 s+0.008}{s^{3}+2.9438 s^{2}+2.9174 s+0.9736}$ \\
\hline Fourth-Order & $G(s)=\frac{0.02533 s^{3}+0.0473 s^{2}+0.0937 s+0.01336}{s^{4}+3.366 s^{3}+4.1777 s^{2}+2.2397 s+0.428}$ \\
\hline
\end{tabular}

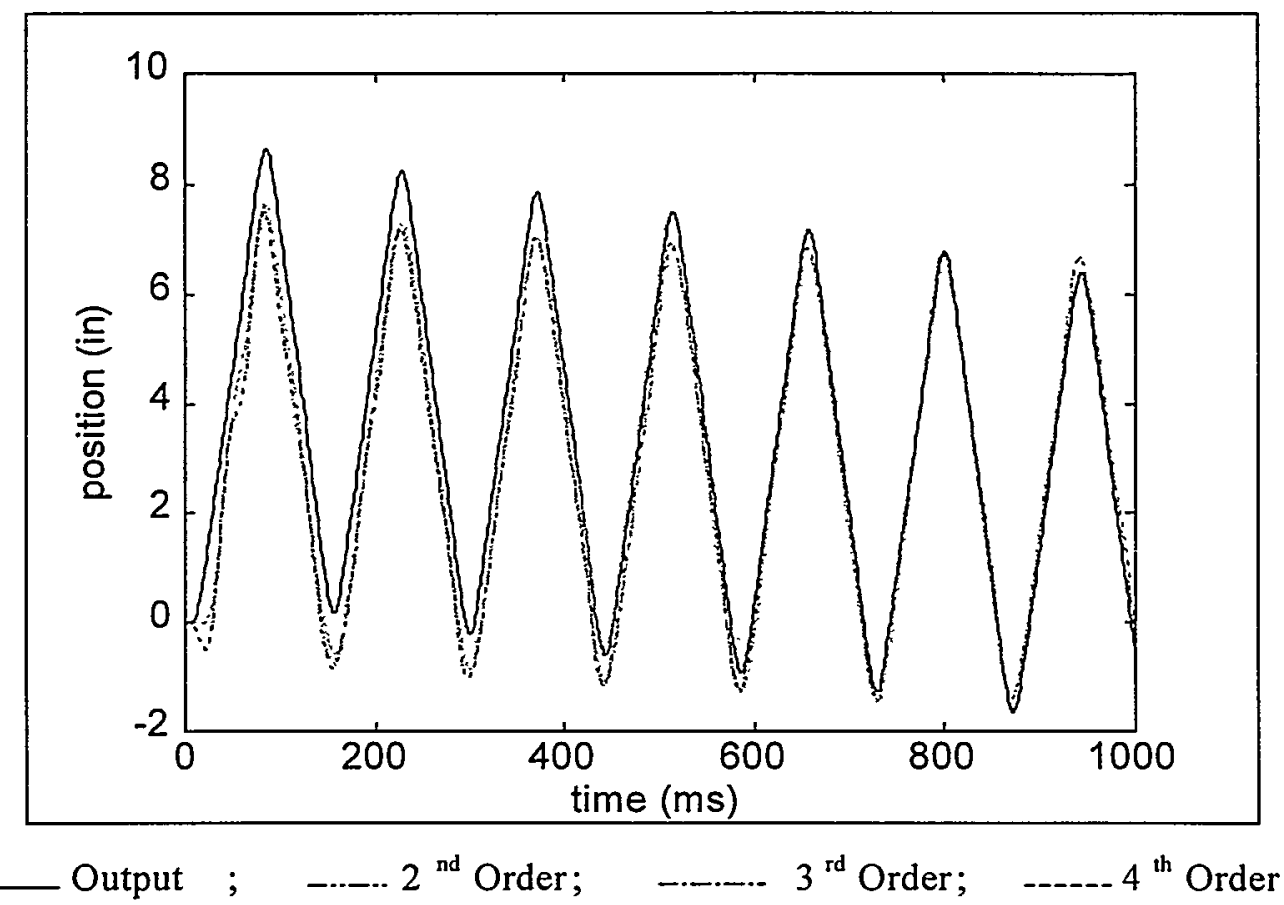

Figure 4-4. Comparison of the Actual System Response with Second-, Third-, and Fourth-Order Model Outputs.

As can be seen, the second- and third-order models produce output that match as the actual system output fairly well, whereas the fourth-order model tails away at the end. Thus, either the second- or third-order system can be used as a model for this system. For simplicity, the secondorder model is used to represent the 1-DOF FRMC prototype system dynamics.

Therefore, the selected model is represented as 


$$
G(s)=\frac{0.0296 s+0.042}{s^{2}+1.8944 s+0.8950}
$$

\subsection{MODEL VALIDATION}

To verify the accuracy of the model, the servo loop of the U500 controller was numerically simulated on the computer. Figure 4-5 illustrates the U500 servo loop where

$K_{P}$ is Proportional Gain

$K_{I}$ is Integral Gain

$K_{D}$ is Derivative Gain

$V_{f f}$ is Velocity Feedforward Gain

$A_{f f}$ is Acceleration Feedforward Gain

$F_{s}$ is Sampling Frequency

Further details of the U500 control scheme are discussed in the next section. 


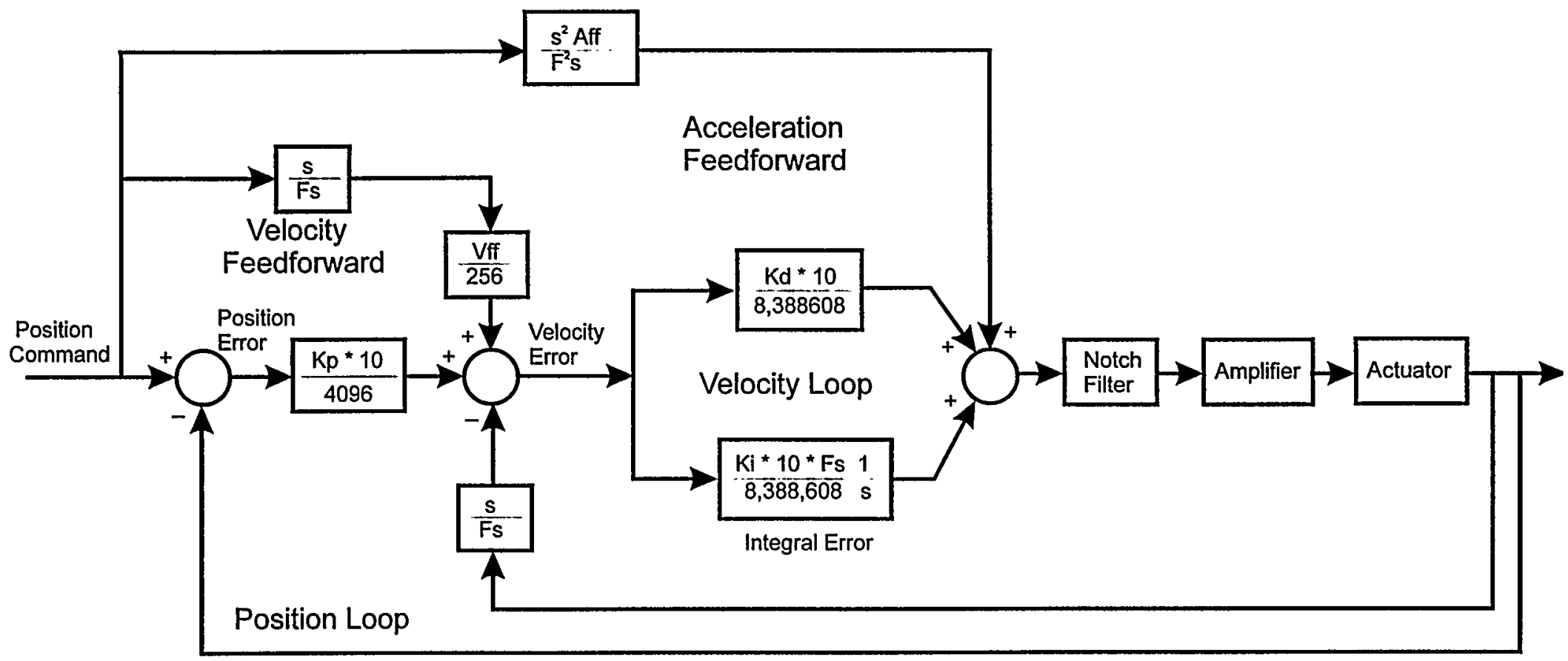

Figure 4-5. Servo Loop of U500 Controller. 

The control method of the U500 controller is based on the traditional PID feedback with velocity and acceleration feedforward loops. It uses a dual control loop having an inner velocity loop and an outer position loop. The block diagram was created using the SIMULINK program to represent the servo loop of the U500 controller. Figures 4-6, 4-7, and 4-8 compare the system response between the model and the actual system of different gains represented in Table 4-9. The sampling time in this experiment is 0.001 second, whereas the amplifier block is modeled as a gain whose value is set to 100 .

Table 4-9.

Gains Used in the System Identification Process

\begin{tabular}{|c|c|c|c|}
\hline & $\mathrm{K}_{\mathrm{P}}$ & $\mathrm{K}_{\mathrm{I}}$ & $\mathrm{K}_{\mathrm{D}}$ \\
\hline ID1 & 4 & 10,000 & 20,000 \\
\hline ID2 & 8 & 30,000 & 20,000 \\
\hline ID3 & 10 & 20,000 & 40,000 \\
\hline
\end{tabular}

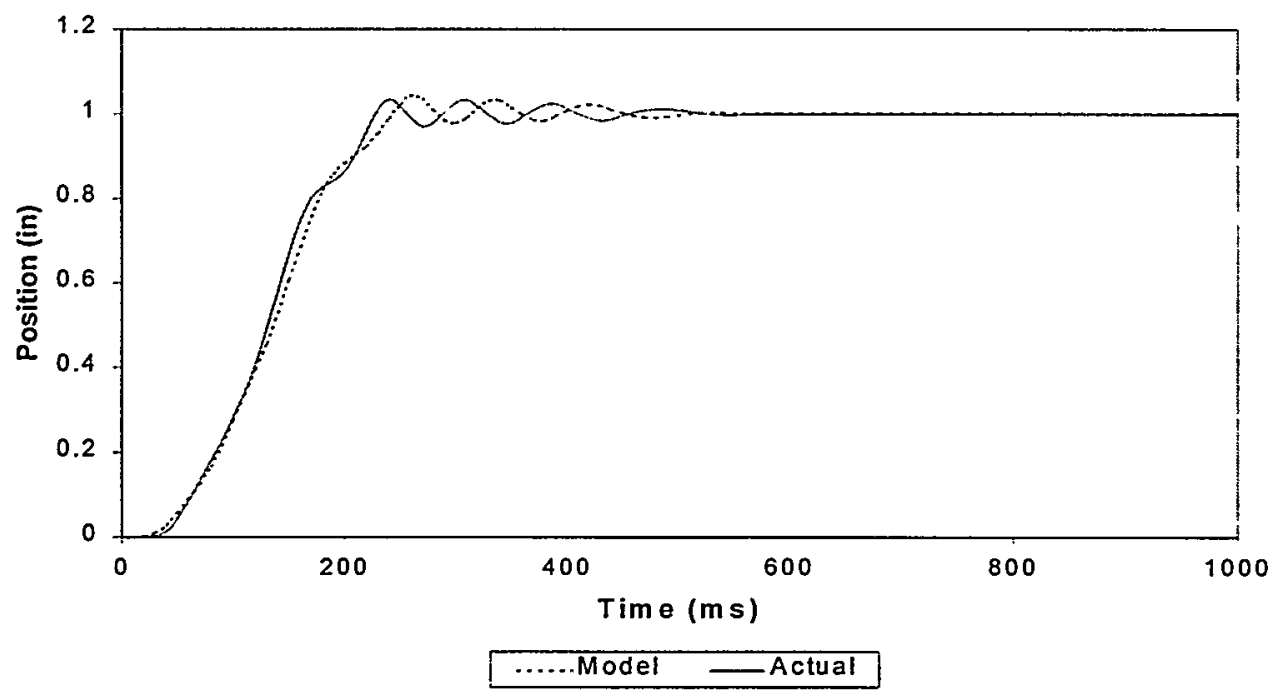

Figure 4-6. Comparison of the System Response between the Model and Actual System for the Gain Set ID1. 


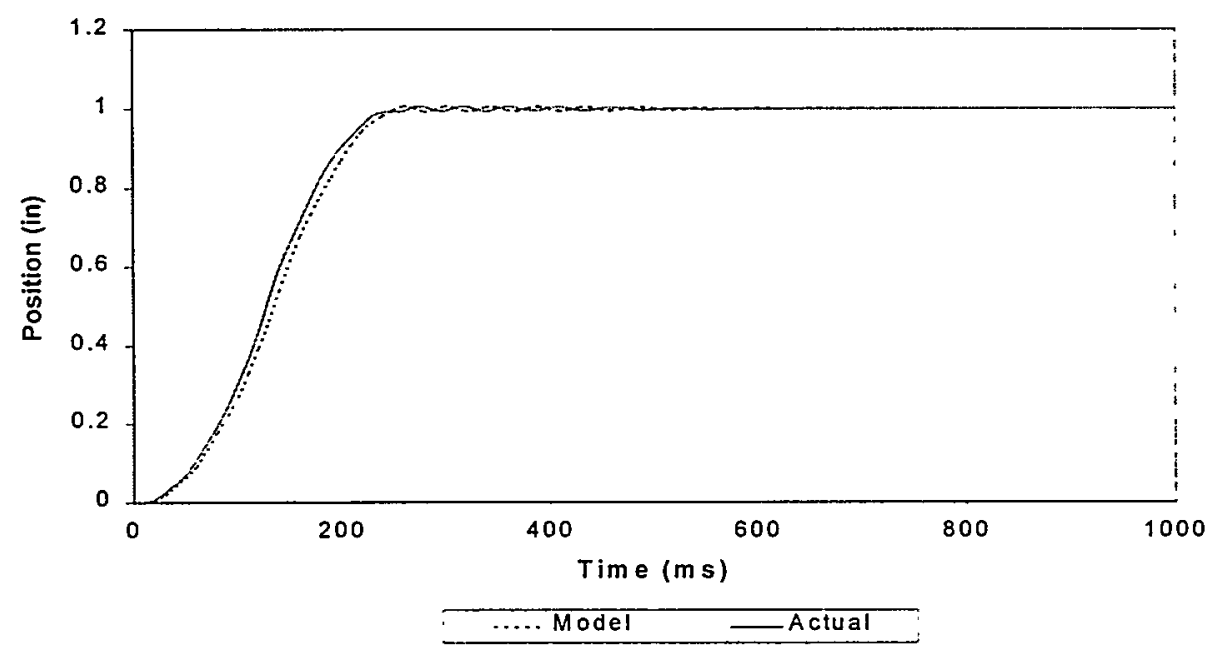

Figure 4-7. Comparison of the System Response between the Model and Actual System for the Gain Set ID2.

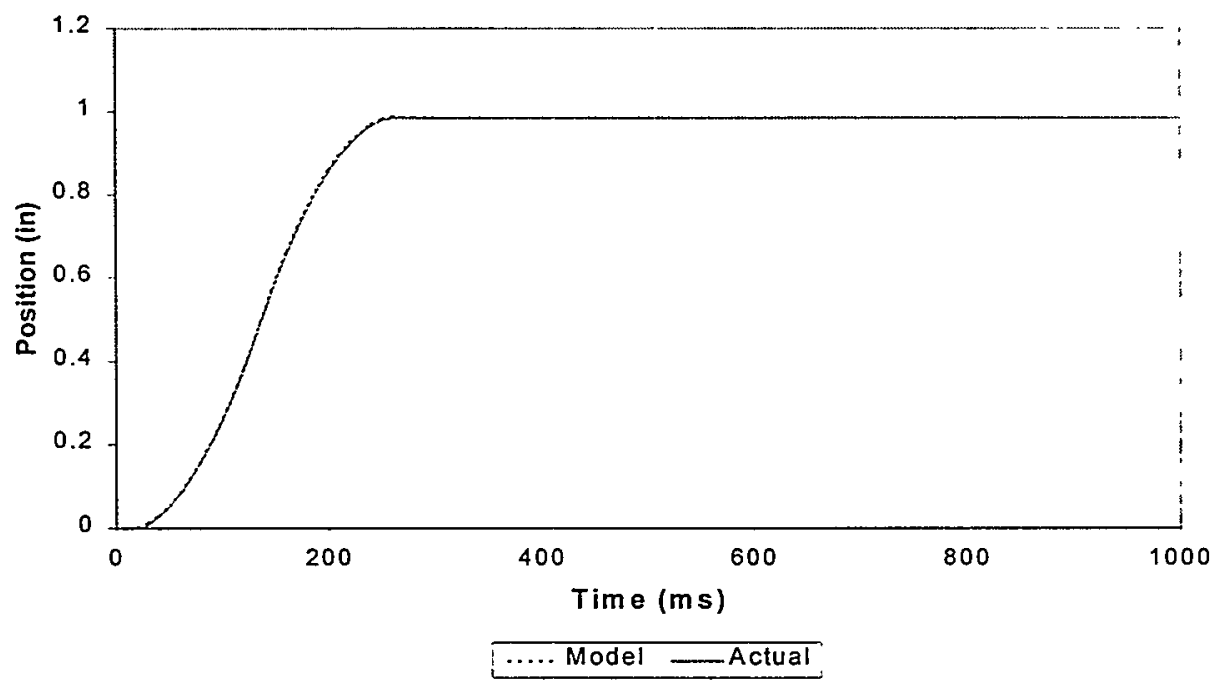

Figure 4-8. Comparison of the System Response between the Model and Actual System Output for the Gain Set ID3.

In Figures 4-6 and 4-7, the model does not yield the output that matches exactly with the actual system response. However, it displays similar behavior, considered as the most important aspect when constructing the model. The discrepancy between the model response and the actual system output can be explained by unmodeled friction and unmodeled high-frequency, lowmagnitude system dynamics. Because the FRMC system is direct-drive and has only one degree of freedom, the friction is minimal and omitted in the model [Batsomboon et al. 1998]. With a better set of gains, ID3, Figure 4-8 shows that the model is able to produce the result that closely 
matches the actual system response. Therefore, it can be concluded that the second-order model obtained in the previous section is sufficiently accurate to represent the actual system to test the performance of various controllers. 


\subsection{TESTING AND EVALUATION OF CONTROL METHODS FOR THE 1-DOF FRMC}

In this section, two control algorithms are experimentally tested on the 1-DOF FRMC testbed. These two control methods are 1) the PID feedback with velocity and acceleration feedforward and 2) the fuzzy logic controller. The response of the system to each of the methods is analyzed and evaluated. Numerical simulation results obtained from the mathematical model are compared with that of experimental data for both types of controllers.

\subsection{PID CONTROLLER}

The PID controller discussed in this section uses the control loops as presented in Section 4.0. The control loop is shown again here in Figure 5-1.

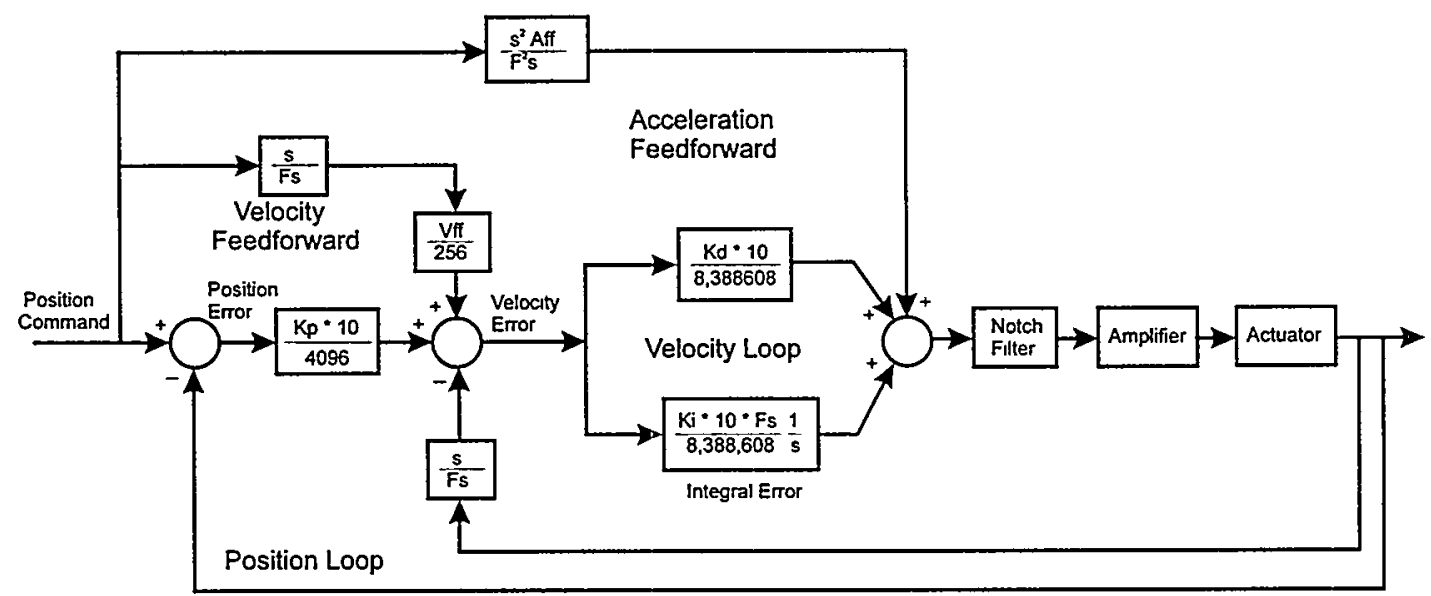

Figure 5-1. U500 PID Controller

As stated earlier, the control method of the U500 controller is the PID with velocity and acceleration feedforward. It uses a dual control loop having an inner velocity loop and an outer position loop. The system performance can be obtained in two distinct aspects: first, the attempt to obtain the smallest amount of position error that is allowable by pre-defined tolerances and has smooth motion; second, the attempt to obtain the smallest amount of position error that is allowable by pre-defined tolerances and have minimal settling time with no concern for smoothness of motion. The optimal performance, therefore, would be to combine both aspects.

\subsubsection{Simulation of PID Controller}

PID controller simulation is performed by developing a $\mathrm{C}$ program in an attempt to mimic the PID of U500 controller. Using the mathematical model obtained in the previous section, 


$$
G(s)=\frac{0.0296 s+0.042}{s^{2}+1.8944 s+0.8950}
$$

the above equation can be written as

$$
\left(s^{2}+1.8944 s+0.8950\right) Y(s)=(0.0296 s+0.042) X(s)
$$

Equation (5.1) is transformed to differential equation as

$$
\ddot{y}+1.8944 \dot{y}+0.8950 y=0.0296 \dot{x}+0.042 x=u
$$

According to the Figure 5-1, $\mathrm{u}$ (input torque) is represented as

$$
u=\ddot{y}+\left[e *\left(\frac{K_{p} * 10}{4096}\right)+\dot{e}\right] *\left(\frac{K_{d} * 10}{8,388,608}\right)+\left(\frac{K_{i} * 10}{8,388,608}\right) *\left[e *\left(\frac{K_{p} * 10}{4096}\right)+\dot{e}\right] d t
$$

Equation (5.2) is written in the form of two first-order differential equations as

$$
\begin{aligned}
& \dot{x}_{1}=x_{2}=\dot{y} \\
& \dot{x}_{2}=\ddot{y}=-1.8944 \dot{y}-0.8950 y+u
\end{aligned}
$$

or

$$
\begin{aligned}
& \dot{x}_{1}=x_{2} \\
& \dot{x}_{2}=-0.8950 x_{1}-1.8944 x_{2}+u
\end{aligned}
$$

With these two first-order differential equations, the system response is obtained from the $C$ program simulation by numerical integration. Figure 5-2 shows one of the simulated results for the set of gains of $K_{p}=10, K_{I}=28,000$, and $K_{D}=40,000$. In this simulation, parabolic function input is used as the desired path instead of the step input. The reason is that the ramp input does not create large errors initially as in the case of step input. As a result, this eliminates undesired system response due to system shocks introduced by a large difference between the actual and desired inputs. This process provides a realistic situation where the smoothness of the system is one of the desired characteristics of the FRMC performance. As can be seen in Figure 5-2, the model follows the desired path fairly well without oscillations or any deviation away from the desired behavior. Transient response as well as the steady-state response are observed to be quite acceptable. 


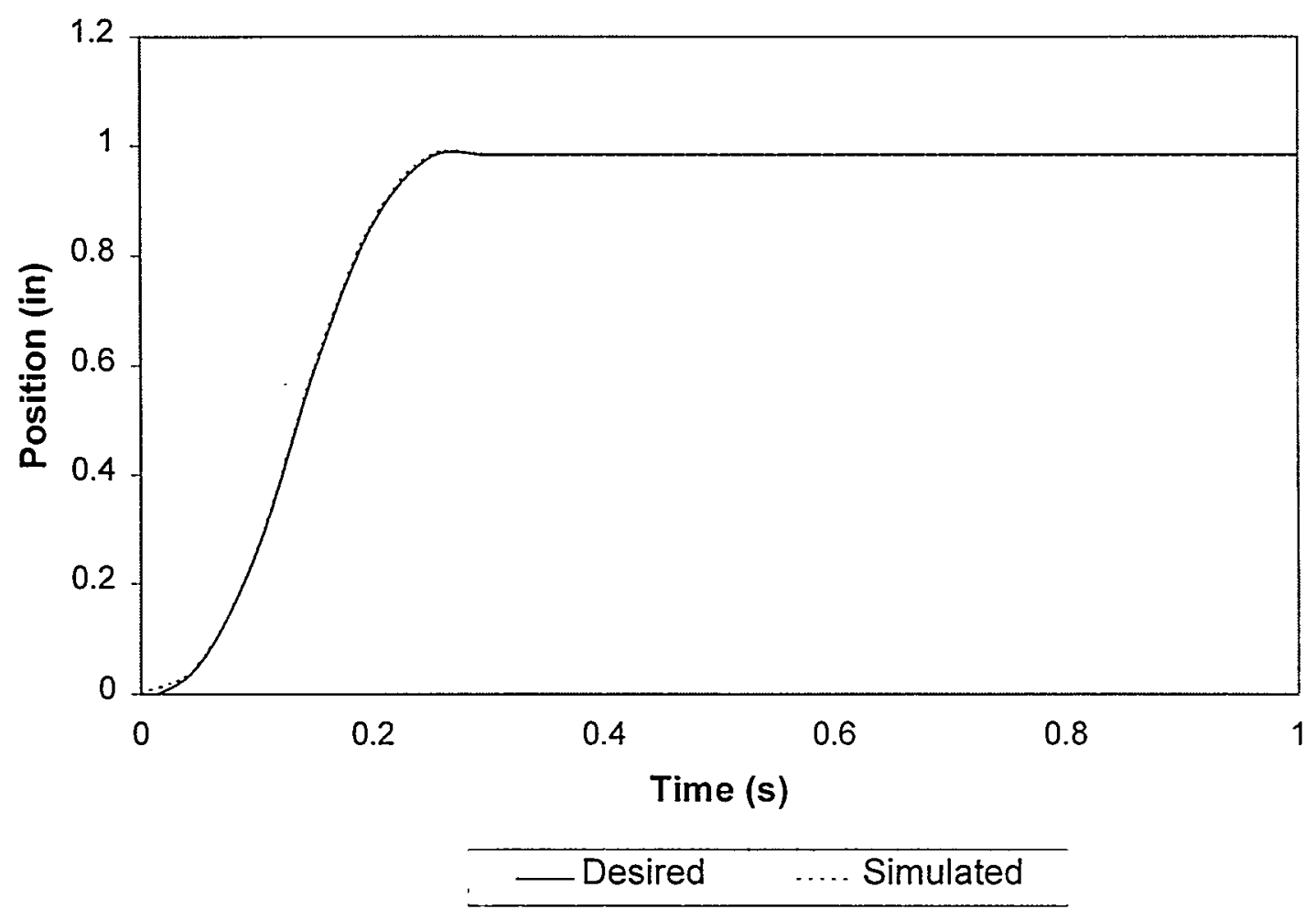

Figure 5-2. Simulated System Response under PID Controller

\subsubsection{Experiments on 1-DOF FRMC by Implementing the PID Controller}

The objective of a PID controller is to determine the values of the three gains, $K_{P}, K_{I}$, and $K_{D}$, so that the performance of the system meets the design requirements. Here, the subscript $\mathrm{P}$ stands for "proportional," I for "integral," and D for "derivative" to indicate various gains used in the feedback loops. In this section, different gains are tested experimentally to obtain the best possible system response. Although the simulations of the PID controller have been performed earlier, the real-life situations often give different results because of the unmodeled dynamics in the simplified system model.

Figures 5-3, 5-4, and 5-5 show some of the system responses of the gains in Table 5-1 versus system position command where the plots on the left side provide the entire view of system response and the plots on the right focus on the steady-state portion. Figure 5-6 compares the system response errors in these experiments. 
Table 5-1.

Gains Used in Experiments on the Actual System

\begin{tabular}{|c|c|c|c|}
\hline & $\mathrm{K}_{\mathrm{P}}$ & $\mathrm{K}_{\mathrm{I}}$ & $\mathrm{K}_{\mathrm{D}}$ \\
\hline PID1 & 10 & 28,000 & 40,000 \\
\hline PID2 & 2 & 20,000 & 40,000 \\
\hline PID3 & 4 & 20,000 & 40,000 \\
\hline PID4 & 2 & 10,000 & 10,000 \\
\hline PID5 & 12 & 10,000 & 10,000 \\
\hline PID6 & 8 & 30,000 & 20,000 \\
\hline
\end{tabular}
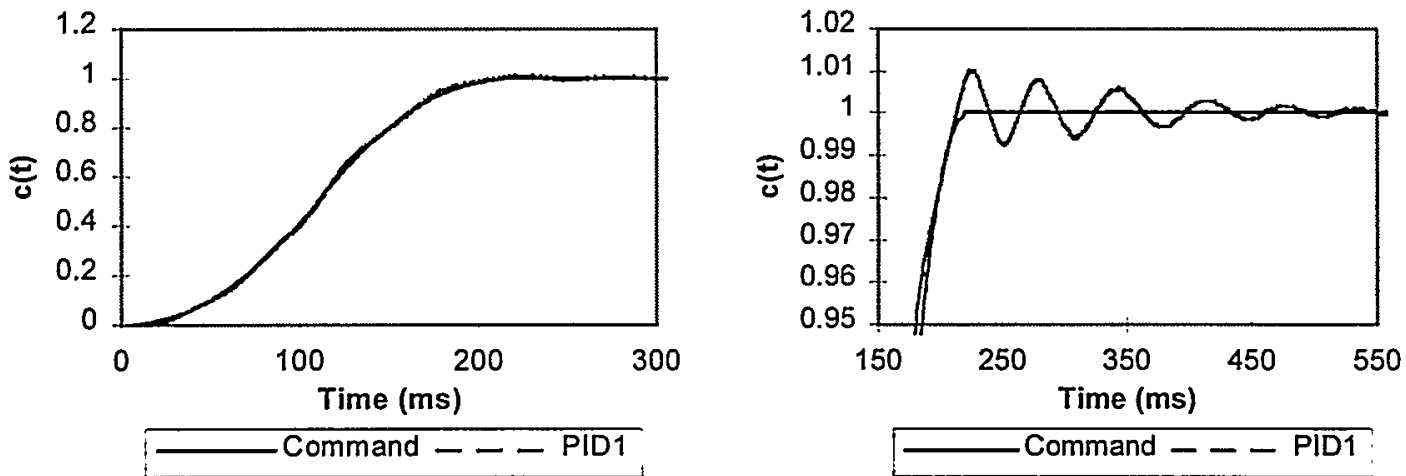

Figure 5-3. Position Command and System Response of PID1 Gains
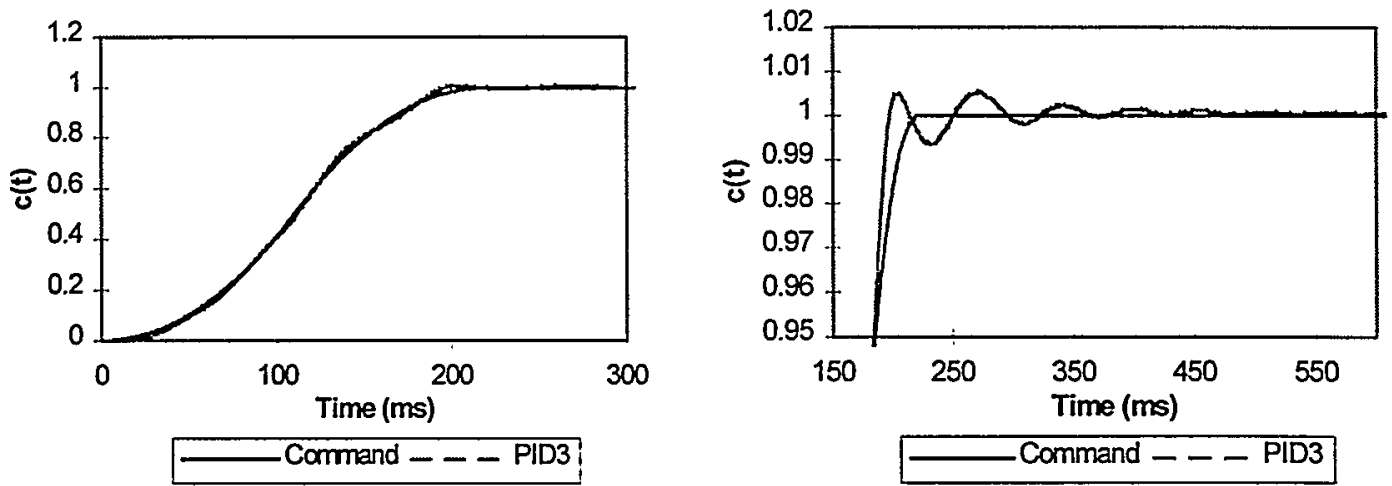

Figure 5-4. Position Command and System Response of PID3 Gains 

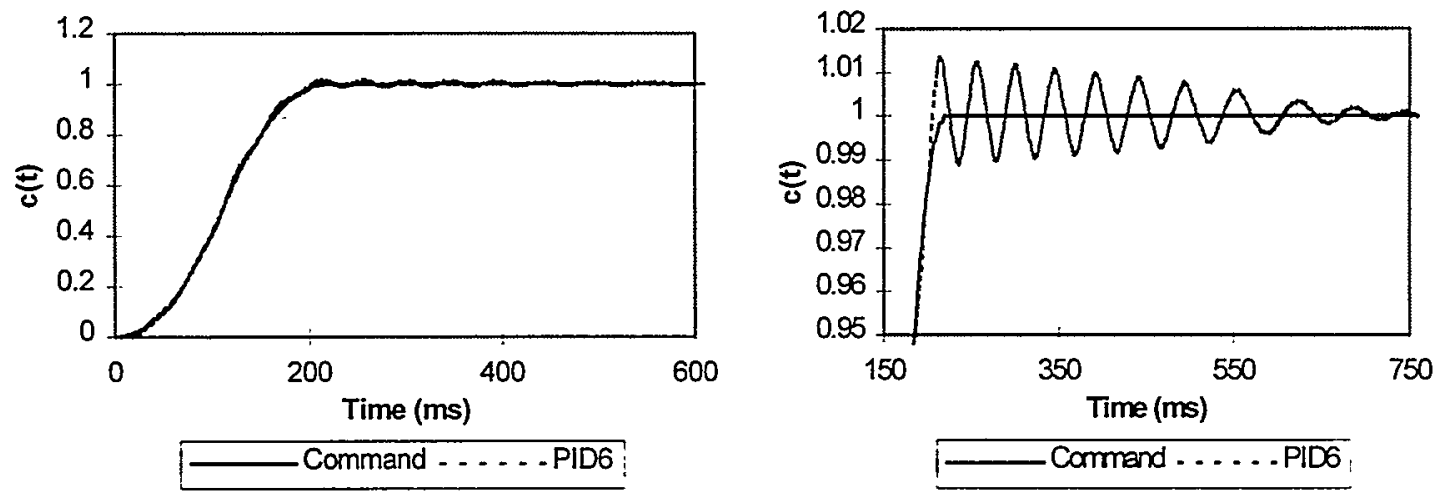

Figure 5-5. Position Command and System Response of PID6 Gains.

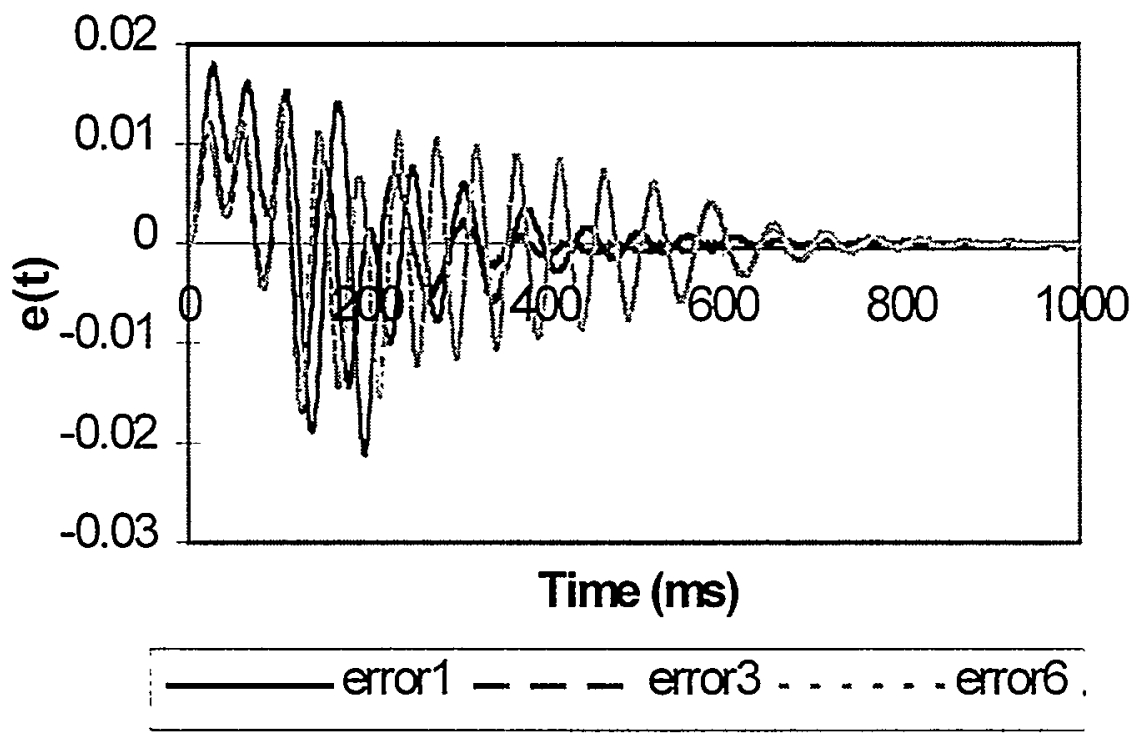

Figure 5-6. Comparison of the Response Errors.

As expected, the experimental results are somewhat different from the simulated results. The actual system response shows oscillations and steady-state error, while the model does not. This can be explained by the fact that the model does not include the nonlinear terms, such as friction in the system. The model also does not include the so-called "unmodeled dynamics," which are characterized by low-magnitude and high-frequency motion. The overshoot and subsequent oscillations shown in the actual system are caused from the excessive and retarding torque developed by the motor as the PID controller tries to compensate for the friction. Other factors, such as Coulomb friction, dead zone, and quantization error, also contribute to these errors. These factors are discussed in detail later in this section. 
Among the three system responses shown in Figures 5-3, 5-4, and 5-5, PID1 (Figure 5-3), which consists of $\mathrm{K}_{\mathrm{P}}=10, \mathrm{~K}_{\mathrm{I}}=28,000$, and $\mathrm{K}_{\mathrm{D}}=40,000$, shows the best system response. One may argue that PID3 (Figure 5-4) has a faster settling time than PID1, but notice that the steady-state error of PID3 does not go to zero as shown in Figure 5-6. On the other hand, for PID6 (Figure 55), which shows that the steady-state error eventually becomes zero, the system has a longer settling time than PID1.

\subsection{DEVELOPMENT OF FUZZY LOGIC CONTROLLER}

Fuzzy logic was first introduced by Lofti Azdeh of the University of California at Berkeley in 1965. Since then, fuzzy logic has become one of the most successful control system schemes. Fuzzy logic provides a bridge in control system design between mathematical approaches (e.g., linear control design) and logic-based approaches (e.g., expert systems). While other approaches require an accurate model to represent the real system, fuzzy design can accommodate the ambiguities of real-world human language and logic. It provides both an intuitive method for describing systems in human terms and automation for the conversion of those system specifications into effective models.

Simplicity, flexibility, and cost-effectiveness are among the other benefits of fuzzy logic. Fuzzy logic is capable of handling problems with imprecise data, and it can model nonlinear functions of arbitrary complexity. Not only do the rule-based approach and flexible membership function scheme make fuzzy systems straightforward to create, but they also simplify the design of systems and ensure that the system designer can easily update and maintain the system over time.

The fuzzy controller consists of a set of user-supplied rules of which the inputs and outputs are both fuzzy values. All control rules are used in parallel, and the recommended actions are combined according to the fuzzy control rules, which are weighted by the degree of satisfaction of the antecedent. This implies that the fuzzy controller has the ability to control systems in an uncertain or unknown environment. However, one of the fundamental problems of fuzzy control is how to establish the control rules without human expertise and knowledge of the plant [Fukumi et al. 1996].

A user-supplied rule consists of IF-THEN statements that provide the output of a system. The rule mechanism is generally of the form:

$$
\begin{gathered}
R^{(l)}: \text { IF } x_{l} \text { is } F_{1}{ }^{l} \text { and } x_{2} \text { is } F_{2}{ }^{l} \text { and } \ldots \text { and } x_{n} \text { is } F_{n}{ }^{l}, \text { THEN } y^{l}=c^{l} \\
R^{(k)}: \text { IF } x_{l} \text { is } F_{1}{ }^{k} \text { and } x_{2} \text { is } F_{2}{ }^{k} \text { and } \ldots \text { and } x_{n} \text { is } F_{n}{ }^{k}, \text { THEN } y^{k}=c^{k} \\
R^{(m)}: \text { IF } x_{1} \text { is } F_{l}^{m} \text { and } x_{2} \text { is } F_{2}{ }^{m} \text { and } \ldots \text { and } x_{n} \text { is } F_{n}{ }^{k}, \text { THEN } y^{m}=c^{m}
\end{gathered}
$$

where $R^{(k)}$ means the $k^{\text {th }}$ rule

$x_{i}$ is a real-valued input variable

$F_{i}^{k}$ is a fuzzy set specified by membership functions

$\mu_{f}\left(x_{i}\right)$ is a membership function (often defined as triangular functions)

$n$ specifies the number of input variables

$c^{k}$ is a real-valued constant 
$y^{k}$ is the system output for this rule.

If there are $m$ rules defined in the rule base, the system output is

$$
y=\Lambda \frac{\sum_{k=1}^{m} w^{k} \cdot c^{k}}{\sum_{k=1}^{m} w^{k}}
$$

where $w^{k}$ represents a variable weight assigned to the corresponding constant $c$

$\Lambda$ is defined as a scaling and tuning term.

The individual weights are computed as

$$
w^{k}=\prod_{i=1}^{n} \mu_{F_{r}^{k}}\left(x_{i}\right)
$$

To apply fuzzy logic to a robotics control system, the position and velocity feedback are used to compare the desired values given by the operator. The resulting errors are then used to compute the input torque of the actuator. This input torque can be considered as the torque to compensate for these errors. Therefore, the IF-THEN rules are written in the form:

$$
\text { IF } e_{1} \text { is } E_{j} \text { and } e_{1} \text { is } C E_{\mathrm{i}} \text {, THEN } y=C_{i j}
$$

where $e_{l}$ is defined as position error

$c e_{1}$ is defined as velocity error

$E_{j}$ is the linguistic measure of the fuzzy sets of position error

$C E_{i}$ is the linguistic measure of the fuzzy sets of velocity error

$C_{i j}$ is a constant representing the torque to be applied found on a look-up table

The membership functions provide the continuity of control inputs rather than the on/off Boolean logic strategy. The weights of Equation (5.2) are now computed as:

$$
\underline{w}_{\mathrm{ij}}=\underline{\mu}_{E \mathrm{j}}(e) \cdot \underline{\mu}_{C E \mathrm{i}}(\dot{e}) \cdot C_{\mathrm{ij}}
$$

since $n=2$ (position and velocity errors). Substituting these weights into Equation (5.1),

$$
\underline{\boldsymbol{u}}=\Lambda \frac{\sum_{i=1}^{q} \sum_{\mathrm{j}=1}^{\mathrm{v}} \underline{\mu}_{E_{j}}(e) \cdot \underline{\mu}_{C E_{i}}(\dot{e}) \cdot C_{\mathrm{ij}}}{\sum_{i=1}^{q} \sum_{\mathrm{j}=1}^{\mathrm{v}} \underline{\mu}_{E_{j}}(e) \cdot \underline{\mu}_{C E_{i}}(\dot{e})}
$$

where $q$ and $v$ define the size of the look-up table.

\subsubsection{Fuzzy Logic Controller Simulation}

The fuzzy logic control scheme developed for the 1-DOF FRMC prototype uses the triangular membership functions as shown in Figure 5-7 (Position error) and Figure 5-8 (Velocity error). 


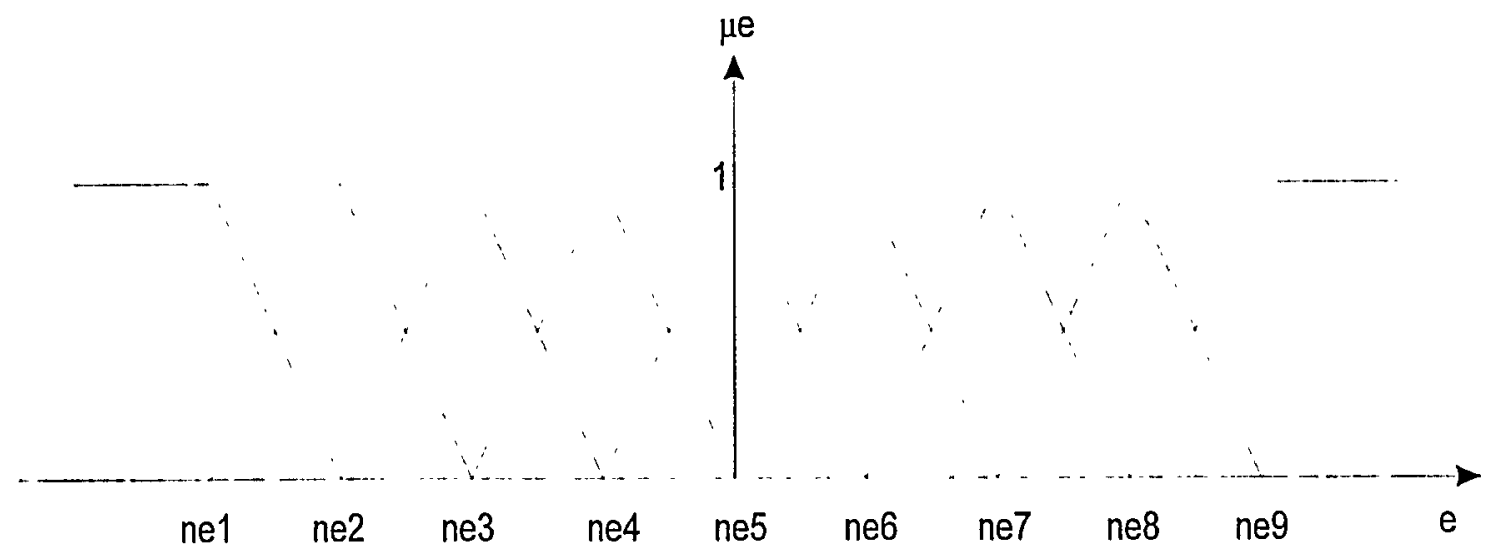

Figure 5-7. Position Error Membership Functions.

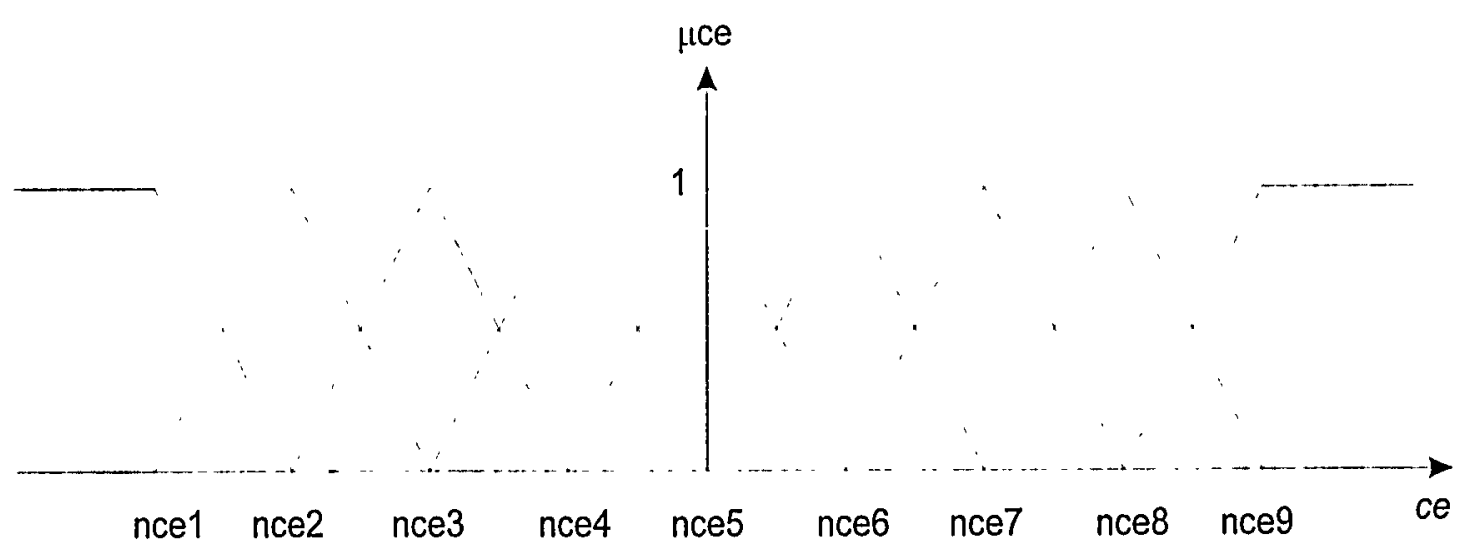

Figure 5-8. Velocity Error Membership Functions. 
These membership functions represent a total of 81 rules (nine linguistic measures for position error and nine linguistic measures for velocity error) with the centers of the fuzzy sets shown in Table 5-2. Although different spacing between the centers can be done, the centers of the fuzzy sets in this experiment are equally spaced so that they can be changed easily without complicating the program. Note that it is important that a fuzzy set center be located at ne $=0$ so that the errors may converge to zero. Otherwise, continuous oscillations of the joint errors will result at about zero or at convergence to a nonzero value at which the system provides no error compensation [Monteverde 1997]. Crossover of the non-zero membership functions is limited to one crossover for any point along the error and velocity error axes, although different schemes can be used that may be more effective.

Table 5-2.

Centers for Position Error and Velocity Error for the Membership Functions from Figures 5-7 and 5-8

\begin{tabular}{|c|c|c|c|}
\hline Position error center & Value (radians) & Velocity error center & Value (rps) \\
\hline ne1 & -0.25 & nce1 & -1.5 \\
\hline ne2 & -0.1875 & nce2 & -1.125 \\
\hline ne3 & -0.125 & nce3 & -0.75 \\
\hline ne4 & -0.0625 & nce4 & -0.375 \\
\hline ne5 & 0.0 & nce5 & 0.0 \\
\hline ne6 & 0.0625 & nce6 & 0.375 \\
\hline ne7 & 0.125 & nce7 & 0.75 \\
\hline ne8 & 0.1875 & nce8 & 1.125 \\
\hline ne9 & 0.25 & nce9 & 1.5 \\
\hline
\end{tabular}

The membership functions vary from 0 to 1 and can be calculated from Figures 5-7 and 5-8 with knowledge of the position error and velocity error. The control input (Equation 5.5) can then be determined utilizing the membership functions and the look-up table of constant input values (Table 5-3) with $q=9$ and $v=9$. The model obtained in the previous section is used to simulate the 1-DOF FRMC prototype. Moreover, the constant values in Table 5-3 represent the values of input voltage that can be provided by the actual actuator of the 1-DOF FRMC. A look-up table has to be generated that, in essence, is a set of gains for the system. According to Cha [Cha et el. 1996], the performance of a teleoperation system is greatly influenced by the force-reflection gain. If the gain is too small, the performance is poor. If the gain is too large, the system is 
unstable. To simplify this process, the look-up table is set up as a function of a single base value. The base value is multiplied by the weighting corresponding to the position in the table.

In the simulations and actual experiments of the 1-DOF FRMC system, the gain matrix for scaling and tuning is set to 1 .

Table 5-3.

Look-Up Table Representing Input Voltage of the Actuator

\begin{tabular}{|c|c|c|c|c|c|c|c|c|c|}
\hline & ne1 & $\mathrm{Ne} 2$ & $\mathrm{Ne} 3$ & $\mathrm{ne} 4$ & ne5 & ne6 & ne7 & ne8 & ne9 \\
\hline nce1 & $-4.0 * \mathrm{~b}$ & $-4.0 * \mathrm{~b}$ & $-3.0 * \mathrm{~b}$ & $-3.0 * \mathrm{~b}$ & $-2.0 * \mathrm{~b}$ & $-2.0 * \mathrm{~b}$ & $-2.0 * \mathrm{~b}$ & $-1.0 * \mathrm{~b}$ & $-1.0 * \mathrm{~b}$ \\
\hline nce2 & $-4.0 * \mathrm{~b}$ & $-4.0 * \mathrm{~b}$ & $-3.0 * \mathrm{~b}$ & $-3.0 * \mathrm{~b}$ & $-2.0 * \mathrm{~b}$ & $-2.0 * \mathrm{~b}$ & $-1.0 * \mathrm{~b}$ & $-1.0 * \mathrm{~b}$ & $-1.0 * \mathrm{~b}$ \\
\hline nce3 & $-3.0 * \mathrm{~b}$ & $-3.0 * \mathrm{~b}$ & $-3.0 * \mathrm{~b}$ & $-3.0 * \mathrm{~b}$ & $-2.0 * \mathrm{~b}$ & $-2.0 * \mathrm{~b}$ & $-1.0 * \mathrm{~b}$ & $-1.0 * \mathrm{~b}$ & $-1.0 * \mathrm{~b}$ \\
\hline nce4 & $-2.0 * \mathrm{~b}$ & $-2.0 * \mathrm{~b}$ & $-2.0 * \mathrm{~b}$ & $-2.0 * \mathrm{~b}$ & $-2.0 * \mathrm{~b}$ & $-2.0 * \mathrm{~b}$ & $1.0 * \mathrm{~b}$ & $1.0 * \mathrm{~b}$ & $1.0 * \mathrm{~b}$ \\
\hline nce5 & $-2.0 * \mathrm{~b}$ & $-1.0 * \mathrm{~b}$ & $-1.0 * \mathrm{~b}$ & $-1.0 * \mathrm{~b}$ & 0.0 & $1.0 * \mathrm{~b}$ & $1.0 * \mathrm{~b}$ & $1.0 * \mathrm{~b}$ & $1.0 * \mathrm{~b}$ \\
\hline nce6 & $-1.0 * \mathrm{~b}$ & $-1.0 * \mathrm{~b}$ & $1.0 * \mathrm{~b}$ & $2.0 * \mathrm{~b}$ & $2.0 * \mathrm{~b}$ & $2.0 * \mathrm{~b}$ & $2.0 * \mathrm{~b}$ & $2.0 * \mathrm{~b}$ & $2.0 * \mathrm{~b}$ \\
\hline nce7 & $-1.0 * \mathrm{~b}$ & $1.0 * \mathrm{~b}$ & $2.0 * \mathrm{~b}$ & $1.0 * \mathrm{~b}$ & $2.0 * \mathrm{~b}$ & $2.0 * \mathrm{~b}$ & $3.0 * \mathrm{~b}$ & $3.0 * \mathrm{~b}$ & $3.0 * \mathrm{~b}$ \\
\hline nce8 & $1.0 * \mathrm{~b}$ & $1.0 * \mathrm{~b}$ & $2.0 * \mathrm{~b}$ & $2.0 * \mathrm{~b}$ & $2.0 * \mathrm{~b}$ & $2.0 * \mathrm{~b}$ & $3.0 * \mathrm{~b}$ & $4.0 * \mathrm{~b}$ & $4.0 * \mathrm{~b}$ \\
\hline nce9 & $1.0 * \mathrm{~b}$ & $1.0 * \mathrm{~b}$ & $2.0 * \mathrm{~b}$ & $2.0 * \mathrm{~b}$ & $2.0 * \mathrm{~b}$ & $2.0 * \mathrm{~b}$ & $3.0 * \mathrm{~b}$ & $4.0 * \mathrm{~b}$ & $4.0 * \mathrm{~b}$ \\
\hline
\end{tabular}

$\mathrm{b}$ - base value 
The look-up table coefficients as illustrated in Table 5-3 are chosen with the aim of sending the position and velocity errors to their respective zero value as shown in Figures 5-7 and 5-8 [Erbatur et al. 1995]. The location where both the position and velocity have a large negative error receives a large negative torque and vice-versa for the positive end. For the case where there is large positive position error and large negative velocity error, the corresponding table location receives a small input torque due to the correctness of the situation being somewhere in between the two error values. The same applies for the case of large positive velocity error and large negative position error. The values in between these cases are chosen in the same manner so as to produce a continuous table flow towards zero.

Figure 5-9 depicts one of the simulated results using a fuzzy logic controller where the base value is 0.5 . Again, the parabolic function input is used here as the desired path for the reason stated earlier.

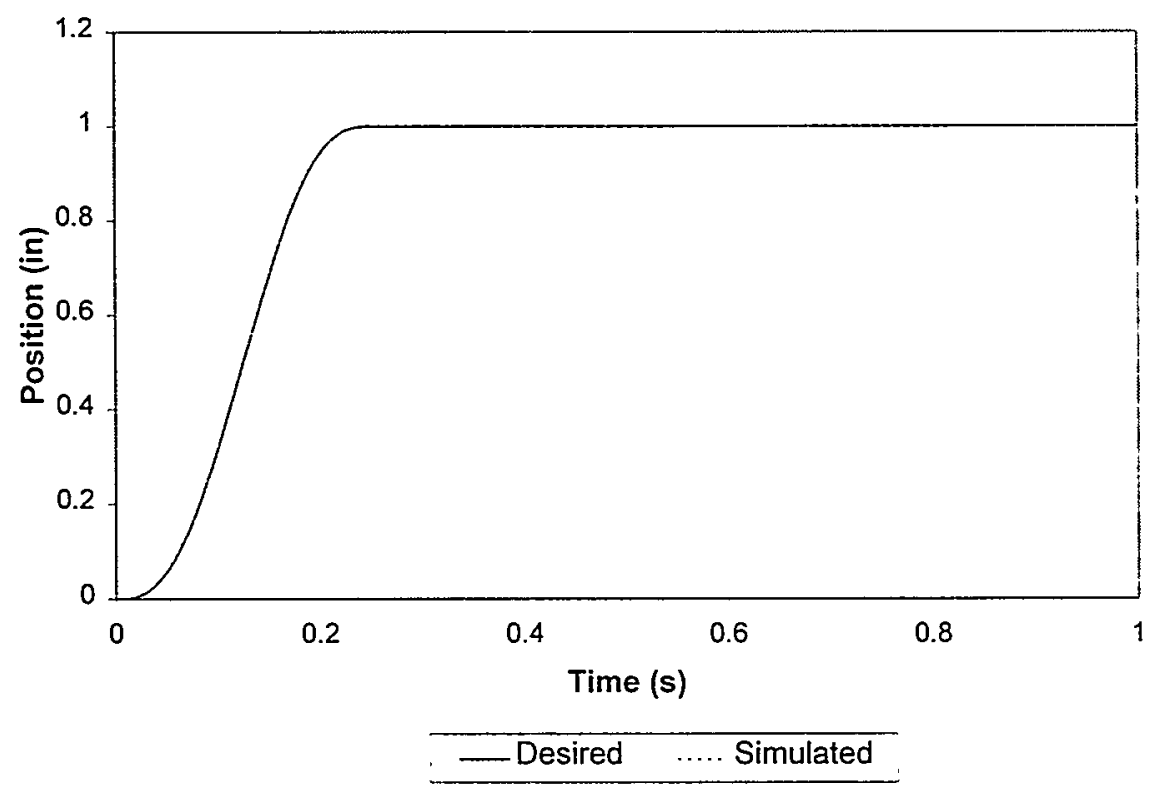

Figure 5-9. Simulated System Response under Fuzzy Logic Controller.

As shown on Figure 5-9, the model under fuzzy logic controller follows the desired path exactly. However, this may not be the case for the actual system, as demonstrated in the next section.

\subsubsection{Experiments on the 1-DOF FRMC by Implementing the Fuzzy Logic}

\section{Controller}

The fuzzy logic control method developed in the previous section is implemented on the 1-DOF FRMC prototype. All of the parameters used in the simulation are applied to the actual system. One of the main objectives of the experiments is to compare the numerical results obtained from the mathematical model and those of laboratory data. In doing so, the 0.5 base value is used in the experiments. Figure 5-10 shows the response obtained from the actual system with $b=0.5$. 


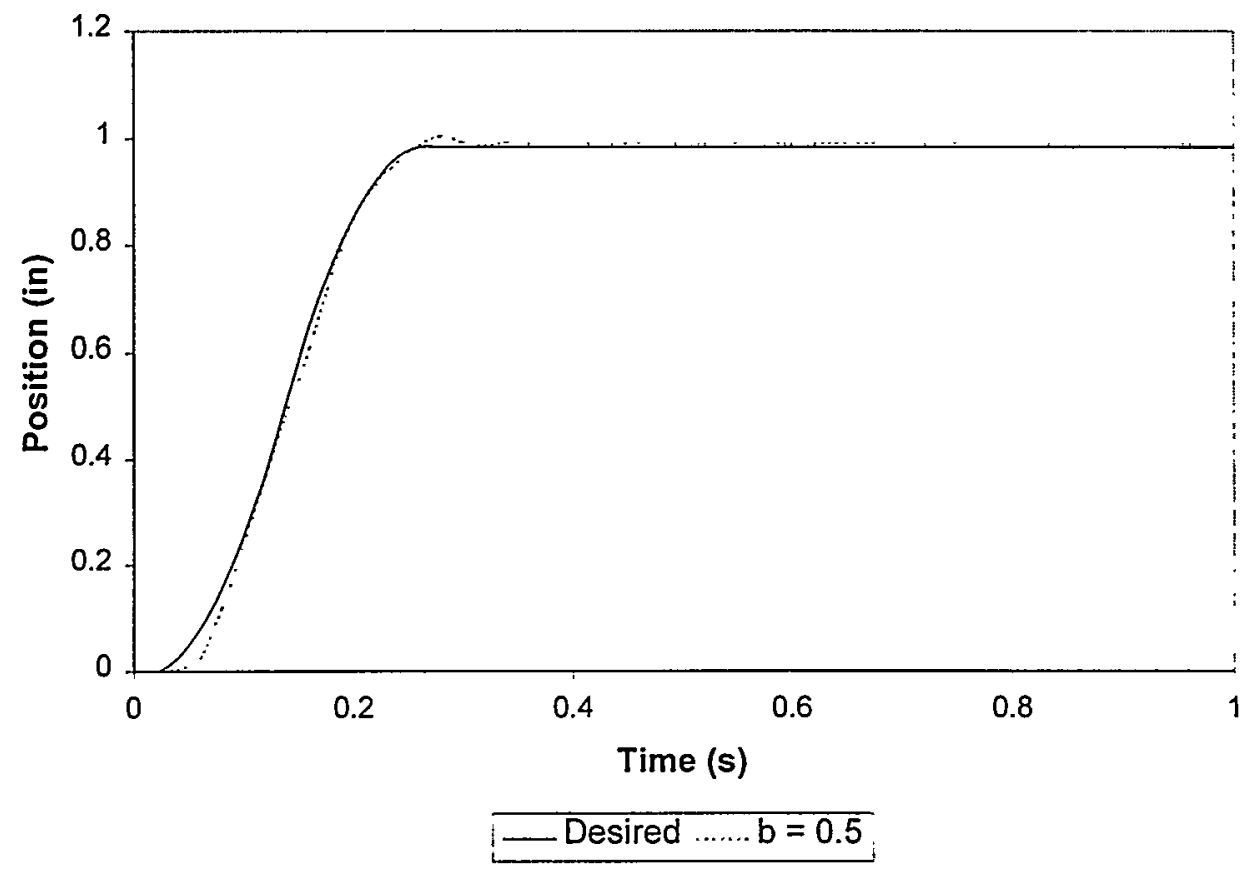

Figure 5-10. Actual System Response under Fuzzy Logic Controller of Base Value of 0.5.

When the experimental data (Figure 5-10) are compared with the simulation results obtained from the mathematical model (Figure 5-9), they match quite well, with the exception of a slight overshoot in the transient behavior and minimal steady-state error. This is because, as explained earlier, in a real system there are friction and other nonlinear system characteristics, such as dead zone and quantization errors that are not considered in the simulation. These errors in a control system are almost unavoidable. The next section discusses these errors in detail.

Figures 5-11 and 5-12 show the actual system response of the 1-DOF FRMC testbed under fuzzy logic controller with various base values. 


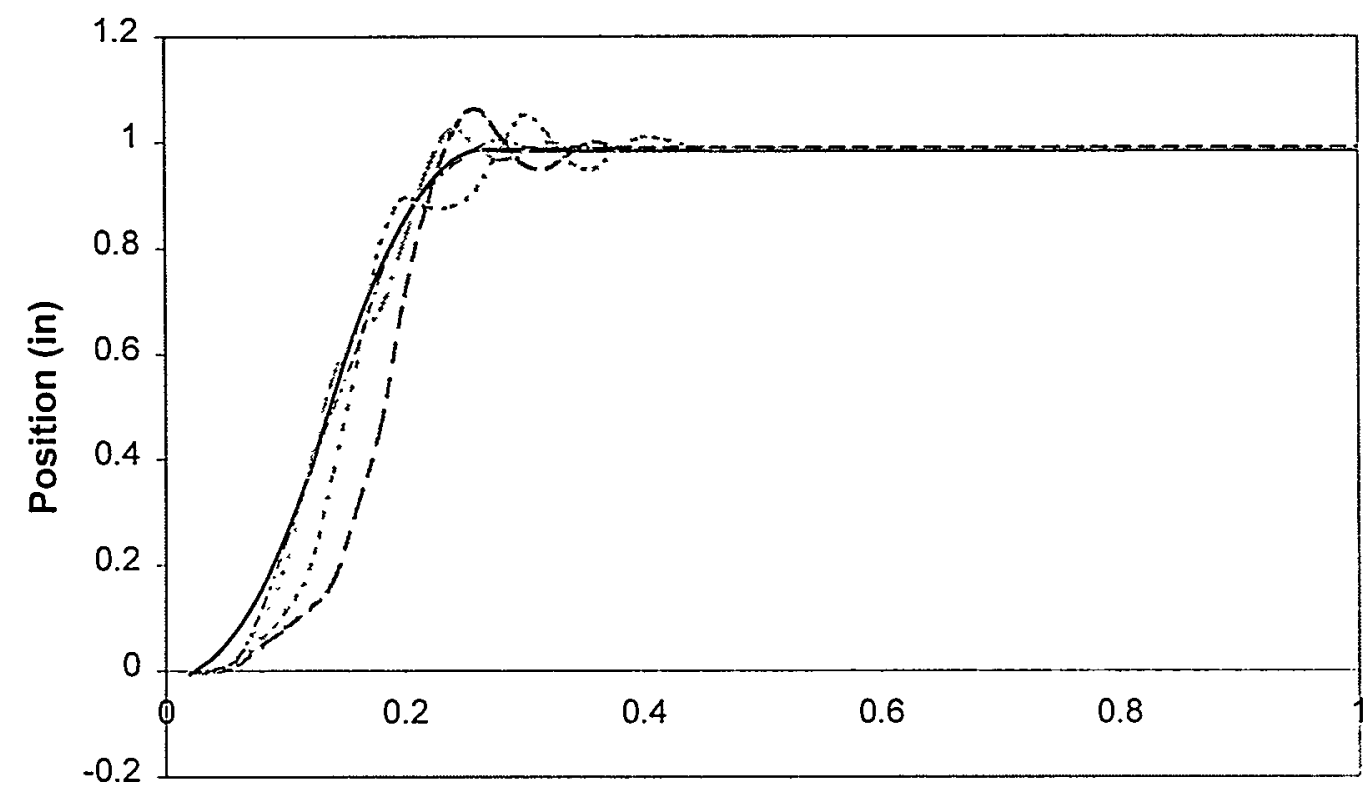

Time (s)

Desired $--b=0.35 \ldots b=0.4 \ldots b=0.45-\cdots-b=0.5$

Figure 5-11. Actual System Response with Base Values between 0.35 to 0.5 .

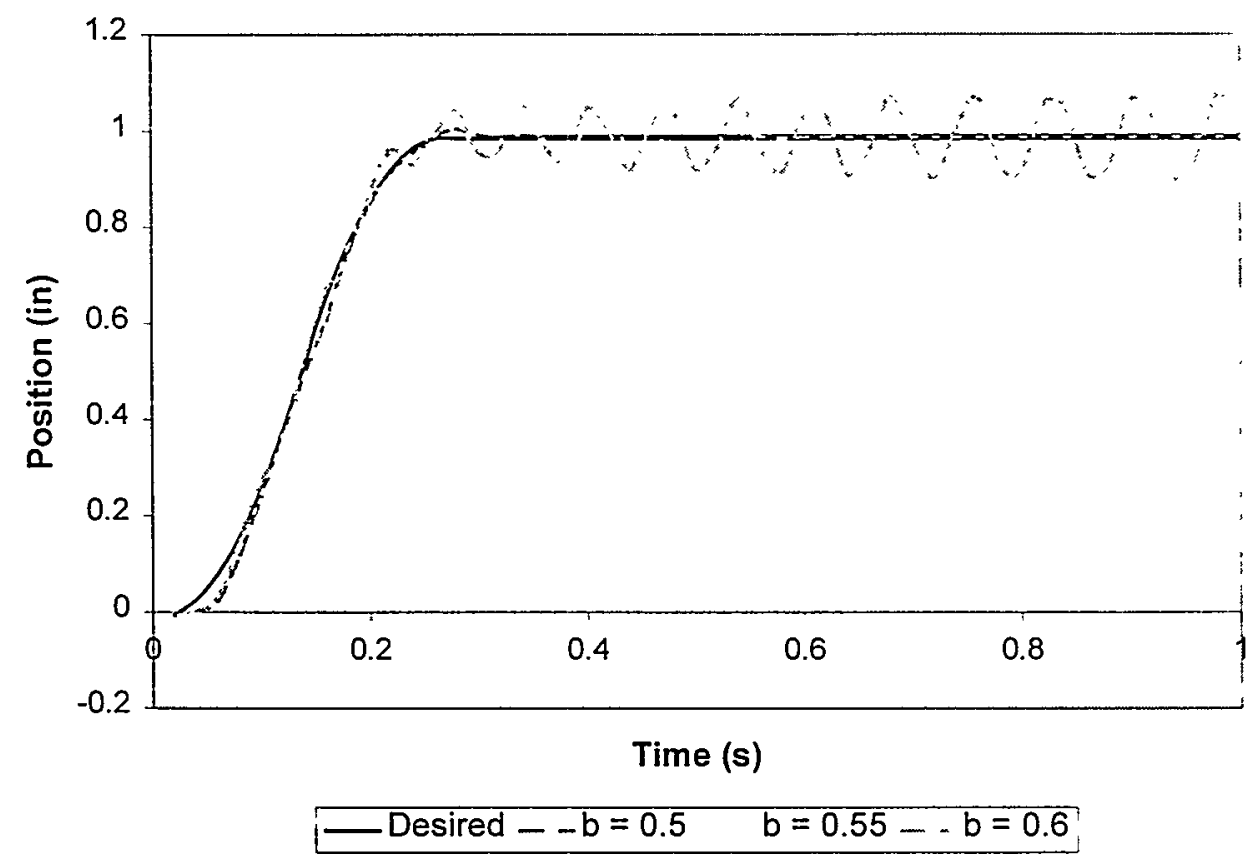

Figure 5-12. Actual System Response with Base Values between 0.5 to 0.6. 
As can be seen from the above figures, different base values produce different system response. Thus, with the fuzzy logic controller, as is the case with most controllers, the selection of the system gain is one of the most important factors that determine the performance of the system. In the case of the 1-DOF FRMC, the most appropriate base value is 0.5 for the look-up table represented in Table 5-3. Note that the results obtained above were in the case where the operator held the joystick with a loose grip.

A soft grip uses lower gains, while a firm grip uses higher gains in order to provide a forcereflection sensation. As for the 1-DOF FRMC, the experiments show that for the stable region of the soft grip, the base value is in the range of 0.35-0.55; whereas for the firm grasp, the base value can be as much as $0.8-1.0$. If the base value falls below the above values, poor performance results and higher base value cause the system to be unstable.

\subsection{A COMPARISON OF THE SYSTEM PERFORMANCE OF PID CONTROLLER AND FUZZY LOGIC CONTROLLER}

A comparison of the system response between PID controller and fuzzy logic controller is shown in Figure 5-13. All of the system parameters used in this experiment are the same as before where the gains for PID controller are set as $K_{P}=10, K_{I}=28,000$, and $K_{D}=40,000$, and the base value (b) for fuzzy logic controller is selected as 0.5 .

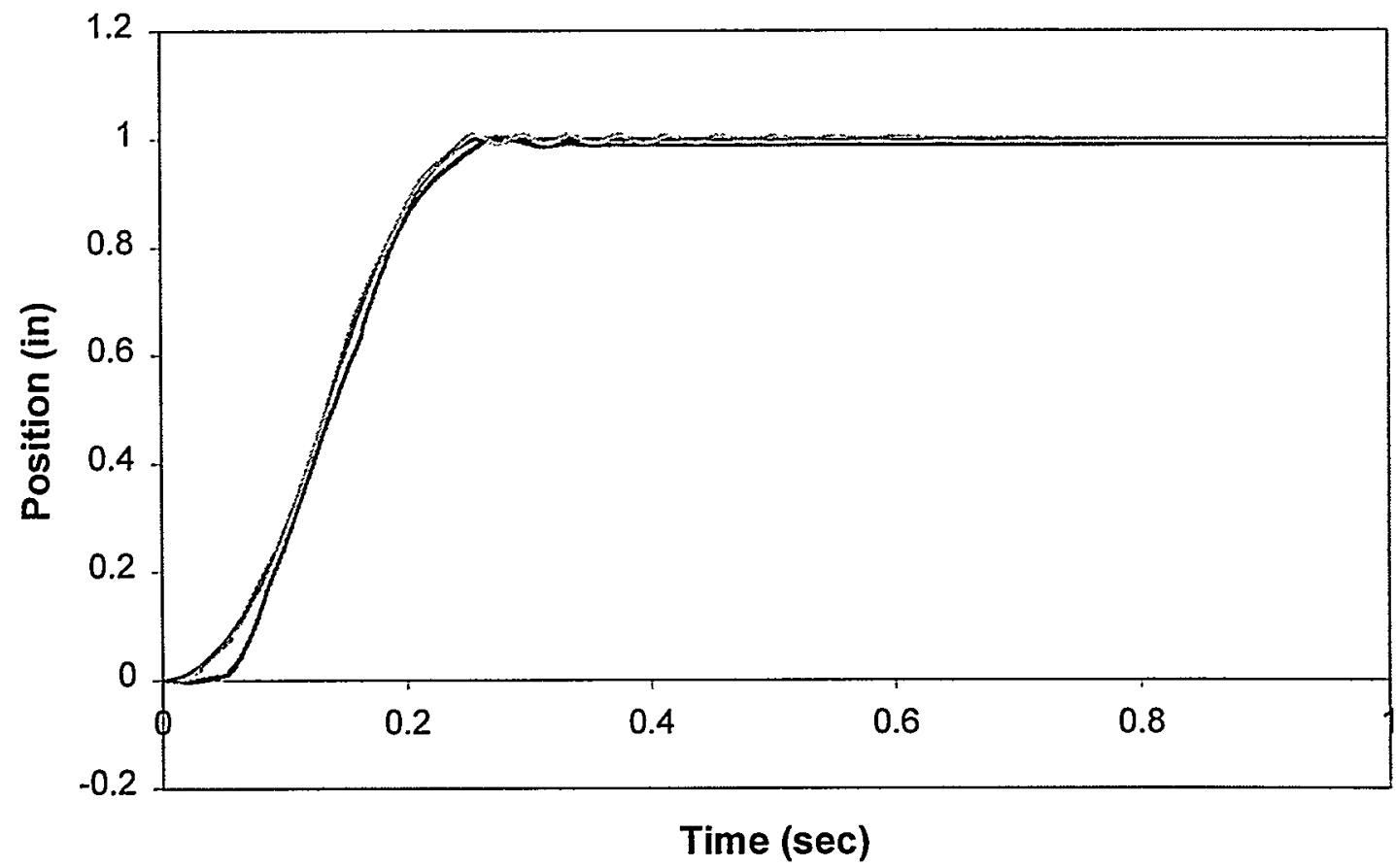

-Desired —-Fuzzy -.. PID

Figure 5-13. A Comparison of System Response between PID and Fuzzy Logic Controllers. 
As shown in Figure 5-13, both controllers follow the desired path quite well. The differences are that PID shows an overshoot and transient oscillations but has no steady-state error, whereas the fuzzy logic controller produces no oscillations, but it displays steady-state error and can not catch up with the desired path at the beginning as well as PID. Therefore, the choice of selecting a controller between the PID and fuzzy logic approaches will depend largely on the operator and the requirements of the tasks, since each has its benefits and drawbacks. However, for the purpose of force-reflecting manual controller application, where very high precision is not required due to the limitations on human perception, the performance of both controllers are judged to be acceptable.

\subsection{ERRORS CAUSED BY NONLINEAR SYSTEM ELEMENTS}

According to Figure 5-6 (PID system response errors) and Figure 5-10 (Fuzzy logic system response), errors of control systems are attributed to static and dynamic friction and some nonlinear system characteristics. Static friction or stiction represents a retarding force that tends to prevent motion from beginning. The static friction force can be represented by the expression

$$
f(t)= \pm\left(F_{s}\right)_{j=0}
$$

In Equation (5.6), $f(t)$ is defined as a frictional force that exists only when the body is stationary but has a tendency of moving. The sign of the friction depends on the direction of motion or the initial direction of velocity.

The force-to-velocity relation of static friction is illustrated in Figure 5-14. Notice that once the motion begins, the static friction vanishes, and dynamic or viscous friction takes over. For the 1DOF FRMC, the static friction torque is measured to be around $0.27 \mathrm{lb}$-in.

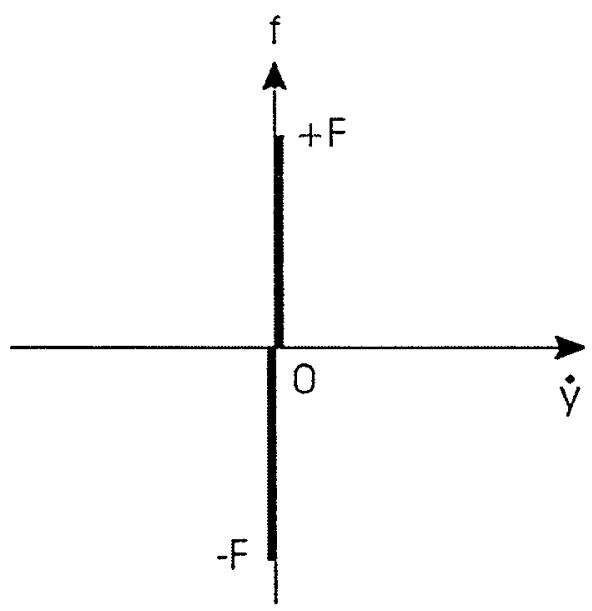

Figure 5-14. Force-to-Velocity Relation of Static Friction.

The errors at the transient portion and at the steady state are usually caused by nonlinear system elements. According to Kuo [Kuo 1991], steady-state errors of control systems are attributed to some nonlinear system characteristics such as nonlinear friction or dead zone. The amplifier used in the control system often has the input-output characteristics shown in Figure 5-15. When the 
amplitude of the amplifier input signal falls within the dead zone, the output of the amplifier will be zero, and the control will not be able to correct the error if any exists. Dead-zone nonlinearity characteristics shown in Figure 5-15 are not limited to amplifiers. The flux-to-current relation of the magnetic field of an electric motor often exhibits a similar characteristic. Thus, as the current of the motor falls below the dead zone $\mathrm{D}$, no magnetic flux and, thus, no torque will be produced by the motor. On the other hand, when the input-signal magnitude exceeds a certain level, the amplifier may be subject to saturation characteristics as in Figure 5-15. Similarly, when the magnetic field of the motor is saturated, increasing the armature current will no longer produce additional torque.

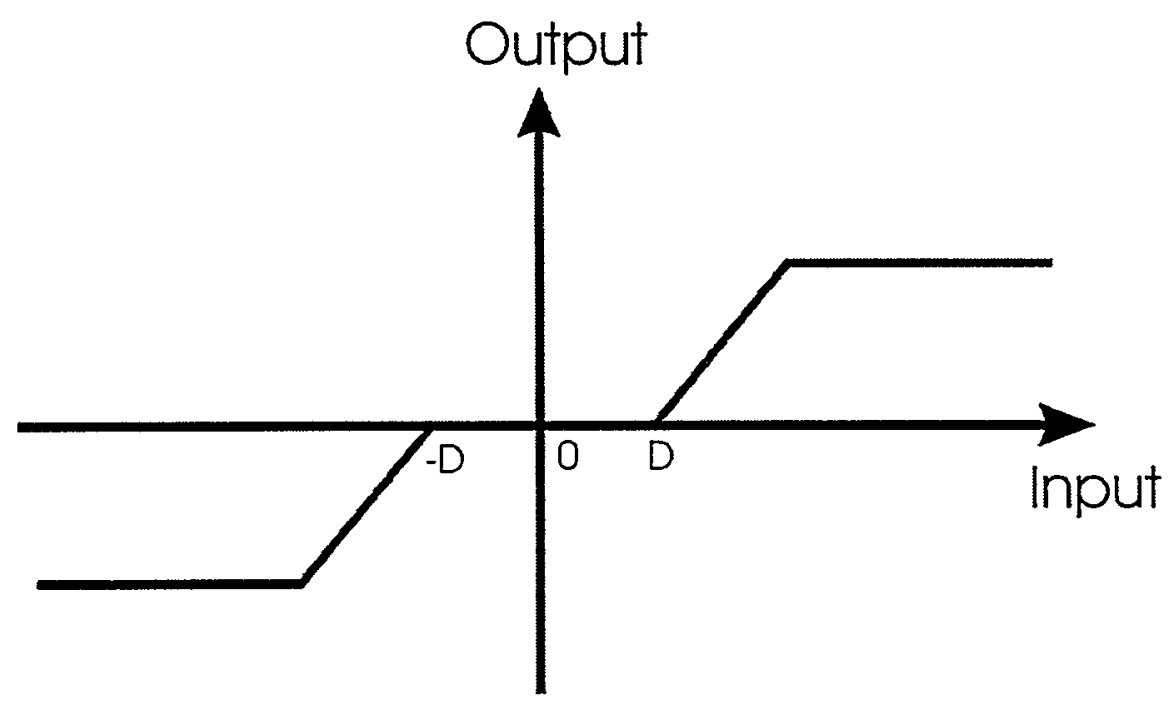

Figure 5-15. Typical Input-Output Characteristics of an Amplifier with Dead Zone and Saturation.

The output signals of digital components used in control systems, such as microprocessors, can take on only discrete or quantized levels. This property is illustrated by the quantization characteristics shown in Figure 5-16. When the input to the quantizer is within $+/-0.5 q$, the output is zero, and the system may generate an error in the output whose magnitude is related to $+/-0.5 q$. 


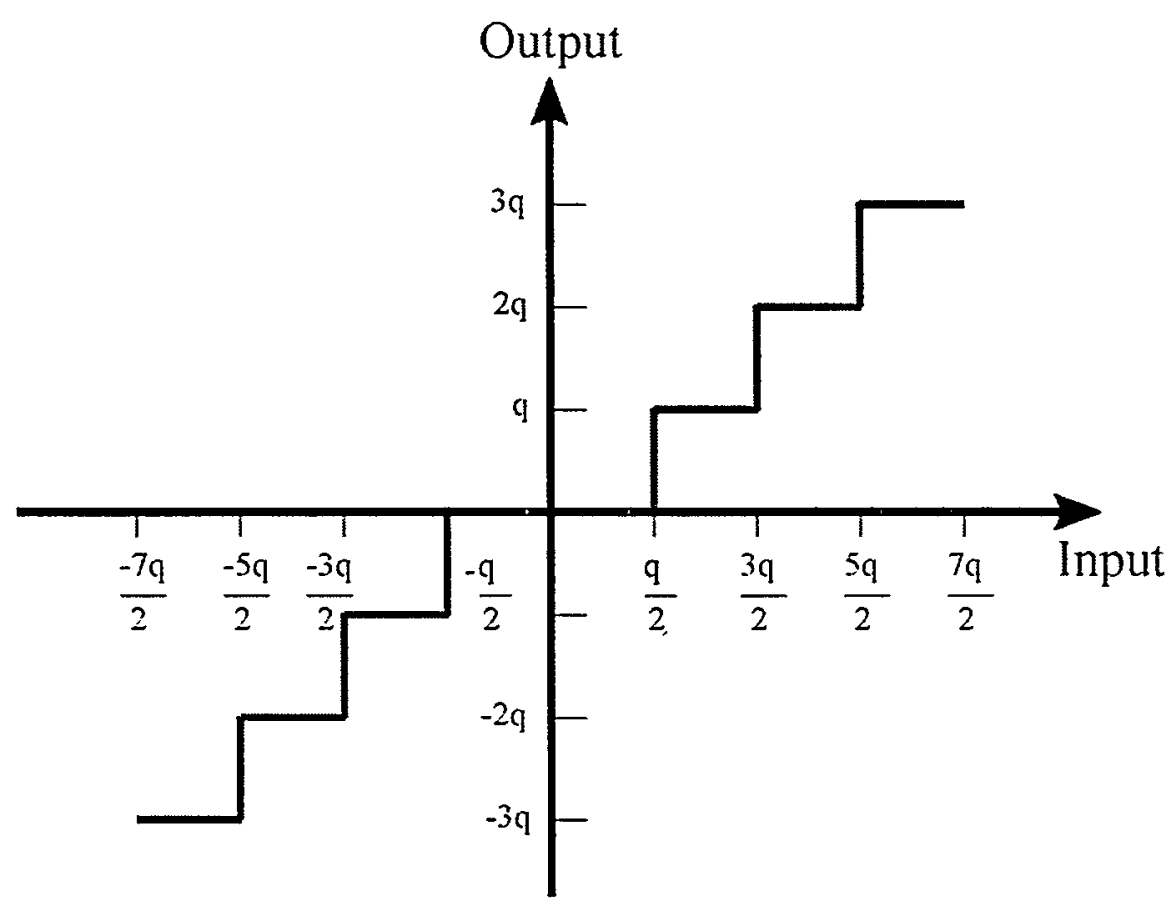

Figure 5-16. Typical Input-Output Characteristics of a Quantizer.

Coulomb friction is also a common cause of steady-state position errors in control systems. Coulumb friction is a retarding force that has a constant amplitude with respect to the change in velocity, but the sign of the frictional force changes with the reversal of the direction of velocity. The mathematical relation for the Coulomb friction is given by

$$
f(t)=F_{c} \frac{\left[\frac{d y(t)}{d t}\right]}{\left.\mid \frac{d y(t)}{d t}\right] \mid}
$$

Figure 5-17 shows a restoring-torque-versus-position curve of a control system. The torque curve typically can be generated by a step motor or a switched-reluctance motor or from a closed-loop system with a position encoder. The point 0 designates a stable equilibrium point on the torque curve, as well as the other periodic points along the axis where the slope on the torque curve is negative. The torque on either side of the point 0 represents a restoring torque that tends to return the output to the equilibrium point when some angular-displacement disturbance takes place. When there is no friction, the position error should be zero, since there is always a restoring torque so long as the position is not at the stable equilibrium point. If the rotor of the motor sees a Coulomb friction torque $\mathrm{T}_{\mathrm{F}}$, then the motor torque must first overcome this frictional torque before producing any motion. Thus, as the motor torque falls below $T_{F}$ as the rotor position approaches the stable equilibrium point, it may stop at any position inside the shaded band shown in Figure 5-17, and the error band is bounded by $+/-\theta_{e}$. 


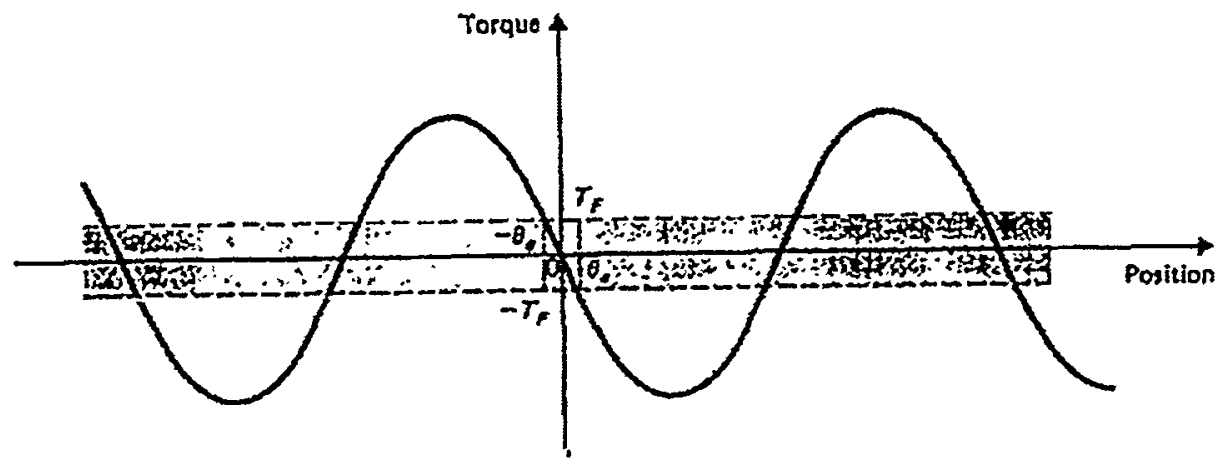

Figure 5-17. Torque-Angle Curve of a Motor or Closed-Loop System with Coulomb Friction (Adapted from Kuo 1991). 


\subsection{DEVELOPMENT OF A TELESENSATION SYSTEM}

In this section, the ongoing development of a telesensation system that is being developed at the Robotics and Automation Laboratory at Florida International University in Miami is presented. Such a system consists of three distinct components: Virtual Reality (VR) unit, Force-Reflecting Manual Controller (FRMC), and Graphical User Interface (GUI). An overview of VR units is given. Furthermore, an extensive survey of commercial VR units has been conducted in order to identify the most appropriate unit for the telesensation system. Later, the design of the 3-DOF FRMC is presented. This includes a review of the actuator system design alternatives and a survey of the actuator system available commercially. In addition, various design alternatives for the 3-DOF FRMC are presented. The relative merits of different options are also discussed. Finally, the development of the GUI software is presented.

\subsection{VIRTUAL REALITY UNIT}

A Virtual Reality (VR) unit is a visual device, similar to a helmet, that enables a person to perceive and interact with a virtual environment as if it were real [Miner and Stansfield 1994]. In telesensation systems, the VR unit provides the view of the remote site as the operator turns or tilts his/her head, which corresponds to a remote system camera. A VR system not only provides the operator with the 3-D view of the remote site but also sound feedback, voice input, and motion tracking [Christopher and Stansfield 1994]. A standard TV monitor is not able to provide the operator with a sense of a 3-D view of the working environment. Thus, the feeling of presence and sensation is reduced, which results in poor performance [Trivedi and Chen 1993].

One of the major advantages of having a VR unit is that the actual manipulator can be removed from the training loop while the operator is being trained. This training approach can be quite beneficial because the robot cannot be damaged by any mistreatment by an operator and the operator should feel more comfortable during the training exercise. In addition, training scenarios can be set up easily. These scenarios usually include an emergency situation procedure training. Should the actual emergency occur, the operator would be much better at handling the situation [Miner and Stansfield 1994]. Also, the cost associated with training personnel reduces significantly, since direct hardware usage is significantly reduced.

\subsubsection{The Current State-of-the-Art VR Systems}

\section{Vision}

VR systems usually include stereo vision. Two types of displays used in lower-cost systems are Liquid Crystal Displays (LCD) and CRT. The CRT display areas are usually small with high light output, while flat-panel LCD displays have low weight and optional color but poor resolution and relatively low light output. Thus, CRTs are preferable in display design with folded optical paths.

In terms of complexity and realism, VR units have similar objectives of visual image generation to those in aircraft simulation. However, faster scene changes are required in the VR systems as a result of user head movements. VR units must be able to provide effective visual simulation that 
requires computational complexity in order to eliminate hidden lines and produce effective perspective [Burdea 1994]. In addition, computational speed must be fast enough to provide the operator with acceptable scene update rates. Currently, one of the most powerful and popular work stations is produced by Silicon Graphics.

The image generator produces an output by receiving the signal from the measurement of head movements that are measured optically, acoustically, mechanically, or magnetically. One of the most popular systems is the Polhemus Spasyn system. This technique requires only small sensors to be mounted on the head and is insensitive to most interference. However, one of the biggest disadvantages of this system is that the accuracy is affected by metal, and the environments must be mapped extensively.

\section{Audio}

An audio system is one of the most important elements in VR units. Spatially distinct sounds are important attributes of a convincing virtual reality. One approach to produce a successful virtual 3-D sound is to apply a mathematical function called Head-Related Transfer Function or HRTF. The HRTF relates to an individual's ear shape, but generalized HRTFs have been successfully created that work for most people. Research has shown that perceptual errors can cause problems, such as sounds behind the head that are perceived as if they were in the front of the head. These types of problems cannot be solved even when generalized HRTFs are used [Vince 1995].

One of the most efficient VR systems, built at the Armstrong Aerospace Medical Research Laboratory, is called the Visually Coupled Airborne Systems Simulator (VCASS). The system uses miniature CRTs as image resources to produce high-resolution displays. VCASS provides a binocular field of view of 120 degrees horizontal and 60 degrees vertical. It has high bandwidth video amplifiers, programmable analog circuits for pre-distorting the images, and many other features. Other proficient VR units have been produced by Honeywell for use in the "Falcon Eye," the F-16 night attack system, in the Apache attack helicopter, and in other various British research projects.

Extensive teleoperation research projects using the VR technology have been developed at NASA's AMES Research Project [Stark et al. 1987]; at the Jet Propulsion Laboratory (JPL) to control remotely deployed robots [Bejczy 1980]; at the Automation and Robotics (A\&R) Division at the Johnson Space Center (JSC) for telepresence research, robotics, and extravehicular activities (EVA) analysis and training [Read et al. 1994]; at the Advanced Controls Manipulation Laboratory (ACML) at Sandia National Laboratories for waste remediation technologies; at the University of Tennessee at Knoxville Mobile-Manipulator Robotics Research (M2R2); and at the Oak Ridge National Laboratory (ORNL) Advanced Servo Manipulator (ASM)-based Decontamination and Decommissioning (D\&D) [Trivedi and Chen 1993].

Some of the commercial VR units available on the market are briefly reviewed below. These include the Visual Immersion Module (VIM), Liquid Image MRG2.2, Virtual Research Systems VR4, and Personal Use Stereoscopic Haptic (PUSH) virtual reality systems. 
Visual Immersion Module (VIM)

The Visual Immersion Module (VIM), as shown in Figure 6-1, is produced by Kaiser ElectroOptics, Inc. There are two models available: $500 \mathrm{HRpv}$ and $1000 \mathrm{HRpv}$. The 500HRpv employs two full-color, 0.7" Active Matrix LCD (AMLCD) displays with a resolution of 180,000 pixels per LCD. The field of view (FOV) is approximately $50^{\circ}$, and it weighs only $26 \mathrm{oz}$. The $1000 \mathrm{HRpv}$ provides four full-color displays instead of two and has a vertical FOV of $30^{\circ}$ and $100^{\circ}$ horizontally. Both provide built-in Sennheiser 2-channel stereo headphones [Batsomboon et al. 1996c].

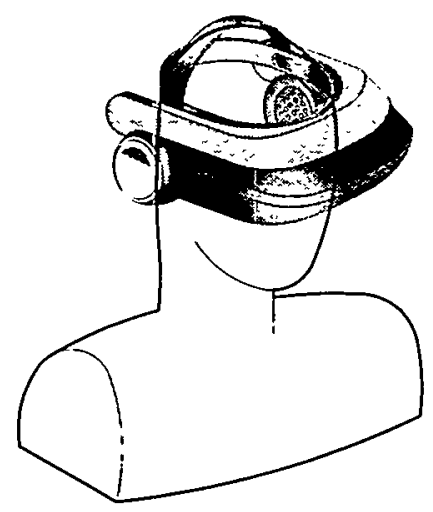

Figure 6-1. Visual Immersion Module (VIM).

\section{Liquid Image MRG2.2}

The MRG2.2 (Figure 6-2) is one of various VR units manufactured by the Liquid Image Corporation. The unit employs a single, full-color AMLCD display type with a resolution of 240 $\times 720$ pixels per eye. It has a FOV of $84^{\circ}$ horizontally and $65^{\circ}$ vertically. Internally mounted microphones and positional tracker are two of the many options that can be incorporated.

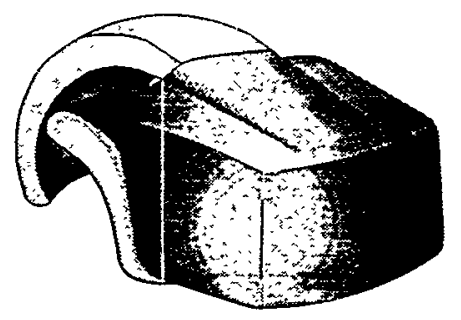

Figure 6-2. Liquid Image MRG2.2. 


\section{Virtual Research Systems VR4}

The VR4 (Figure 6-3) is manufactured by Virtual Research Systems, Inc. This light-weight unit (33 oz.) has a field of view of $60^{\circ}$ diagonal at $100 \%$ overlap and $67^{\circ}$ at $85 \%$ overlap. Each eye has a resolution of $742 \times 230$ pixels, which is equivalent to 56,887 triads. The VR4 employs a 1.3" diagonal AMLCD display type and Sennheiser HD440 digitally compatible headphones [Batsomboon et al. 1996c].

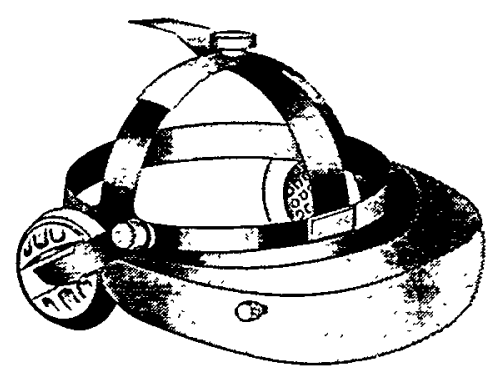

Figure 6-3. Virtual Research Systems VR4.

Personal Use Stereoscopic Haptic (PUSH)

The Personal Use Stereoscopic Haptic (PUSH), as shown in Figure 6-4, is a desktop immersive display produced by Fakespace. The unit provides an adjustable field of view of $30^{\circ}$ to $140^{\circ}$ with a resolution of $1280 \times 1024$ triads per eye. It has 6-DOF control with 3-DOF PUSH interface. A test has been conducted by Fakespace to examine the unit. Users ranging from expert to novice were asked to navigate through a virtual test environment. With PUSH technology, the company claims that the users were able to navigate in a large virtual space or zoom in to see the objects from different viewpoints.

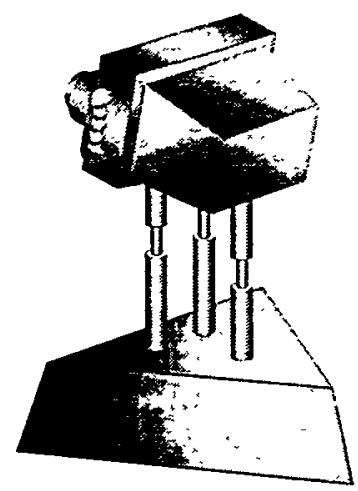

Figure 6-4. Personal Use Stereoscopic Haptic (PUSH).

For the purpose of implementing a VR unit in a telesensation system, although any of the systems reviewed above might be used, either the VIM 1000HRpv or VR4 would be more 
suitable. Both systems provide built-in stereo headphones and a good range of field of view with fine resolution. They are lightweight, and reasonable costs make them more attractive.

\subsection{DESIGN OF A 3-DOF FORCE-REFLECTING MANUAL CONTROLLER}

A force-reflecting manual controller (FRMC), or joystick, is one of the devices that can be used to control remote systems in teleoperation. A joystick is often a better control device than other available options, such as a mouse, switchbox, keyboard, or touch-screen input, because the operator identifies better with the task [Johnsen and Corliss 1971]. However, to apply the concept of telesensation to a conventional teleoperation system, the joystick should be able to reflect forces experienced at the remote site. Force feedback is one of the most significant elements of feedback information for a telesensation system. It is fundamental for mechanical support, sense of balance, and a feel of touching real objects. It conveys information that is essential in many activities, such as training, design analysis, and hazardous-environment task simulations [McNeely et al. 1995]. The FRMC provides a virtual force [Repperger et al. 1995] that enhances the realism of the virtual reality-based telesensation system; thus, the performance of the operator is greatly improved.

Unfortunately, most of the force-reflecting manual controllers are bulky, complex, and high cost. In order to improve the design to meet criteria such as compactness, portability, and low costs, the motors currently available on the market from various companies have been surveyed. The actuators to be used in constructing the 3-DOF FRMC will be based upon the data obtained. In addition, a variety of conceptual designs of the 3-DOF FRMC are proposed.

\subsubsection{Actuator System Design Alternatives}

Currently, two actuator system designs, motor and speed reducer combination and direct drive, have been implemented in the development of the force-reflecting manual controller.

\section{Motor and Speed Reducer Combination System}

This traditional system has been implemented in the majority, if not all, of force-reflecting manual controllers. The system consists of a servo motor and gear reduction in order to satisfy the output torque requirement. One of the advantages of this system is that the motors can be very small and use high gear ratio sets to obtain the desired output torque [Tosunoglu et al. 1996b].

Table 6-1 summarizes the surveyed data of the brushless DC servo motors that will be matched with the suitable gearhead so that the system provides the desired torque. 
Table 6-1.

Brushless DC Motors with Frame (see notes below)

\begin{tabular}{|l|c|c|c|c|c|c|c|}
\hline Manufacturer & Sipco & Compumotor & \multicolumn{2}{|c|}{$\begin{array}{c}\text { Sierracin/ } \\
\text { Magnedyne }\end{array}$} & \multicolumn{3}{|c|}{$\begin{array}{c}\text { Inland } \\
\text { (RBEH Series) }\end{array}$} \\
\hline Model & 17 PL030 & ML 1620 & $566-15$ & $535-01$ & 00510 & 00412 & 00511 \\
\hline $\begin{array}{l}\text { Peak Torque } \\
\text { (oz-in) }\end{array}$ & 8.5 & 70 & 38 & 120 & 7.04 & 11.1 & 15.5 \\
\hline $\begin{array}{l}\text { Cont. Torque } \\
\text { (oz-in) }\end{array}$ & 6.5 & 15 & & & 3.12 & 4.13 & 6.91 \\
\hline $\begin{array}{l}\text { Inertia } \\
\text { (oz-in-sec }{ }^{2} \text { ) }\end{array}$ & & & .00012 & .0009 & $4.5 \mathrm{E}-5$ & $3.6 \mathrm{E}-5$ & $5.0 \mathrm{E}-5$ \\
\hline $\begin{array}{l}\text { Diameter } \\
\text { (in) }\end{array}$ & 1.34 & 2.25 & 1.25 & 2.5 & 1.4 & 0.96 & 1.4 \\
\hline $\begin{array}{l}\text { Length } \\
\text { (in) }\end{array}$ & 3.7 & 5.51 & 2.04 & 2.2 & 1.35 & 1.74 & 1.605 \\
\hline $\begin{array}{l}\text { Weight } \\
\text { (lb) }\end{array}$ & 0.88 & 2.9 & 0.31 & 2 & 0.24 & 0.17 & 0.28 \\
\hline
\end{tabular}

Note 1: Sizes shown indicate motor dimensions only.

Note 2: Highlighted motor indicates the most suitable selection in this group.

Spur and planetary gears are the most suitable for this type of application. A high gear ratio and nearly zero backlash can be obtained from planetary gears. However, because of the tight. mechanism, the contact area between the teeth is relatively large, which makes them suffer from high friction. While spur gears have relatively lower friction than planetary gears, spur gears have more backlash.

An example of a system that combines a DC brushless motor and gearhead can be obtained from the SIPCO company. The system consists of the motor model 17PL030 (the technical data is given in Table 6-1) combined with the compatible planetary gearhead model RE 34/50, with a ratio of $50: 1$, a length of 1.61 inches, and a weight of $0.46 \mathrm{lb}$. Thus, the actuator will provide a peak torque of $425 \mathrm{oz}$-in, and the system will have a force reflection of $4.43 \mathrm{lb}$. The overall dimensions of the actuator are 5.31 inches in length, 1.34 inches in diameter, and $1.34 \mathrm{lb}$. in total weight.

The most compact actuator found is from the Inland Company. The system consists of the motor model RBEH 00412 (Table 6-1) with a gearhead ratio of 45:1, a length of 1.68 inches, and a weight of $0.65 \mathrm{lb}$. Hence, the actuator will provide the peak torque of $500 \mathrm{oz}$-in, and the system will be capable of reflecting forces up to $5.20 \mathrm{lb}$. The overall size of the actuator is 3.42 inches in length, $0.96 \mathrm{inch}$ in diameter, and a total weight of $0.93 \mathrm{lb}$.

Table 6-2 lists some of the important properties of the two systems described above. 
Table 6-2.

Motor and Speed Reducer Combination Systems

\begin{tabular}{|c|c|c|}
\hline Manufacturer & Sipco & Inland \\
\hline Motor Model & 17PL030 & RBEH 00412 \\
\hline Gearhead Ratio & $50: 1$ & $45: 1$ \\
\hline Peak Torque (oz-in) & 425 & 500 \\
\hline Diameter (in) & 1.34 & 0.96 \\
\hline Overall Length (in) & 5.31 & 3.42 \\
\hline Overall Weight (lb.) & 1.34 & 0.93 \\
\hline
\end{tabular}

One of the major drawbacks of this system, however, is the friction and backlash problems caused by the gearing system. Other disadvantages include poor dynamic response and difficulty in controlling torque and fine movement.

\section{Direct Drive System}

A direct drive system couples the system's load directly to the motor without the need of intermediate transmission elements such as gears or belts. Such a system is brushless and gearless; it eliminates friction and backlash problems. As a result, better accuracy and smooth rotation can be obtained. The reliability of the system is also improved because a smaller number of components is used.

However, the motors need to have an efficient cooling system since the motor must carry the entire load directly and continuously; otherwise, the motor may be overheated and burned out. Thus, the actuators must be carefully selected.

The following table (Table 6-3) presents some of the sample surveyed data obtained from different manufacturers regarding rare-earth permanent magnet brushless DC motors. The motors represented in the table below have the range of required torque with reasonable sizes for the 3-DOF FRMC design. 
Table 6-3.

Surveyed Data of Frameless Brushless DC Motors Properties

\begin{tabular}{|l|c|c|c|c|c|c|}
\hline Manufacturer & QMC & \multicolumn{2}{|c|}{ Sierracin/Magnedyne } & \multicolumn{3}{|c|}{ Inland (RBE series) } \\
\hline Model & 2183 & $\begin{array}{c}588-05 \\
\text { w/sensor }\end{array}$ & $\begin{array}{c}559-12 \\
\text { w/o sensor }\end{array}$ & 01516 & 01812 & 02111 \\
\hline $\begin{array}{l}\text { Peak Torque } \\
\text { (oz-in) }\end{array}$ & 327 & 525 & 300 & 489 & 654 & 576 \\
\hline $\begin{array}{l}\text { Cont. Torque } \\
\text { (oz-in) }\end{array}$ & 109 & & & 154 & 173 & 224 \\
\hline $\begin{array}{l}\text { Inertia } \\
\left.\text { (oz-in-sec }{ }^{2}\right)\end{array}$ & 0.0055 & 0.005 & 0.012 & 0.0114 & 0.0122 & 0.0001 \\
\hline $\begin{array}{l}\text { Diameter } \\
\text { (in) }\end{array}$ & 2.00 & 2.00 & 3.35 & 2.40 & 3.00 & 3.73 \\
\hline $\begin{array}{l}\text { Length } \\
\text { (in) }\end{array}$ & 4.80 & 3.70 & 1.30 & 2.60 & 1.55 & 1.40 \\
\hline $\begin{array}{l}\text { Weight } \\
\text { (lb) }\end{array}$ & 2.40 & 2.00 & 1.25 & 2.09 & 1.70 & 2.20 \\
\hline
\end{tabular}

Of these various manufacturers, Inland is judged to be the most suitable company for the development of a 1-DOF FRMC prototype. It provides high-performance motors with relatively smaller sizes than the other companies. Among the Inland actuators, three models in Table 6-3 provide the range of desired torque with the most compact sizes.

Aside from the output torque, the size of these motors is of great importance in this project. The configuration of model 01516 is similar to those of conventional motors, where the length is longer than the diameter, while the models 01812 and 02111 are of the pancake type, where the diameters are larger than the lengths. The influence of these different configurations will have great effects on the design of the 3-DOF FRMC.

\section{Proposed Actuator System Design for the 3-DOF Force-Reflecting Manual Controller}

Table 6-4 compares some of the important characteristics and properties of the system with the gearhead and the direct drive system. These are the actual numbers obtained from the surveyed data. 
Table 6-4.

Comparison of Speed Reducer System and Direct Drive Properties

\begin{tabular}{|c|c|c|}
\hline Property & Motor with Speed Reducer & Direct Drive \\
\hline Motor Model & RBEH 00412 & RBE 01812 \\
\hline Gearhead Ratio & $45: 1$ & NONE \\
\hline Peak Torque (oz-in) & 500 & 654 \\
\hline Diameter (in) & 0.96 & 3.00 \\
\hline Length (in) & 3.42 & 1.55 \\
\hline Weight (lb) & 0.93 & 1.70 \\
\hline
\end{tabular}

As can be seen from the above review of two alternative designs, the direct drive system can be as compact as the traditional system with motor and gearhead. Therefore, at the current state, the proposed design of the 3-DOF FRMC will be of the direct drive structure using a brushless DC motor as the actuator to drive the system. The possible motor to be used in this development is manufactured by the Inland Company. Figure 6-5 shows the dimensions of the selected model.
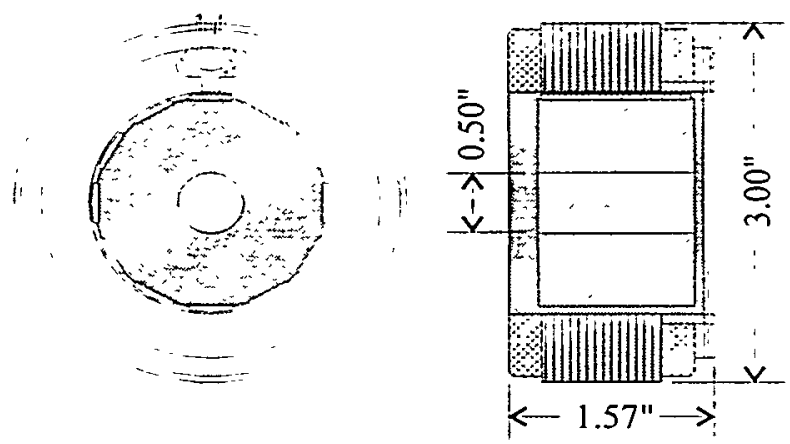

Figure 6-5. Inland brushless DC Motor Model RBE 01812.

Such a system will most likely satisfy the criteria of the design with advantages as follows:

- Compact size

- Light weight

- Minimal friction

- Zero backlash 
- Precise

- Responsive

- Low noise

- Reliable

- Infrequent maintenance requirements

- Clean and quiet operation.

\subsubsection{3-DOF FRMC Design Alternatives}

A variety of design alternatives have been developed for the 3-DOF FRMC with some promising results. Most of these are in the form of parallel structure since it allows a movement in any axis without causing force and inertia components on the other two axes. The serial structure is also being considered because of its simple configuration and large workspace.

The general design criteria include the following:

- Compact arrangement for portability and easy operation

- Simple mechanism for inexpensive construction and reliable operation

- Minimum friction and backlash for precise operation

- Direct drive configuration for the elimination of gear sets.

The removal of gear sets will cause a growth in actuator size due to the absence of speedreducing mechanisms in the system. However, it in turn provides a simpler arrangement with a quicker response, a wider margin of reliability, and longer life since there are fewer parts in the system that are prone to loads, fatigue, and breakage. The following section describes the four most promising design alternatives.

\section{Design Alternative 1}

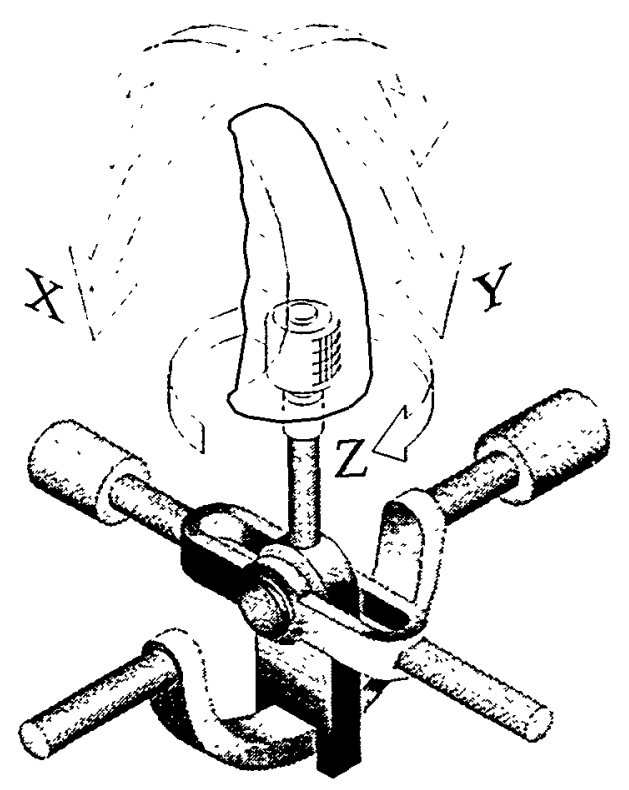

Figure 6-6. Proposed Design 1 (Parallel Configuration). 
In this design, the $\mathrm{X}$ - and $\mathrm{Y}$-direction actuators are located in the same plane, an arrangement that reduces the height of the controller but also uses extra space in the horizontal dimensions.

The design of the vertical shaft assembly (piece 1) provides a slim connection with both horizontal shafts (pieces 2 and 3) (see Proposed Design 1 in Appendix for definition of various pieces). This offers an excellent reduction in friction, although it may be prone to backlash. The vertical shaft assembly does not allow the positioning of the Z-direction actuator to be inside the mechanism. Instead, the Z-direction actuator is best placed within the handle grip itself for compactness. However, in order to be able to place the actuator inside the handle, the actuator must be sufficiently small. As a result, the force-reflection capability is reduced.

The shape of the X-direction shaft (piece 2) poses some challenges and may cause extra expenses during manufacturing. The X-direction shaft has a complex form with solid circular rod-shaped ends merged with a slotted center for passage of the vertical shaft assembly. A detailed illustration of the alternative designs is provided in the Appendix.

\section{Design Alternative 2}

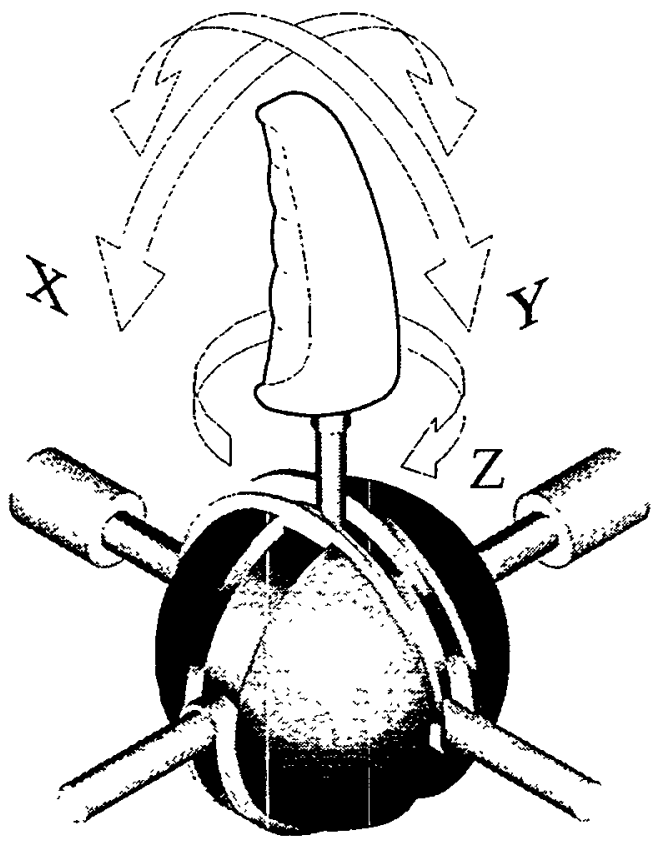

Figure 6-7. Proposed Design 2 (Parallel Configuration).

Figure 6-7 shows the second proposed design for the 3-DOF force-reflecting manual controller. This design utilizes a sphere as a guide to the movement of the mechanism.

The handle shaft (piece 1) is directly connected to the sphere to provide the movement for the Xand Y-direction shafts in all directions. The sphere also houses the Z-direction servo motor. The size of this actuator determines the minimum dimensions of the sphere. 
The sphere reduces the number of different parts of the mechanism but increments its friction due to the large contact area. The use of teflon in the grooves will reduce the friction. The multiple tasks of the sphere dictate an inherently intricate design. Because of this, the manufacturing and assembly of the sphere will increase the cost of the unit.

The sphere creates other problems in servicing the system, since it shields the third actuator, and the whole controller has to be completely disassembled to reach this servo motor. Another concern is how the location of the wiring connecting this actuator with the rest of the system will be achieved.

\section{Design Alternative 3}

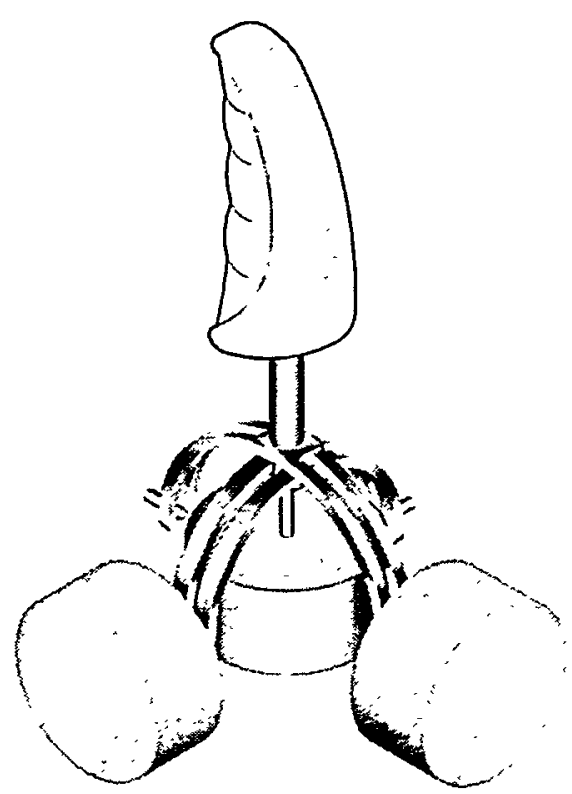

Figure 6-8. Proposed Design 3 (Parallel Configuration).

Figure 6-8 demonstrates the third proposed design, a gimbal type assembly. The arrangement offers one of the best alternatives for the controller. The gimbal arcs occupy less space than a sphere, and they are much simpler to design and manufacture. They provide adequate space to locate the Z-direction servo motor and yet offer excellent accessibility without having to disassemble the entire system.

The design of the universal connection (piece 1 in Appendix) is critical for the proper operation of the entire controller; it is the most complex part of the design. This part allows the displacement of the gimbals in all directions, operating precisely with minimum friction and backlash. Both the handle and the frame of the Z-direction actuator are attached to it at each end, demanding a sturdy construction. The connecting shaft between them must pass through piece 1 with enough play to provide precise operation but also with enough tightness to avoid any unnecessary play. All these conditions need to be considered carefully in the structural design of the controller. 
Design Alternative 4

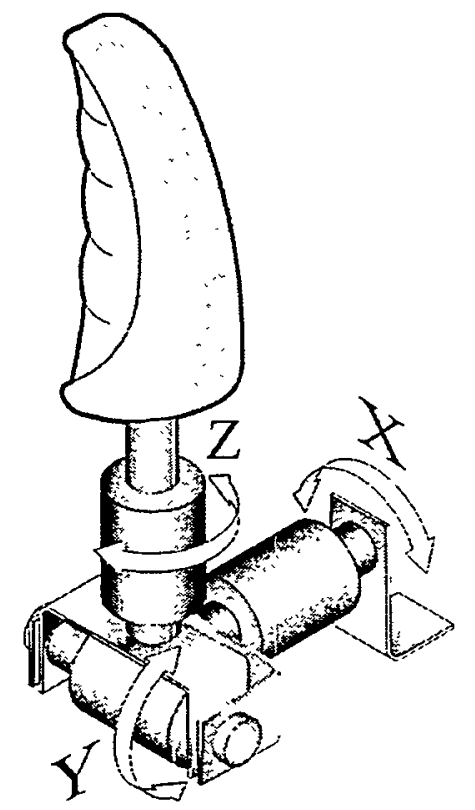

Figure 6-9. Proposed Design 4 (Serial Configuration).

Figure 6-9 depicts the design alternative in serial structure. This design provides the largest workspace among the above designs. This simple configuration makes it easy to manufacture, assemble, and disassemble.

However, this serial structure has a major advantage inherent to serial systems. The actuator that rotates about the $\mathrm{X}$ axis must carry the weight of the two actuators that rotate about the $\mathrm{Y}$ and $\mathrm{Z}$ axes, and likewise, the actuator that rotates about the $Y$ axis must carry the weight of the actuator that rotates in the $Z$ direction. As a result, the actuators will have to be selected such that they are capable of carrying the load of the other and at the same time of providing the required force reflection. This, in turn, influences the size of the actuator and the oversize of the entire system.

With the above consideration, the serial configuration may not be as compact as expected. In addition, the stiffness and precision of the system become questionable because of this arrangement.

\section{Comparison of Design Alternatives}

Table 6-5 provides a comparative summary of the principal design parameters considered and how each alternative meets these parameters. 
Table 6-5.

Comparison of Design Parameters among Design Alternatives

\begin{tabular}{|c|c|c|c|c|}
\hline & $\begin{array}{c}\text { Alternative } \\
\mathbf{1}\end{array}$ & $\begin{array}{c}\text { Alternative } \\
\mathbf{2}\end{array}$ & $\begin{array}{c}\text { Alternative } \\
\mathbf{3}\end{array}$ & $\begin{array}{c}\text { Alternative } \\
\mathbf{4}\end{array}$ \\
\hline Direct drive & Yes & Yes & Yes & Yes \\
\hline Simplicity of mechanism & Fair & Good & Good & Better \\
\hline Compactness of design & Good & Better & Better & Fair \\
\hline Access to components & Good & Fair & Good & Good \\
\hline Number of different parts & Fair & Better & Good & Better \\
\hline Friction & Low & High & Medium & High \\
\hline Ease of assembly & Good & Fair & Better & Better \\
\hline
\end{tabular}

The four design alternatives offer room for improvement, especially in the location of the actuators and general dimensions, which are largely determined by the commercially available motors. Alternatives 2 and 3 offer greater flexibility in the servo motor location, which is impaired by alternative 1 where the location of actuators cannot be easily changed.

Alternative 3 offers a better arrangement for actuator location than alternative 2, and the latter offers an advantage by using simpler parts. Despite the advantages of the parallel structure, alternative 4 with a serial structure can be an attractive design alternative because of its simple arrangement.

\subsection{DEVELOPMENT OF GRAPHICAL USER INTERFACE (GUI)}

Computer-based simulations and training are very important tools in critical operations where the task needs to be performed without an error. Otherwise, the operator does not have the opportunity to practice and gain expertise in the operation. Creating a realistic simulation assists the operator in learning the process before the actual operation occurs. Thus, the performance of the operator is greatly improved when operating on the actual task. For advanced operations such as hazardous material handling in nuclear reactors and space missions, real-time graphical simulation is considered to be one of the most important tools for an advanced teleoperator system [De Rossi et al. 1997].

The goal of the development of advanced graphical user interface (GUI) software for a teleoperation system is to provide the operator with various options of operating modes such that the tasks can be achieved with relative ease and fidelity. However, the package should be easy to use and relatively simple to implement for any remote system. 
The software package demonstrates that it is capable of accepting multiple inputs from different devices. In this case, it provides connections to video cameras, CCD cameras, force-reflecting manual controller, and virtual reality unit. Unlike many other software packages developed on mainframe workstations, the proposed GUI software operates on a standard PC computer. This allows for a reduction in costs and simplifies the entire process considerably.

The graphical user interface is being developed in a $\mathrm{C}++$ environment. Several versions of the interface software have been developed. One of the earlier versions, shown in Figure 6-10, was developed in the Windows environment. This version seemed to be more user-friendly, since it facilitated the manipulation of different windows. However, programming in a Windows platform requires much more space and memory than on a DOS platform [Ezzell 1990].

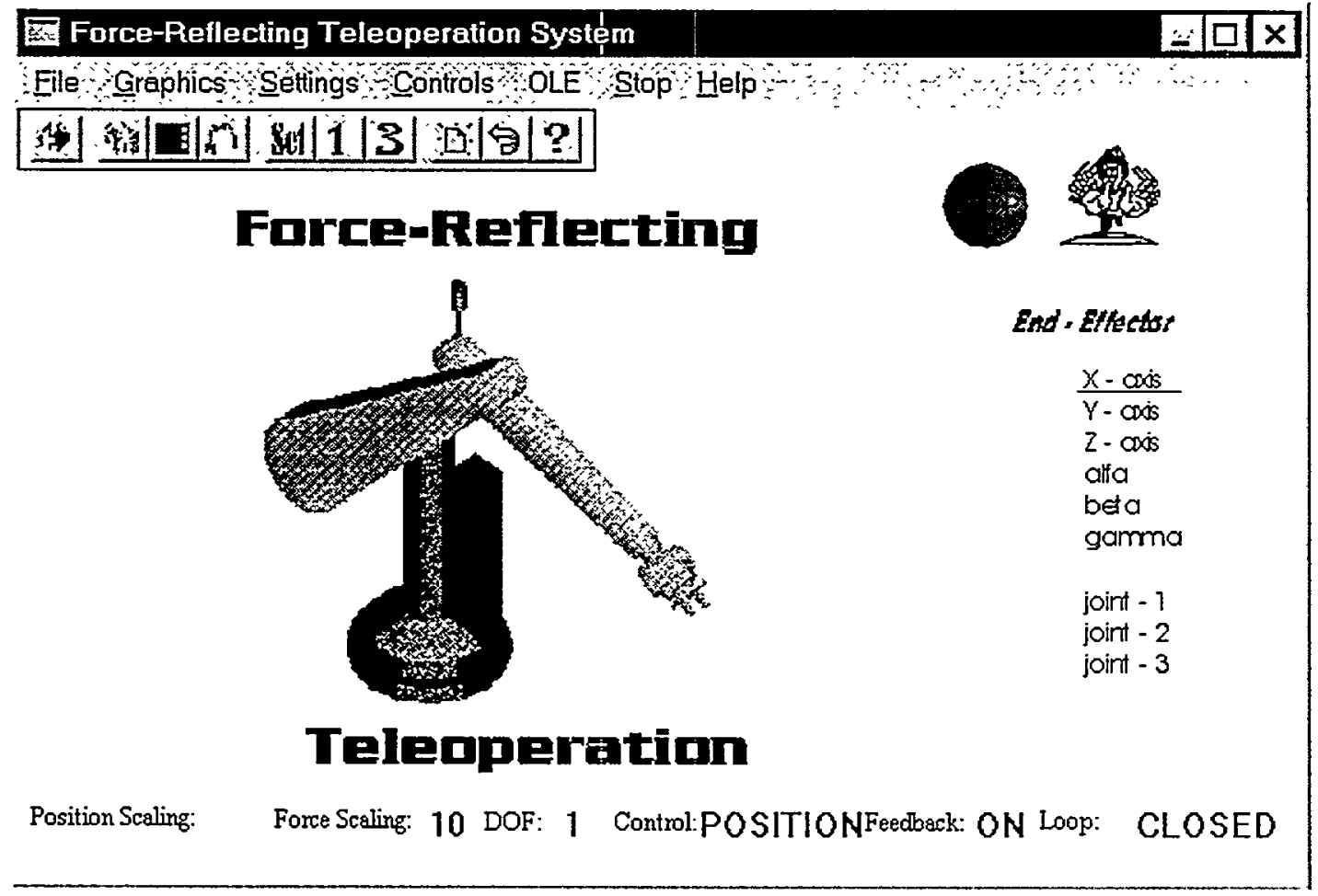

Figure 6-10. Windows-Based Version of the Interface Software.

Figure 6-11 shows the most recent version of the interface software, which is being developed on a DOS platform. The software is written using the concept of object-oriented programming: the same concept applied to the Windows environment [Ezzell 1990]. One of the advantages of working on the DOS platform is that the program is developed in terms of modularity. This allows the system designer to easily add or remove any features from the package. Thus, the software can be used for any remote system. 


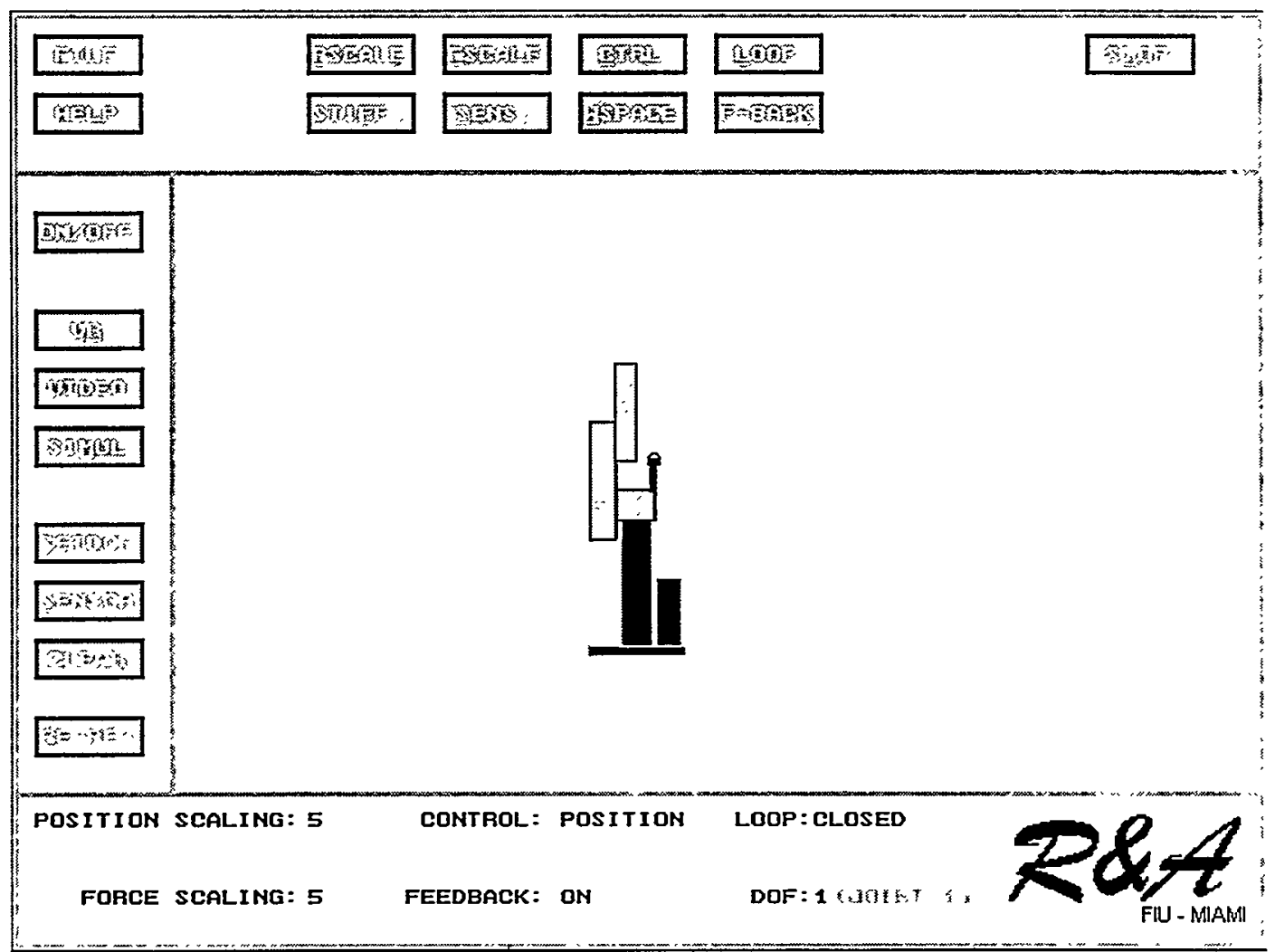

Figure 6-11. DOS-Based Version of the Interface Software.

As illustrated in Figure 6-11, the system parameters for the telesensation system include position scaling, force scaling, force/torque sensor sensitivity, and robot workspace. Other features include rereferencing, control mode (position or velocity), control scheme (open or closed loop), and Degree of Freedom (DOF) setting (joint mode, Cartesian mode, orientation mode). In addition, a number of different windows (video, simulation, VR) of graphical presentation can be viewed simultaneously to enhance the perception of the operator. At the bottom of the screen, the status bar provides the information on all the system parameters and other settings. In the event that the program detects a problem, it alerts the operator with a message status bar.

The flowchart diagram of a recent version of the interface software is shown in Figure 6-12. The software continuously receives signals from different devices, interprets the data, and processes the data depending on the source of the signals. The input data is received from various sources:

- Mouse and Keyboard: The mouse and keyboard provide system parameters set by the user.

- Encoder: The encoder provides the manual controller position as the user controls the robot with the force-reflecting manual controller.

- Force/Torque (FT) Sensor: The force feedback is provided by the FT sensor in the event that the robot experiences external forces. 
- Head-Mounted Display (HMD): The HMD tracks the movement of the user's head and provides $3-\mathrm{D}$ visual effects.

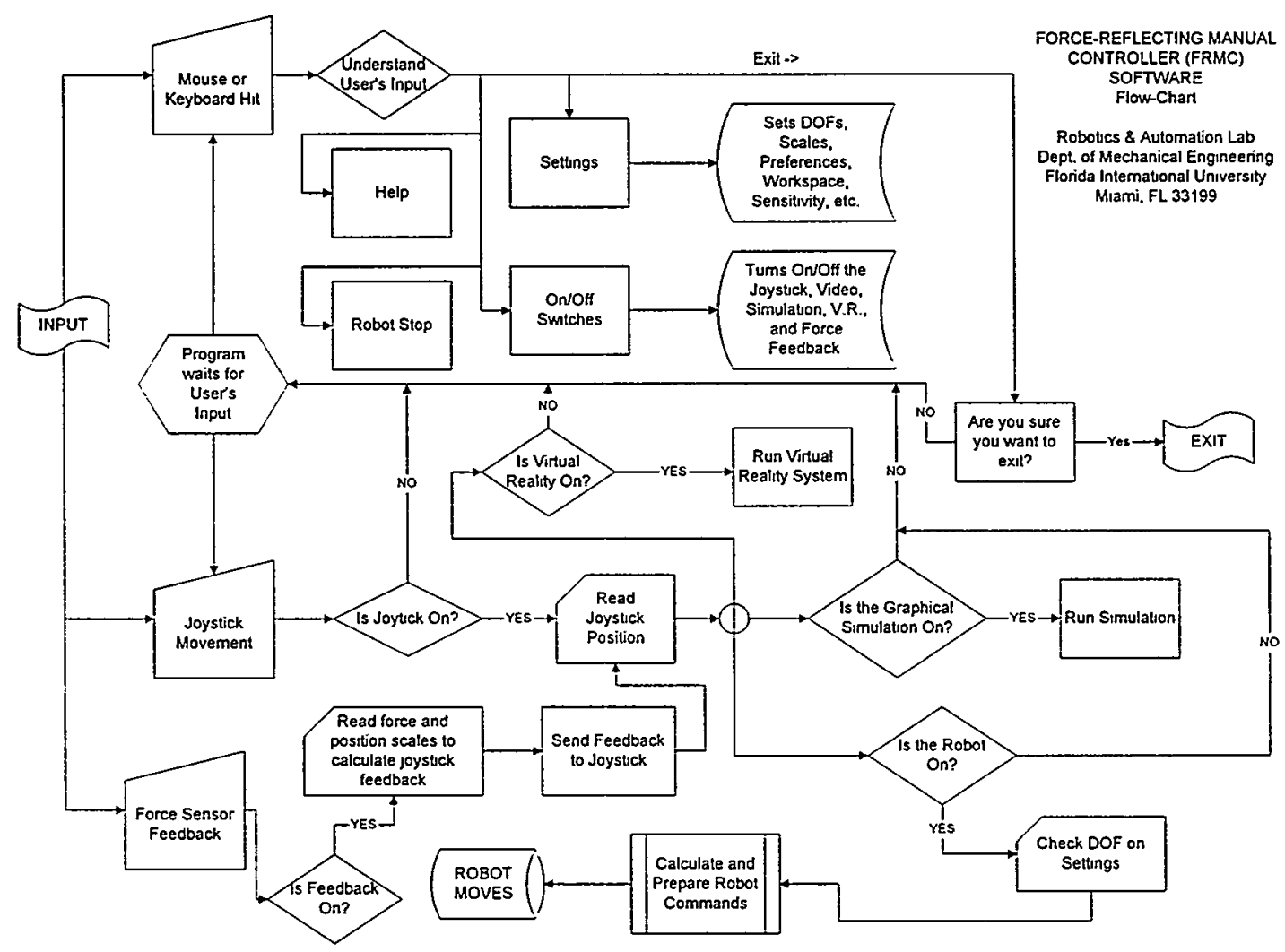

Figure 6-12. Flowchart of the Interface Software.

The system parameters can be changed at any instant, even during the operation, since the program routinely updates the variables. After the changes are made, the program stores and saves the new variables within its own database. This software is written in the simplest manner so that real-time operation is achieved. 


\subsection{CONCLUSIONS, RECOMMENDATIONS, AND FUTURE WORK}

A teleoperator system extends the intelligence and capabilities of humans and robots by feeding back visual and force information, whereas a telesensation system attempts to achieve the same goal by providing multi-sensory feedback to the operator in a virtual reality environment. In either case, force reflection represents an important component of these systems. This component also makes the mechanical design of the overall system quite challenging, since most of the force-reflecting manual controllers are bulky, complex, and expensive.

\subsection{CONCLUSIONS}

In an effort to develop the system that meets criteria such as simplicity, portability, low cost, ease of use, and ease of manufacture, section 2 reviews some of the previous designs of the force-reflecting manual controller. This includes mechanical design and control strategies. The serial and parallel architectures are compared, and the conventional and emerging control strategies are addressed.

In section 3, the fundamental components of force-reflecting teleoperation systems are reviewed. These are actuators, transmission systems, sensors, computer hardware, computer interface, and computer software.

In section 4, a 1-DOF FRMC prototype is designed and developed to demonstrate the principle of the force-reflecting manual controller. The specifications of the system components are outlined. These include a brushless DC motor, encoder, amplifier, interface board, force/torque sensor, and PUMA 760 industrial robot. The system parameters are then identified for the purpose of constructing a mathematical model. The least squares method is used to obtain the model in the form of an ARX model. A variety of different order systems are obtained to compare the system response with the actual response. The results show that the second- and third-order system models are capable of producing the output fairly well. However, for simplicity, the second-order model is selected to represent the 1-DOF FRMC prototype system dynamics.

The model validation is performed by creating the block diagram of the servo loop U500 controller and simulating its performance numerically. The results are compared with the actual system response for different sets of gains. Although the model yields output slightly different from the actual response, it displays a very similar behavior of the actual response. Considering this criterion, the model is judged to be valid.

In section 5, two control methods, PID and fuzzy logic controllers, are numerically simulated, using the model obtained from the previous section, and experimentally tested on the 1-DOF FRMC prototype. A comparison of the system response between the output produced by the model and the actual system for both types of controllers is conducted. The results show that the actual system displays oscillations and steady-state error, while the model does not. This is true for both PID and fuzzy logic controllers. It is concluded that these errors are caused by nonlinearities and high-frequency dynamics terms that are not included in the model. Unmodeled dynamics are characterized by low-magnitude and high-frequency motion, and nonlinear terms include Coulomb friction, dead zone, and quantization errors. 
Furthermore, the range of the system gains for the fuzzy logic control method is established for two types of grasp motion: loose grasp and firm grasp. In order for the system to stay in the stable region, low gains are used for the soft grip, whereas higher gains are required for the firm grip to provide a stronger sensation force reflection. From the experimental results, the base value of $0.35-0.5$ is to be used for the soft grasp and $0.8-1.0$ for firm grasp. (The base value was defined in section 5.2.)

In addition, the performance of PID and fuzzy logic controllers on the 1-DOF FRMC is compared. The results show that each has its benefits and drawbacks. For instance, PID produces transient oscillations but no steady-state error, while the fuzzy logic controller shows slower response and displays some steady-state error but no oscillations. Note that these errors are minimal such that a human cannot detect, and as a result, both controllers are considered to be acceptable for the purpose of force-reflecting manual controller application.

In section 6 , the concept of the telesensation system is presented. The main components of the system, which includes the Virtual Reality unit, Force-Reflecting Manual Controller, and Graphical User Interface, are discussed. Commercial VR units are presented in order to identify a suitable unit for the ongoing development of the telesensation system. After a thorough study of these units, either Kaiser Electro-Optics' VIM 1000HRpv or Virtual Research Systems' VR4 can be implemented in the system. Both systems provide built-in stereo headphones and a good range of field of view with fine resolution. Their light weight and reasonable costs make them more attractive. In the section on force-reflecting manual controllers, the results of a survey on the electric motors currently available in the market are presented, and the four design alternatives are proposed. At this stage, it is concluded that the parallel configuration (design alternative 3 with gimbal configuration) with direct-drive actuator system is the most compact and promising design because it provides a good range of workspace and ease of assembly. Finally, the graphical user interface software is developed in the $\mathrm{C}++$ environment. Both Windows-based and DOS-based versions are developed. However, the final decision is made to fully develop the software on a DOS-based platform because it is relatively faster when real-time operation is one of the measurements. The software is used to interface with various components, such as CCD camera, encoder, force/torque sensor, and VR unit in the future.

\subsection{RECOMMENDATIONS}

Although the goal of this work has been achieved, areas can be identified where further improvement can be introduced. In this work, a better controller card may have been selected for the 1-DOF testbed.

The compatibility of the $\mathrm{C}$ library of the controller card is limited to an older version of the $\mathrm{C}++$ compiler (Borland $\mathrm{C}++$ version 4.0) than is available currently. This restriction made it impossible to develop the GUI software in the newer version of the $\mathrm{C}++$ compiler. As a result, the GUI software took longer to develop, since the older version of the $\mathrm{C}++$ compiler is not as user-friendly as the latest version.

\subsection{FUTURE WORK}

As for future work, the concept of the telesensation system will be fully implemented. This includes the development of a 3-DOF FRMC, the addition of the VR unit, and the complete 
version of the GUI software package. Each of these components will involve the work described below.

\subsubsection{The Development of a 3-DOF FRMC}

A 3-DOF FRMC will be developed based on the design alternatives from this work. The main concern in developing this system is the size of the actuator because the size of the system will be determined mainly from the size of the actuator. Therefore, an extensive survey of actuators must be conducted in order to identify the most compact system available in the market. In addition, a direct-drive configuration is considered to be the most promising candidate, since the actuators today are small, powerful, and capable of carrying loads without the need of transmission elements such as gears. This, in turn, will dramatically reduce backlash and friction.

\subsubsection{The Implementation of a VR Unit}

A VR unit will be implemented as an additional visual feedback augmenting the CCD camera that is attached on the remote system. This unit will greatly improve the visual perception of the operator, since it is generally easier to identify 3-D objects than two-dimensional objects. A survey of the commercial units has been conducted in this work, but a more detailed study must be performed, especially on the software package. The software program must provide built-in features to create new environments. For instance, a description of the remote environment (such as the nuclear reactors) must be developed with relative ease. In addition, the software needs to be compatible with the FRMC and GUI software.

\subsubsection{The Development of a Complete GUI Software}

A GUI software package will be fully developed for the use of the 3-DOF FRMC. Various components, such as VR unit, microphone, speakers, must be integrated into this software with relative ease. The software should also be developed to the point where it can control and manipulate a 6-DOF or even redundant (robots with more than 6 degrees of freedom) remote systems. This may be possible by developing a toggle button through which the operator can control a group of joints at a time and switch the control mode between translational and rotational motions. Alternatively, two 3-DOF joysticks may also be developed for this purpose.

After the development of above components, a full-scale prototype can be built and its operation improved as a testing program is carried out and modifications in mechanical design, controller, and software are implemented. Once the laboratory evaluations and system modifications are completed, the system can be tested in the field in a suitable application. 


\section{REFERENCES}

Batsomboon, P., and Tosunoglu, S., 1996a,"A Review of Teleoperation and Telesensation Systems," 1996 Florida Conference on Recent Advances in Robotics, Florida Atlantic University, Boca Raton, Florida, pp. 281-285, April 11-12.

Batsomboon, P., Tosunoglu, S., and Repperger, D. W., 1996b, "Component Technologies for Virtual Reality-Based Telesensation Systems," The Third ASME Biennial Joint Conference on Engineering Systems Design \& Analysis, ASME ESDA'96, Montpellier, France, Vol. 2, pp. 229-236, July 1-4.

Batsomboon, P., Tosunoglu, S., and Repperger, D. W., 1996c, "A Survey of Telesensation and Teleoperation Technology with Virtual Reality and Force Reflection Capabilities," submitted for publication, Journal of Modeling and Simulation.

Batsomboon, P., Tosunoglu, S., and Repperger, D. W., 1997, "Design and Construction of a Prototype Force-Reflecting Manual Controller," 1997 Florida Conference on Recent Advances in Robotics, Florida International University, Miami, Florida, pp. 1-7, April $10-$ 11.

Batsomboon, P., Tosunoglu, S., and Repperger, D. W., 1998, "System Identification and Experiments on a One-Degree-of-Freedom Force-Reflecting Manual Controller Prototype," 1998 Florida Conference on Recent Advances in Robotics, Florida Institute of Technology, Melbourne, Florida, March 26-27.

Bejczy, A. K., 1980, "Sensors, Controls, and Man-Machine Interface for Advanced Teleoperation," Science, Vol. 208, No. 4450, pp. 1327-1335.

Bejczy, A. K., Kim, W. S., and Venema, S., 1990, "The Phantom Robot: Predictive Displays for Teleoperation with Time Delay," Proceedings of the IEEE International Conference on Robotics and Automation, pp. 546-551.

Bejczy, A. K., and Salisbury, J. K., 1980, "Kinesthetic Coupling Between Operator and Remote Manipulator," Proceedings of the ASME International Computer Technology Conference, August.

Burdea, G., and Coiffet, P., 1994, Virtual Reality Technology, John Wiley \& Sons, Inc., New York.

Burdea, G., 1996, Force and Touch Feedback for Virtual Reality, John Wiley \& Sons, Inc., New York.

Cha, D. H., Cho, H. S., and Kim, S., 1996, "Design of a Force Reflection Controller for Telerobot Systems using Neural Network and Fuzzy Logic," Journal of Intelligent and Robotic Systems: Theory \& Applications, Vol. 16, No. 1, pp. 1-24, May.

Christopher, C., and Stansfield, S., 1994, "Interactive Graphical Model Building using Telepresence and Virtual Reality," Proceedings of the IEEE International Conference Robotics and Automation, Vol. 2, pp. 1436-1439. 
Conklin, W., and Tosunoglu, S., 1996, "Conceptual Design of a Universal Bilateral Manual Controller," 1996 Florida Conference on Recent Advances in Robotics, Florida Atlantic University, Boca Raton, Florida, April 11-12.

De Rossi, V., Batsomboon, P., Tosunoglu, S., and Repperger, D. W., 1997, "Interactive Modular Graphical User Interface Development for Telesensation Systems," Computational Cybernetics and Simulation, 1997 IEEE International Conference on Systems, Man, and Cybernetics, IEEE SMC'97, Orlando, Florida, Vol. 2, pp. 1604-1608, October 12-15.

Davies, B. R., 1993, "Remediating Hazardous Waste Robotically Using a High-Level Control System and Real-time Sensors," Proceedings of the SPIE International Symposium on Optical Tools for Manufacturing and Advanced Automation.

Draper, J. V., 1995, "Teleoperators for Advanced Manufacturing: Applications and Human Factors Challenges," The International Journal of Human Factors in Manufacturing, Vol. 5, No. 1, pp. 53-85.

Draper, J. V., Herndon, J. N., Weil, B. S., and Moore, W. E., 1987, "Effects of Force Reflection on Servomanipulator Performance," Proceedings of the International Topical Meeting on Remote Handling and Robotics in Hostile Environments, pp. 654-660.

Erbatur, K., Kaynak, O., and Rudas, I., 1995, "A Study of Fuzzy Schemes for Control of Robotic Manipulators," Proceedings - 1995 IEEE International Conference on Industrial Electronics, Control, and Instrumentation, Part 1, pp. 63-68, Orlando, FL.

Ezzell, B., 1990, Graphics Programming in Turbo C++, Addison-Wesley, Reading, Massachusetts.

Ferrell, W. R., 1966, “Delayed Force Feedback," Human Factors, pp. 449-455, October.

Fukumi, J., Kamano, T., Suzuki, T., and Kataoka, Y., 1996, "Fuzzy Two-Degree-of-Freedom Speed Control System," Japan/USA Symposium on Flexible Automation, Vol. 1, pp. 383386, July.

Hsia, T. C., 1977, System Identification: Least-Squares Methods, Lexington Books, Massachusetts.

Hnatek, E. R., 1976, $A$ User's Handbook of $D / A$ and $A / D$ converters, John Wiley \& Sons, Inc, New York.

Ishii, M., and Sato, M., 1993, "A 3D Interface Device with Force Feedback: A Virtual Work Space for Pick-and-Place Tasks," IEEE Virtual Reality Annual International Symposium (VRAIS), New York, pp. 331-335, September.

Jacobsen, S., Smith, F., Backman, D., and Iversen, E., 1991, "High Performance, High Dexterity, Force Reflective Teleoperator II," ANS Topical Meeting on Robotics and Remote Systems, New York, February.

Jansen, J. F., Burks, B. L., Babcock, S. M., Kress, R. L., and Hamel, W. R., 1991, "Long-Reach Manipulation for Waste Storage Tank Remediation," Modeling and Control of Compliant and Rigid Motion Systems, Vol. 31, pp. 67-73. 
Johnsen, E. G., and Corliss, W. R., 1971, Human Factors Applications in Teleoperator Design and Operation, John Wiley \& Sons, Inc., New York.

Kim, W., 1991, “A Study on the Design and Operation of Force Feedback Controllers," Ph.D. Dissertation, University of Texas at Austin, January.

Kim, W. S., 1993, "Graphical Operator Interface for Space Telerobotics," Proceedings of the IEEE International Conference Robotics and Automation, Vol. 3, pp. 761-768.

Kim, W. S., and Bejczy, A. K., 1991, "Graphics Displays for Operator Aid in Telemanipulation," Proceedings of the IEEE International Conference on Systems, Man and Cybernetics, Vol. 2, pp. 1059-1067.

Kim, W. S., and Bejczy, A. K., 1993, "Demonstration of a High-Fidelity Predictive/Preview Display Technique for Telerobotic Servicing in Space," IEEE Transactions on Robotics and Automation, Vol. 9, No. 5, pp. 698-702, October.

Kim, W. S., Hannaford, B., and Bejczy, A. K., 1992, "Force Reflection and Shared Compliant Control in Operating Telemanipulators with Time Delay," IEEE Transactions on Robotics and Automation, Vol. 8, No. 2, pp. 176-185, April.

Kim, W. S., Schenker, P. S., Bejczy, A. K., and Hayati, S., 1993, "Advanced Graphics Interfaces for Telerobotic Servicing and Inspection," International Conference on Intelligent Robots and Systems, pp. 303-309.

Kotoku, T., Husler, E., Tanie, K., and Fujikawa, A., 1989, "The Development of a Direct Drive Master Arm," Journal of Robotics and Mechatronics, Vol. 2, No. 6, pp. 49-56.

Kotoku, T., Komoriya, K., and Tanie, K., 1992, "A Force Display System for Virtual Environments and its Evaluation," Proceedings of IEEE International Workshop on Robot and Human Communication, pp. 246-251, September.

Kuo, B. C., 1991, Automatic Control System, $6^{\text {th }}$ edition, Prentice Hall, Englewood Cliffs, New Jersey.

Lee,S., Bekey, G. A., and Bejczy, A. K., 1985, "Computer Control of Space-borne Teleoperators with Sensory Feedback," Proceedings of the IEEE International Conference Robotics and Automation, pp. 205-214.

Lee, S., and Lee, H. S., 1993, "Modeling Design and Evaluation of Advanced Teleoperator Control Systems with Short Time Delay," IEEE Transactions on Robotics and Automation, Vol. 9, No. 5, pp. 607-623, October.

Lindemann, R., Tosunoglu, S., and Tesar, D., 1987, "Construction and Demonstration of a NineString, Six-Degree-of-Freedom Force-Reflecting Joystick for Telemanipulation," Final Report to NASA Johnson Space Center, Grant No. NAG9-188, Department of Mechanical Engineering, University of Texas, Austin, Texas, October.

Ljung, L., 1987, System Identification - Theory for the User, Prentice-Hall, Englewood Cliffs, New Jersey. 
Massie, T. H., and Salisbury, K. J., 1994, "PHANToM Haptic Interface: A Device for Probing Virtual Objects," Dynamic Systems and Control American Society of Mechanical Engineers, Dynamic Systems and Control Division, Vol. 1, pp. 295-299.

Martin, H. L., and Kuban, D. P., 1985, Teleoperated Robotics in Hostile Environments, Robotics International of SME, Michigan.

McNeely, W., Burdea, G. C., Hannford, B., Hirose, M., Jacobsen, S., Salisbury, K., and Tachi, S., 1995, "Whither force feedback?" IEEE Annual Virtual Reality International Symposium, pp. 226-227.

Miner, N. E., and Stansfield, S. A., 1994, "An Interactive Virtual Reality Simulation System for Robot Control and Operator Training," Proceedings of the IEEE International Conference Robotics and Automation, Vol. 2, pp. 1428-1435,.

Monteverde, V., 1997, "Fault Tolerance: Architectures, Capabilities, and Control Strategies for Robotics," Master's Thesis, Florida International University, August.

Mosher, R. S., and Wendel, B., 1960, "Force-Reflecting Electrohydraulic Servomanipulator," Electro-Technology, December.

Poole, H. H., 1989, Fundamentals of Robotics Engineering, Van Nostrand Reinhold, New York,.

Ravindran, R., Assaf, S. A., and Nguyen, P. K., 1984, "Shuttle Remote Manipulator Control System and In-Flight Verification," Int'l. Symp. on Design and Synthesis, Tokyo, July.

Read, D. A., Ruta, K. J., and Bell, B. N., 1994, "Application of Virtual Reality to Space Robotics Operations," ASCE Specialty Conference on Robotics for Challenging Environments Albuquerque, pp. 19-27.

Repperger, D. W., Phillips, C. A., and Chelette, T. L., 1995, "Study on Spatially Induced "Virtual Force' with an Information Theoretic Investigation of Human Performance," IEEE Transactions on Systems, Man and Cybernetics, Vol. 25, No. 10, pp. 1392-1404.

Rochelear, D. N., and Crane, C. D., III, 1991, "Development of a Graphical Interface for Robotic Operation in a Hazardous Environment," Proceedings of the IEEE International Conference on Systems, Man and Cybernetics, Vol. 2, pp. 1077-1081.

Schenker, P. S., Bejczy, A. K., Kim, W. S., and Lee, S., 1991, "Advanced Man-Machine Interface and Control Architecture for Dexterous Teleoperation," Ocean Technologies and Opportunities in the Pacific for the 90's, Vol. 3, pp. 1506-1525.

Sheridan, T. B., 1993, "Space Teleoperation Through Time Delay: Review and Prognosis," IEEE Transactions on Robotics and Automation, Vol. 9, No. 5, pp. 592-606, October.

Sheridan, T. B., 1995, "Teleoperation, Telerobotics and Telepresence: A Progress Report," Control Engineering Practice, Vol. 3, No. 2, pp. 205-214.

Stark, L., et al., 1987, "Telerobotics: Display, Control, and Communication Problems," IEEE Journal of Robotics and Automation, Vol. 3, No. 2, pp. 205-214. 
Terashima, N., 1994, "Telesensation - Distributed Interactive Virtual Reality - Overview and Prospects," IFIP Transactions A: Computer Science and Technology, No. A-51, pp. 4959.

Terashima, N., 1994, "VR and Telesensation: Novel Disciplines for the Next Century," IEEE Symposium on Emerging Technologies \& Factory Automation, pp. 22-28.

Todd, D. J., 1986, Fundamentals of Robot Technology: An Introduction to Industrial Robots, Teleoperators, and Robot Vehicles, Wiley, New York.

Tooley, M., 1988, Bus-Based Industrial Process Control, Heinemann Newnes, Oxford.

Tosunoglu, S., Batsomboon, P., Romero, E., Espina, M., Monteverde, V., and Conklin, W., 1996a, "Force-Reflecting Manual Controller (FRMC) Components," Report to the U.S. Air Force, Air Force Materiel Command, Armstrong Laboratory, Wright Patterson Air Force Base, Dayton, Ohio, Grant No: FY8990-95-00094, Department of Mechanical Engineering, Florida International University, Miami, Florida, September.

Tosunoglu, S., Batsomboon, P., Romero, E., Monteverde, V., and Conklin, W., 1996b, "Review of Actuator Technology and Conceptual Design of a Force-Reflecting Teleoperation System," Report to the U.S. Air Force, Air Force Materiel Command, Armstrong Laboratory, Wright Patterson Air Force Base, Dayton, Ohio, Grant No: FY8990-95-00094, Department of Mechanical Engineering, Florida International University, Miami, Florida, May.

Tosunoglu, S., and Hamel, W. R., 1994, "Robotics Technology Assessment for Decontamination and Dismantle Tasks," Report to the U.S. Department of Energy, Grant No. DE-FG0286NE37966, September.

Trivedi, M. M., and Chen, C., 1993, "Developing Telerobotic Systems Using Virtual Reality Concepts," Proceedings of the IEEE/RSJ International Conference on Intelligent Robots and Systems, pp. 352-359.

Vertut, J., and Coiffet, P., 1986, Robot Technology, Vol. 3A: Teleoperation and Robotics, Prentice Hall Inc.

Vince, J., 1995, Virtual Reality Systems, ACM Press, New York.

Whitney, D. E., 1977, "Force Feedback Control of Manipulator Fine Motions," ASME Transaction Journal of Dynamic Systems, Measurement, and Control, pp. 91-97, June. 